\title{
Historical sunspot records
}

\author{
Rainer Arlt ${ }^{1}$. José M. Vaquero ${ }^{2}$
}

Received: 10 May 2019 / Accepted: 22 January 2020 / Published online: 26 February 2020

(C) The Author(s) 2020

\begin{abstract}
Sunspot observations are available in fairly good numbers since 1610, after the invention of the telescope. This review is concerned with those sunspot observations of which longer records and drawings in particular are available. Those records bear information beyond the classical sunspot numbers or group sunspot numbers. We begin with a brief summary on naked-eye sunspot observations, in particular those with drawings. They are followed by the records of drawings from 1610 to about 1900. The review is not a compilation of all known historical sunspot information. Some records contributing substantially to the sunspot number time series may therefore be absent. We also glance at the evolution of the understanding of what sunspots actually are, from 1610 to the 19 th century. The final part of the review illuminates the physical quantities that can be derived from historical drawings.
\end{abstract}

Keywords Sunspots $\cdot$ Sunspot drawings $\cdot$ Sunspot positions

\section{Contents}

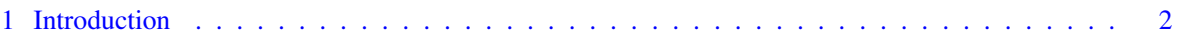

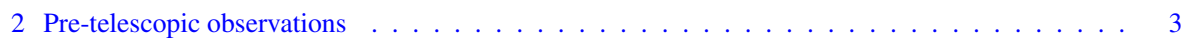

2.1 Naked-eye observations: difficulties of interpretation . . . . . . . . . . . . . . 3

2.2 Evaluation of historical naked-eye observations of sunspots . . . . . . . . . . . . . . 5

2.3 Observations using a camera obscura . . . . . . . . . . . . . . . . . . 6

3 Sunspot positions and areas from historical reports . . . . . . . . . . . . . . . . 6

3.1 Presence of orientation lines . . . . . . . . . . . . . . . . . . . 7

3.2 Rotational matching . . . . . . . . . . . . . . . . . . . . . . . . . . . . . . . . . . 9

3.3 Measurements rather than drawings . . . . . . . . . . . . . . . . . . . . . . . . 10

3.4 Not-to-scale areas . . . . . . . . . . . . . . . . . . . . . . . . . . 11

4 The period before the Maunder minimum . . . . . . . . . . . . . . . . . . . . 11

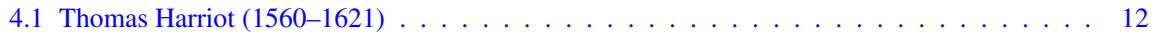

$凶$ Rainer Arlt

rarlt@aip.de

1 Leibniz Institute for Astrophysics Potsdam (AIP), An der Sternwarte 16, 14482 Potsdam, Germany

2 Departamento de Física, Universidad de Extremadura, Mérida, Badajoz, Spain 
4.2 Galileo Galilei (1564-1642, Gregorian; the corresponding Julian date was still in 1641) . . . 13

4.3 Christoph Scheiner $(1573-1650) \ldots \ldots \ldots \ldots$. . . . . . . . . . . . . . . . . . . . . . . . . . . . . . . .

4.4 Johannes Hevelius $(1611-1687) \quad \ldots \ldots \ldots$. . . . . . . . . . . . . . . . . . . . . . . 17

4.5 The Jesuits Malapert, Smogulecz and Schoenberger . . . . . . . . . . . . . . . . . . . . 18

4.6 Pierre Gassendi . . . . . . . . . . . . . . . . . . . . . . . . . . . . . . . . . . . . . . . . . 19

4.7 Georg Marcgraf . . . . . . . . . . . . . . . . . . . . . . . . . . . 19

4.8 Jean Tarde . . . . . . . . . . . . . . . . . . . . . . . . . . . . . . . . . . . . . . . . . . . . . . . . . . .

4.9 Petrus Saxonius . . . . . . . . . . . . . . . . . . . . . . . . . . . 21

5 The Maunder minimum . . . . . . . . . . . . . . . . . . . . . . . . 21

6 The period before the Dalton minimum . . . . . . . . . . . . . . . . . . . 26

6.1 Johann Caspar Staudacher . . . . . . . . . . . . . . . . . . . . . . . . . . . . . . . . . . . . . . . . . .

6.2 Christian Horrebow and colleagues . . . . . . . . . . . . . . . . . . . . . . 28

6.3 Other observers before the Dalton minimum . . . . . . . . . . . . . . . . . . . . . 29

7 The Dalton minimum . . . . . . . . . . . . . . . . . . . . . . 30

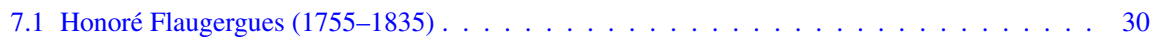

7.2 Other observers near the Dalton minimum . . . . . . . . . . . . . . . . . . . . . . . . . . . . . 32

8 The period before photographic records . . . . . . . . . . . . . . . . . . . 35

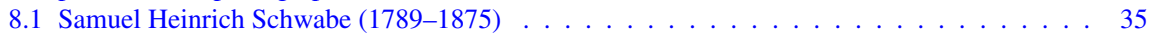

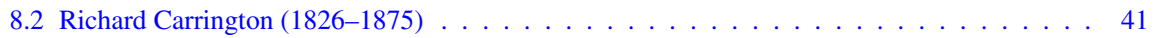

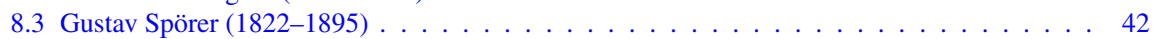

8.4 Further data from the 19 th century . . . . . . . . . . . . . . . . . . . . . 42

9 Collections of sunspot drawings around $1900 \ldots \ldots \ldots \ldots$. . . . . . . . . . . . . . 43

10 The understanding of sunspots over time . . . . . . . . . . . . . . . . . . . . . . . . . . . . . . . . . . . . . . . . .

11 Physical quantities derived from sunspot drawings . . . . . . . . . . . . . . . . . . 47

12 Concluding remarks . . . . . . . . . . . . . . . . . . . . . 51

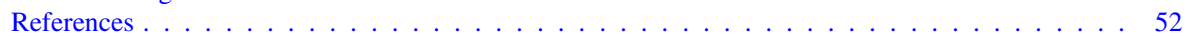

\section{Introduction}

Sunspot observations from the past have an enormous importance not only for solar physicists but also for stellar astrophysicists and Earth scientists. In general, these observations are the only direct evidence we have left of what really happened in the Sun's past. The recovery of this kind of information from different documentary records preserved mostly in historical libraries and archives around the world is essential for a better understanding of the evolution of our Sun during the last centuries (Vaquero and Vázquez 2009).

This is not a review of the history of sunspot observations. Different aspects of this history are very important for a better understanding of the observation techniques, the interests of observers or the equipment used, as recently shown by Muñoz-Jaramillo and Vaquero (2019). Instead, we are compiling actual records of data, particularly of longer duration. This is why, for example, the first publication about the observations of sunspots by Fabricius (1611) will be of marginal importance in this review. Note also that the recovery and utilization of historical sunspot records is an ongoing process, and new sources may become available after this review is published.

We distinguish basically two types of sources: sunspot counts and positional information on sunspots. Sunspot counts have been the focus of long-term sunspot variability studies since the first proposed solar cycle period by Schwabe (1844). The sunspot number tradition created by Rudolf Wolf (1816-1893) led to an enormous amount of data compiled from contemporary and past observations, continued by Alfred Wolfer (1854-1931), William Brunner (1878-1958), and Max Waldmeier 
(1912-2000). The sunspot numbers are generated until the present day by the Sunspot Index and Long-term Solar Observations programme at the Royal Observatory of Belgium, ${ }^{1}$ while the alternative counts of just sunspot groups provides an even longer time series for solar activity (e.g., Hoyt and Schatten 1998; Vaquero et al. 2016). The group count database consists of more than one million individual reports of which the vast majority was compiled in the 1998 reference, while a considerable number of corrections and additions were made in 2016 and is regularly being updated. ${ }^{2}$

Until recently, few publications on the positional information of historical sunspots had been available. In fact, Vaquero (2007) emphasized that "we must make an effort to incorporate the historical information on solar activity into studies of the position of sunspots (differential rotation, active longitudes, north-south asymmetries, etc.)" in a review article on historical sunspot observations. With the advent of the digitization of archival information, positional data from historical sources have become much more accessible and therefore more numerous, and this review article is mostly summarizing the work of the past decade. On the one hand, sunspot positions have been obtained from important collections of sunspot drawings. On the other hand, several numerical catalogues of sunspots from the 19th and 20th centuries have been recovered and digitized, providing machine-readable versions of the original tables. They are demonstrating the importance of long-term solar observing programs (Pevtsov and Clette 2017).

Moreover, a third type of observation contains detailed reports or drawings of particular sunspots, which neither provide information on the total number of sunspots on the solar disk nor on the heliographic positions of the spots described. Very little research effort has been made with this type of observation. Only some morphological details can be recovered and, in general, the area of the spots in these drawings cannot be evaluated due to problems of scale and perspective. However, the observations do contain the ratio of umbral to penumbral areas, for example, which was analyzed from such observations by Carrasco et al. (2018a) for spots observed during the Maunder minimum.

This paper will begin with a brief summary of pre-telescopic observations of sunspots in Sect. 2 and go on to explaining how detailed sunspot information can be derived from drawings and measurements in Sect. 3. Sections 4-8 more or less chronologically cover the periods from before the Maunder minimum to the observations in the 19th century, when photography was gradually gaining importance in astronomy and solar physics. We explicitely mention Julian and Gregorian dates where the observers used the Julian calendar, while all other dates are Gregorian.

\section{Pre-telescopic observations}

\subsection{Naked-eye observations: difficulties of interpretation}

Naked-eye observations of sunspots were considered a mere curiosity by the international astronomical community for a long time. It was found that there were numerous

\footnotetext{
1 http://www.sidc.be/silso/.

2 http://haso.unex.es/haso/index.php/on-line-archive/data/.
} 
examples from different parts of the globe, but in an insufficient number to make serious studies on the long-term behavior of solar activity. However, in the second half of the 20th century, records from regions of China, Japan and Korea were begun to be systematically studied. Thus, several catalogs and important studies appeared on these registers.

After much study (see the bibliography of the Chapter 2 of the monograph by Vaquero and Vázquez (2009), we know that naked-eye observations of sunspots are quite difficult to interpret. On the one hand, these observations are clearly influenced by weather conditions. The presence of a sufficient amount of atmospheric aerosol (fog, haze, dust) that serves as a natural filter was necessary for an early oriental astronomer to observe the phenomenon. Of course, the presence of clouds prevents naked eye observation of sunspots. And a very clean atmosphere, without atmospheric aerosols, makes the Sun too bright for the observer.

Despite this, the most important factor in interpreting this register is the sociological factor. Frequently, sunspots were observed by eastern astronomers who were trying to observe the first lunar crescent (the beginning of a new lunar month) during sunset. To further complicate the interpretation of these records, these observations had an important astrological connotation since the observation of sunspots was interpreted by astrologers as portents, either positive or negative, in the daily life of societies.

As a result, no one would expect that a direct comparison between the solar activity derived from cosmogenic isotopes and the naked-eye observations of sunspots would yield good results. Using a chain of physics-based models, Wu et al. (2018) have obtained decadally-averaged sunspot numbers from concentrations of the cosmogenic isotopes ${ }^{14} \mathrm{C}$ and ${ }^{10} \mathrm{Be}$ preserved in natural archives. Figure 1 shows a direct comparison between the reconstruction of the sunspot number made by Wu et al. (2018) (blue line) and the 50-year moving average of the annual number of naked-eye sunspot observations compiled by Vaquero et al. (2002) (red line). Although the long-term trends do not closely track each other, it is interesting to note that there are several coincidences between the peaks of the two series. The long-term evolution in the number of naked-eye observations of sunspots shows a slope of a bit more than one sunspot per century (see fig. 2.19 in Vaquero and Vázquez 2009).

Another interesting aspect that must be mentioned is the scarcity of graphic representations in the naked-eye observations of sunspots. Figure 2 shows two well-known examples. Stephenson and Willis (1999) discovered the left-hand side drawing which appears in the important manuscript of the chronicle of John of Worcester (that was compiled during the first half of the 12th century) currently in the archives of Corpus Christi College, Oxford (MS 157). The drawing corresponds to 1128 $\mathrm{CE}$, December 8 . The other sunspot drawing (right-hand side image) appears in the manuscript entitled Tiānyuán Yûlì Xiángyìfù, a manuscript in Chinese that is preserved in the National Archives of Japan (Hayakawa et al. 2017b). These two figures illustrate the general problem of determining scale in early isolated sunspot drawings. 


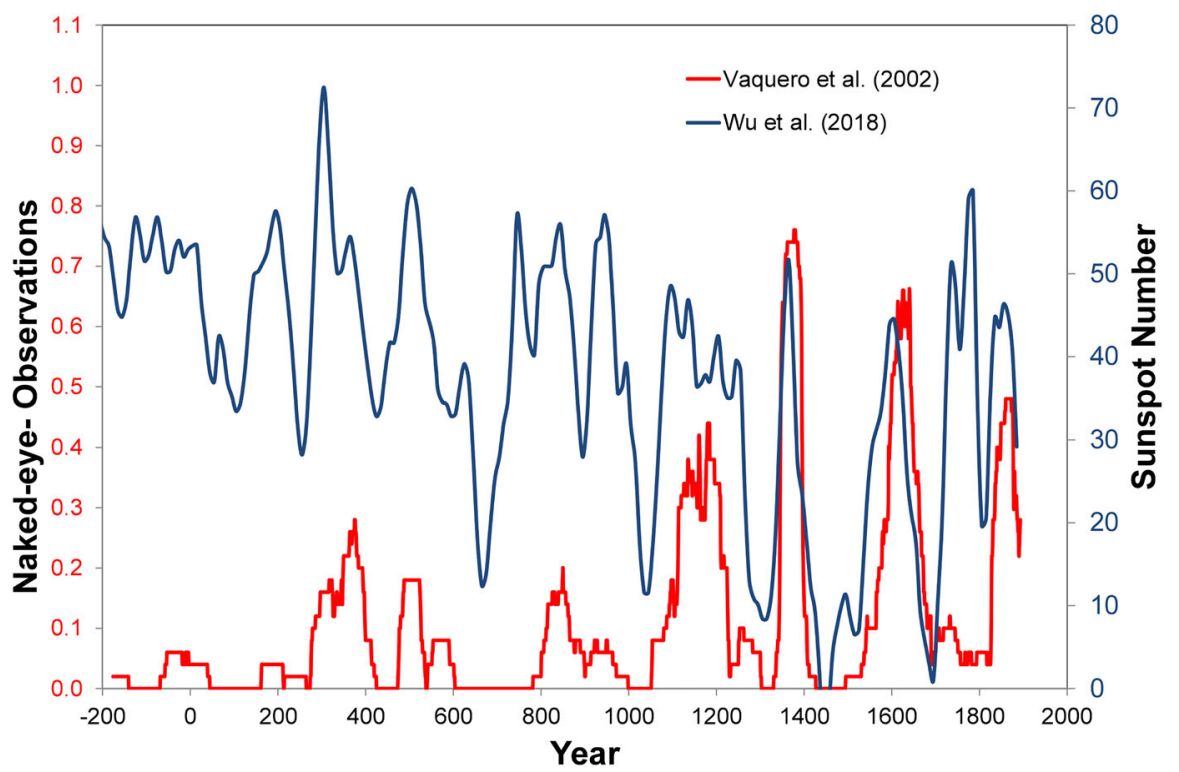

Fig. 1 A direct comparison between the reconstruction of the sunspot number made by Wu et al. (2018) (blue line) and the 50-year moving average of the annual number of naked-eye sunspot observations compiled by Vaquero et al. (2002) (red line)
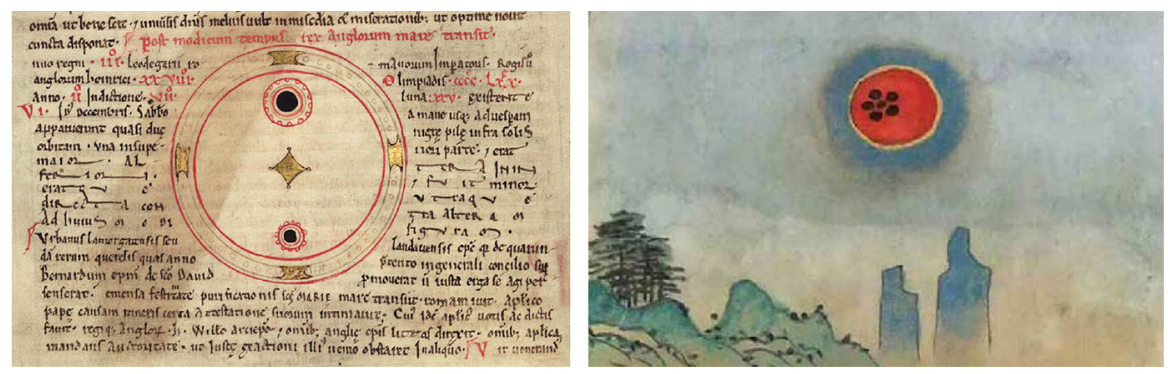

Fig. 2 Early sunspot drawings from naked-eye observations. Left panel: drawing by John of Worcester, observed in 1128 CE (adapted from Vaquero and Vázquez 2009). Right panel: undated drawing from Tiānyuán Yùlì Xiángyìfù, manuscript 305-257 at Naikaku Bunko, Books of Shoheizaka Gakumonjo, in the National Archives of Japan [in Chinese], involved in an imperial manual of Chinese astro-omenological divination compiled in 1424-1425 (adapted from Hayakawa et al. 2017b)

\subsection{Evaluation of historical naked-eye observations of sunspots}

Vaquero and Vázquez (2009) reviewed attempts during recent decades to evaluate the historical naked-eye observation of sunspots for the last milleium. Looking for a better methodology to analyze naked-eye observation time series, Ma and Vaquero (2009) used a modified Lomb-Scargle periodogram which is convenient for the analysis of unevenly sampled data, in order to detect the Suess/de Vries cycle $(\sim 210 \mathrm{yr})$, but rather intermittent (see, e.g., Usoskin 2017, and references therein). Another methodological innovation was made by Vaquero and Trigo (2012) who used the naked-eye 
observations of sunspots (combined with observations of aurorae at medium and low latitude) during the Medieval Climate Anomaly (MCA, 1000-1300 CE) to obtain an average value of the solar cycle length during this period and arrived at a value of $10.7 \pm 0.2 \mathrm{yr}$. It was again studied by Bekli et al. (2017) using a non-parametric data analysis.

Since the publication of the monograph by Vaquero and Vázquez (2009), some lost records of naked-eye observations of sunspots have been published. The records of sunspots that appeared in Chinese official histories and in chronicles of ancient Japan have been reviewed by Hayakawa et al. (2017a, b) and Tamazawa et al. (2017). Evidence of a previously unreported naked-eye sunspot observation in 1604 from a 17th century Hungarian history was presented by Simpson (2018). In addition, Zito (2016, 2017) has presented some interesting results about possible Mesoamerican naked-eye observation of sunspots.

\subsection{Observations using a camera obscura}

Another relatively easy method to observe sunspots without the help of the telescope is with the use of a camera obscura (Hammond 1981). Even Galileo, in his first work on sunspots, indicated that the largest sunspots can be seen taking advantage of the solar rays which cross through a hole in a cracked opal window in a church (used as a gigantic camera obscura) (see Reeves and Van Helden 2010). In fact, large cathedrals were used as huge dark rooms to make astrometric measurements. Figure 3 shows three engravings of solar observations made with this kind of device, where a pinhole has to be so small that rays of light from different places on the observed object fall onto different places of a screen put behind the hole and therefore give an image of the object.

Figure $3 \mathrm{a}, \mathrm{b}$ show the observation of a solar eclipse in 1544 . The reports of this observation do not indicate anything about sunspots. This date is just in the middle of the Spörer minimum of solar activity. Therefore, the probability of a large sunspot to be observed during that time period was very small. Figure $3 \mathrm{c}$ shows the solar observation made by Kepler in 1607 when he noted a small spot in the solar disc. Kepler thought at first that he was observing a planetary transit. Only years later, he realized that he had observed a sunspot (Reeves and Van Helden 2010).

\section{Sunspot positions and areas from historical reports}

The earliest astronomical telescopes were of Galilean and Keplerian style. The observer sees an upright image in the Galilean one when in focus (rays exiting the eyepice in parallel lines). If the eyepiece is moved to a slightly larger distance from the objective lens, the an upside-down image can be projected onto a screen. Conversely, the observer sees an upside-down image in the Keplerian telescope, while again the eyepice can be moved away from the main focal point to project an upright image onto a screen (Fig. 4). Note also that, when looking from the side of the eyepiece into the screen, the projected images are mirrored. 


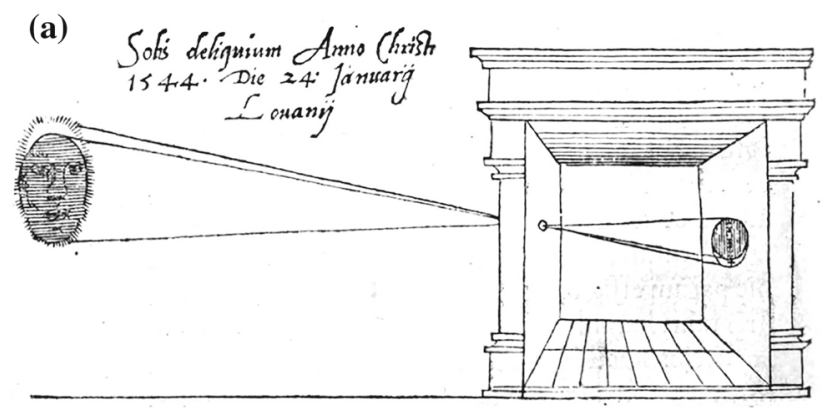

(c) Demonfiratio ocularis.
Subücisturliterk $D$.

(b)
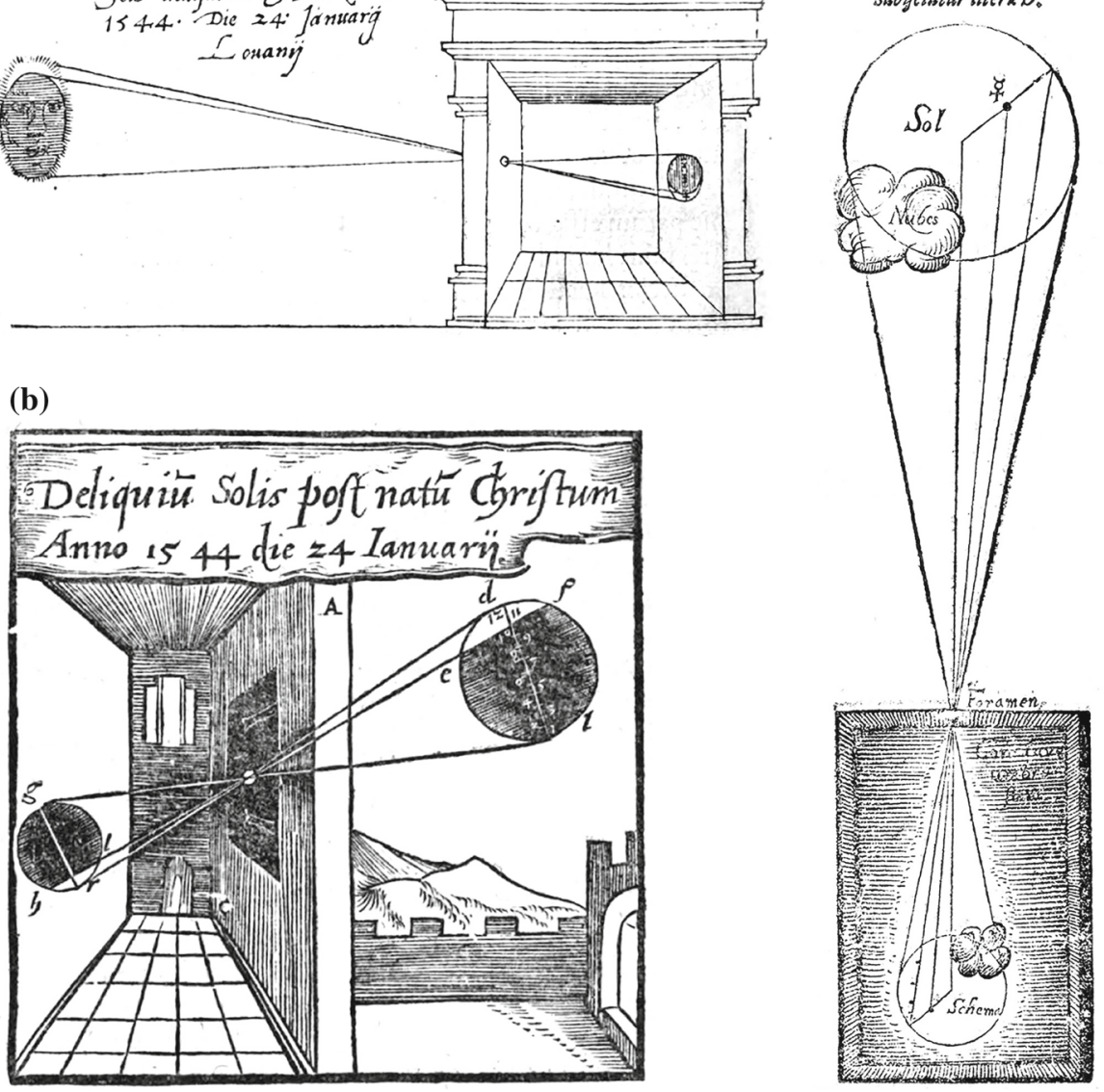

Fig. 3 Some early drawings of the astronomical use of a camera obscura: a the solar eclipse observation by Gemma Frisius on 1544 January 24 (Julian), taken from Frisius (1545), b the same observation from Regiomontanus (1561), and c a sunspot observation in 1607 by Kepler (1609); cf. Vaquero (2007)

\subsection{Presence of orientation lines}

Careful observations include an indication of the position angle of the solar disk. The presence of orientation lines is very patchy among the observers and even within their observing records. A typical orientation line of the 17th century and the early 18 th century is the ecliptic. Note, however, that the ecliptic has to be constructed as it is typically not accessible when making the observation under the sky.

Alternatively, a line parallel to the celestial equator has been drawn especially in the 18th and 19th century. This line became directly accessible during the observations with the more common use of equatorial mounts.

In rare cases, the direction to the local zenith is indicated in the drawings. Even if not drawn, it may have been the reference line for constructing the ecliptic in many cases. 
(a)

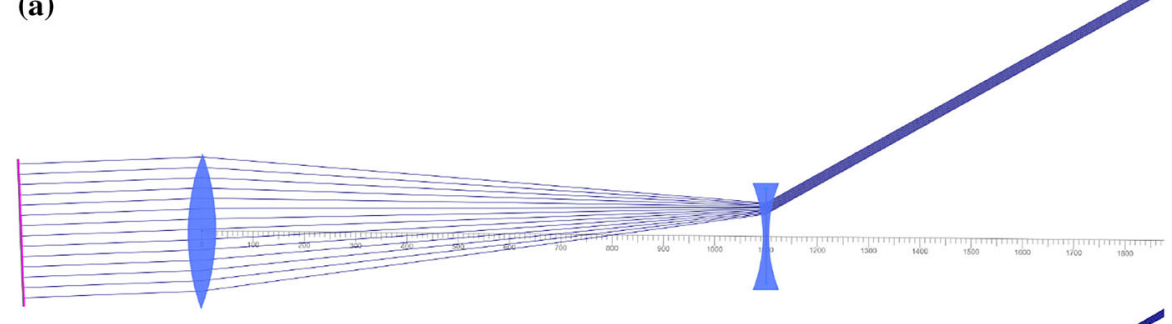

(b)

(c)

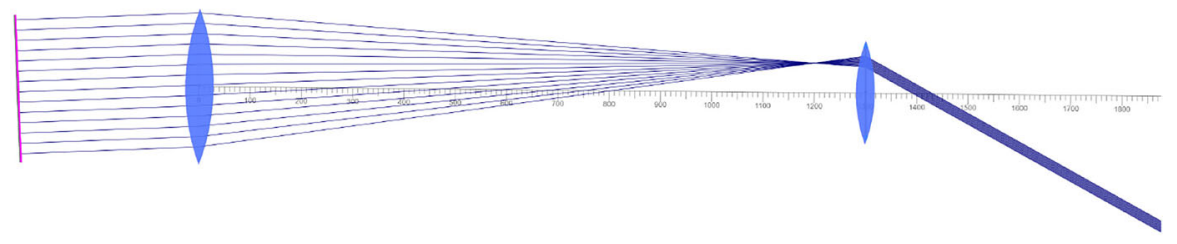

(d)

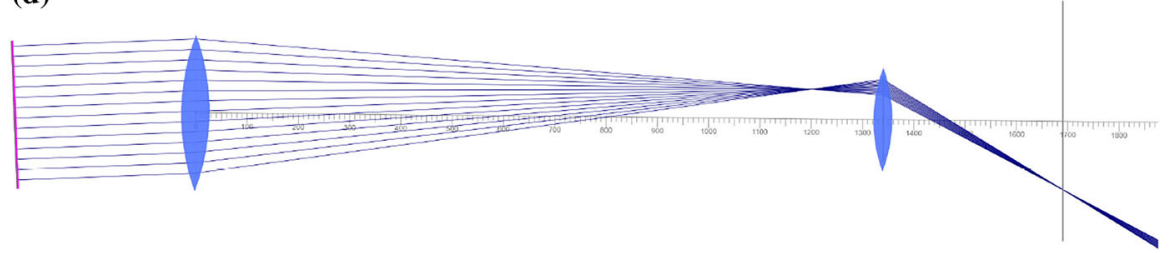

Fig. 4 Refracting telescopes in direct view and projection mode. a Galilean telescope when looking through it, $\mathbf{b}$ Galilean telescope when projecting the image, $\mathbf{c}$ Keplerian telescope when looking through it, and $\mathbf{d}$ Keplerian telescope when projecting the image. Images based on the ray-tracing by https://ricktu288. github. io/ray-optics/

Existing reference lines can be used to define the position angle of the solar rotation axis. Note that simple self-made recipes to define the solar position angle may not hold up over centuries. Care has to be taken that the recipes are really valid for such long periods of time. The results may also not refer to a modern celestial coordinate system, but give results in the frame the observer had access to. A good choice is the ephemeris from the JPL Horizons system. ${ }^{3}$ The positional angle of the solar rotation axis from

$\overline{3 \text { https://ssd.jpl.nasa.gov/?horizons. }}$ 
Fig. 5 Heliographic coordinate lines placed at a position angle $P$ with the celestial north pole and at a tilt towards the line of sight, $B_{0}$, of about $7^{\circ}$

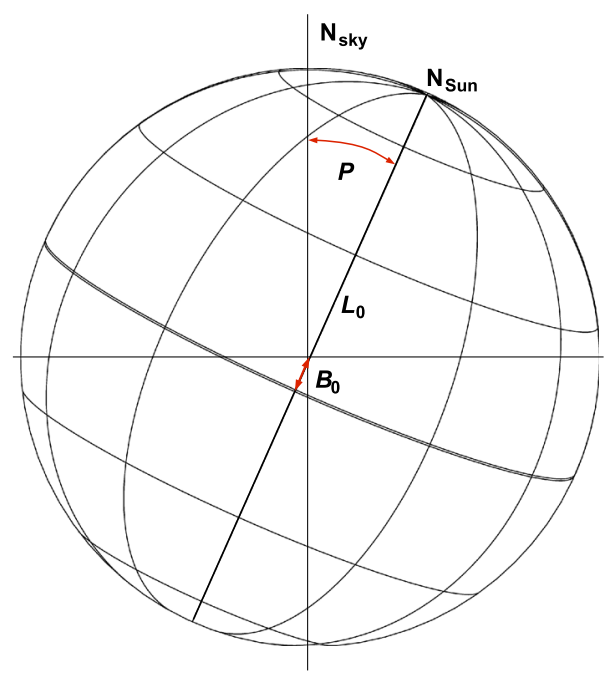

the true-of-date celestial north pole direction can be obtained while employing the full planetary system motion according to the Jet Propulsion Laboratory Development Ephemeris (identified by DE + version number). The table option "Observer sub-lon $\&$ sub-lat" provides the heliocentric coordinates of the solar disk's midpoint, $L_{0}$ and $B_{0}$, if the Sun is selected as the target body. The option "North pole position angle $\&$ distance" gives the position angle $P$ of the solar rotation axis with respect to the celestial north pole as well as the apparent solar radius (Fig. 5). With these quantities, accurate heliographic coordinates can be generated, also with a well-defined reference longitude for the Sun over centuries. Note that $L_{0}$ does not coincide with Carrington's original reference point in longitude.

The position angle between any two points can be computed by transforming the, e.g., celestial coordinates of the two points into a coordinate system in which the disk centre of the Sun is one pole. Then the position angle is the difference in the points' longitudes in these new coordinates. When transforming into such Sun-centred coordinates to obtain the angle between the ecliptical and celestial poles, one can neglect the variation of the ecliptical pole's declination, which changed by only $0.05^{\circ}$ over the last 400 years (Lieske et al. 1977) as long as one stays in true-of-date coordinates for the Earth's north pole. The resulting maximum error in heliographic coordinates is of the same order of magnitude as the ecliptical-pole variation.

\subsection{Rotational matching}

If any indication of the position angle of the drawings is missing, we can still infer the orientation as soon as the same sunspots appear on one or more drawings on other dates. We can then use the knowledge that the spots appear to move as the Sun rotates (Arlt 2009a). There are several levels of assumptions we need to make, depending on the information available. 
Let us for the moment say we know the exact times during the days on which the observations were made. A single spot on two days gives as four values ( $x_{1}$ and $y_{1}$ on one day and $x_{2}$ and $y_{2}$ on the second day). We can therefore obtain an exact solution for four unknowns, which in our case are the longitude and the latitude of the spot and the two position angles of the drawings on the two days. ${ }^{4}$ The latitudinal profile of the solar differential rotation needs to be presumed, as the system would be under-determined otherwise.

Two spots on two days are already much better, since we have 8 data points for the 6 unknowns (two latitudes, two longitudes, two position angles). Alternatively, one spot on three days gives 6 data points for 5 unknowns (latitude, longitude, three position angles). If enough data points are available, other parameters may be inferred from the measurements, such as the exact time difference between the observations if not precisely given (Vokhmyanin and Zolotova 2018b), or the two or three parameters usually used to describe the differential rotation of the Sun (Arlt and Fröhlich 2012, see Sect. 11).

\subsection{Measurements rather than drawings}

In the earlier years, it was quite common to actually measure sunspot locations on the solar disk rather than drawing the spots. We find the vast majority of such measurements between roughly 1700 and 1900 when photographic methods eventually took over at many observatories. Instrumental equipment had improved in a way that drawings were probably considered inferior to measurements.

A simple way of describing the progression of sunspots on the solar disk was the division of the disk into six concentric circles, giving six eastern "bands" and six western "bands" which merge at the meridian through the center of the Sun. With the spots moving in twelfths of the disk, the unit was given as "inches" ("Zoll" in German). In other words, the half-rings left of the vertical or north-south line are inches 1-6, the ones on the right-hand side are numbered 7-12 (see, e.g., Neuhäuser et al. 2018). This style was mostly used throughout the 18th century.

For the determination of the full heliographic coordinates, transit times of spots need to be complemented by a measurement in another direction. This can be an angular-distance measurement in the declination or elevation direction. This can also be achieved by timing transits across inclined wires, as used by Flaugergues around 1800 (which he called 'premier oblique', 'second oblique', see Sect. 7.1). The method goes back to the 17th century. Various reticule cross-hair variants are described by Pearson (1829). The method was similarly used with high accuracy by Carrington (Sect. 8.2) using two oblique wires intersecting at an angle of $90^{\circ}$ (Teague 1996; Galaviz et al. 2016a). While Flaugergues did not compute heliographic positions from his measurements, Carrington and his assistants converted them into data directly usable.

\footnotetext{
4 Note that there are in general two exact solutions, since the apparent solar rotation is approximately symmetric with respect to a certain line close to the equator.
} 


\subsection{Not-to-scale areas}

Many historical drawings do not show the areas of sunspots to scale. One option to resolve this problem is to use arbitrary size or area bins. Each individual spot falls into one of these bins. An abundance distribution is thus obtained for the size bins. The relative abundances in these bins are then compared with a modern data set where areas are to scale. These (nearly continuous) area values are now split into bins of non-equal size in order to match the relative abundances of spots derived from the historical data set. The average values of modern areas in those bins are used as representative values for the historical size bins. The method was used by Senthamizh Pavai et al. (2015) for mapping the areas drawn by Samuel Heinrich Schwabe (Sect. 8.1) to physical areas on the Sun.

The method has one free parameter which is the choice of the smallest area for building the "modern" abundances. The minimum area visible to the historical and to the modern data set are not equal in general (Usoskin et al. 2016). While one would think that this issue can be solved when knowing the telescope used, the minimum plotted area in drawings often depends on the group size. A small group of Waldmeier type A or B has typically 1-3 spots. If the group was detected by the observer, it was very likely to be plotted in full. A large group, however, has so many individual spots that the observer may tend to sketch the group, simplifying the small-scale structures, even though they were detectable with the instrument in use.

Areas may be directly usable when not their absolute values but the ratios of umbral to penumbral areas are employed. See Sect. 11 for further references.

\section{The period before the Maunder minimum}

This Section deals with the telescopic sunspot observations before the Maunder minimum which started around 1650. After the introductory part, the subsections on individual observers are sorted by their birth date.

Telescopic observations of sunspots very likely started in 1610 and were carried out by several observers in 1611. We describe the observations of 1610-1612 here, but deal with Thomas Harriot, Christoph Scheiner and Galileo Galilei only briefly, since their observations are described in detail in dedicated sections.

The oldest telescopic sunspot drawing still available comes from Thomas Harriot of 1610 December 8 (Julian)/December 18 (Gregorian); see Sect. 4.1. Since this observation is separated from the later ones in the manuscript by one year, the description and drawing of the 1610 one may be a recollection rather than an immediate note of the observation.

Christoph Scheiner (see Sect. 4.3) wrote later that he and his associate Johann Baptist Cysat as well as possibly independently his superior at Ingolstadt, Adam Tanner (Tanner 1626; Neuhäuser and Neuhäuser 2016, for a translation), observed sunspots in March 1611 (Reeves and Van Helden 2010).

The first printed publication known is the one by Johannes Fabricius (1611, June), but contains neither sunspot numbers for specific dates nor drawings. A later publica- 
tion by his father names the date of 1611 February 27 (Julian)/March 9 (Gregorian) and the following day as the first observations (Neuhäuser and Neuhäuser 2016).

Simon Marius (German: Simon Mayr) also observed definitely sunspots in 1611. He was born in 1573 and died in 1625 (Gregorian; the Julian date of decease was 1624 December 26) (Wendehorst 1990; Neuhäuser and Neuhäuser 2016) in what is now Bavaria. His observations are among the first telescopic ones of sunspots. The earliest document observation is from 1611 August 3 (Julian)/1611 August 13 (Gregorian). Marius made only one mention of a drawing for 1611 November 17 (Julian)/27 (Gregorian), which has not been recovered, and he usually made no statement on how many spots there were, except for 1612 May 30 (Julian)/1612 June 9 (Gregorian) when he reported 14. There are about a dozen dates of 1611 to 1619 for which Marius commented on sunspots. A detailed discussion of the original texts and a comparison with Galileo Galilei, Christoph Scheiner and Joachim Jungius (all described below) is given by Neuhäuser and Neuhäuser (2016). The paper also hints on short-comings in the group sunspot number database by Hoyt and Schatten (1998), also for other observers, in 1611-1621.

Galileo Galilei (1613) published his sunspot observations two years later (see Sect. 4.2), but wrote in a letter to Maffeo Barberini in June 1612, that he had observed sunspots "about eighteen months ago", which correspond to December 1610. His oldest preserved drawing is from 1612 February 12 (Gregorian; Favaro 1895; Reeves and Van Helden 2010).

Joachim Jungius lived from 1587 to 1657 and, while he was teaching mathematics in Gießen, Germany (Kangro 1974; Guhrauer 1850), observed sunspots in 1611-1612, besides other astronomical objects. He left more than a dozen drawings of the Sun with spots. The drawings look very similar to the ones by Thomas Harriot, but unlike those have no indication of the orientation of the solar disk. The sunspot positions have not yet been derived from Jungius's observations. The example of 1612 May 30 (Julian)/June 9 (Gregorian) shown by Neuhäuser and Neuhäuser (2016) matches up with Galileo's observation fairly well, but not down to single degrees in heliographic coordinates.

\subsection{Thomas Harriot (1560-1621)}

The first telescopic sunspot observation of which we have an actual paper record is by the mathematician, philosopher and astronomer Thomas Harriot (Harriot 1613). ${ }^{5}$ The corresponding drawing of 1610 December 8 (Julian)/18 (Gregorian) shows three spots. Harriot reports

Decemb. 8 mane. $\hbar$. The altitude of the sonne being 7 or 8 degrees. It being a frost $\&$ a mist. I saw the sonne in this manner. Instrument. 10/1.B. I saw it twise or thrise. once with the right ey \& other time with the left. In the space of a minute time, after the sonne was to cleare.

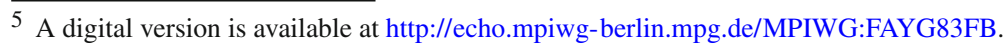


Harriot observed the Sun through the telescope without a filter. He had to use moments near sunrise or sunset when the light was dimmed by fog or mist. He finally mentions that it was about a minute before the Sun became too bright for observations.

There are 201 drawings of the solar disk in the manuscript. Pure textual information is available for 13 additional days. As an aside, Harriot also made probably the first drawing of the Moon as seen through a telescope on 1609 July 26 (Julian)/August 5 (Gregorian) which was a waxing crescent on that date (Shirley 1983).

In the beginning, the drawings also contain two lines, which are compatible with being the direction to the zenith and the ecliptic. Harriot stopped drawing these lines in July 1612 and resumed plotting them in September. On 1611 January 19 (Julian)/29 (Gregorian) Harriot noted:

January.19. $\hbar$. a notable mist. I observed diligently at sondry times when it was fit. I saw nothing but the cleare sonne both with right and left ey.

This experience may have lessened his interest in sunspots as it was not before 1611 December 1 (Julian)/11 (Gregorian) that Harriot again noted sunspots. He returned to drawing sunspots on the date when a possible Venus transit was expected (1611 December 11), if the Ptolemaic system were correct. In fact, it was an upper conjunction of Venus, and Harriot did not mention Venus except for the note " $\odot \odot \%$ " (conjunction of Sun and Venus).

The drawings do not distinguish umbrae from penumbrae. Some occasional penumbral structures are most likely washed-out ink, but Harriot sometimes reports about "ragged" spots and "long" spots (particularly near the limb), and therefore noticed that the phenomenon is not perfectly round.

The textual information is usually the description of the spots and their changes as well as the magnifications used (mostly 10 times and 20 times in the beginning, in 1612 also 30 times). On 1612 January 11 (Julian)/21 (Gregorian), Harriot mentions S.J.H. which is an indication that Harriot did share his observation with Sir John Harington (Shirley 1983, p. 419), an English poet and inventor of the flush water closet.

Apparently, Herr (1978) was the first to measure the sunspots in the drawings of Harriot. The dashed lines indicating the direction to the zenith were used to fix the position angle of the Sun. A total of 690 sunspot positions were derived, describing the evolution of 146 different spots. An example of Harriot's drawings is shown in Fig. 7 for 1612 November 27 (Gregorian) in comparison with a drawing by Christoph Scheiner (Sect. 4.3).

We are not aware of any positions still available from the work by Herr (1978). A new version of positional data from the observations by Harriot is currently being made by Vokhmyanin et al. (submitted).

\subsection{Galileo Galilei (1564-1642, Gregorian; the corresponding Julian date was still in 1641)}

Galileo had observed sunspots probably since late 1610, and published detailed drawings in Galilei (1613). The full-disk drawings cover dates from 1612 February 12 to 
Fig. 6 Earliest available drawing of sunspots in the solar disk by Galileo on 1612 February 12 (Gregorian); from Favaro (1895)

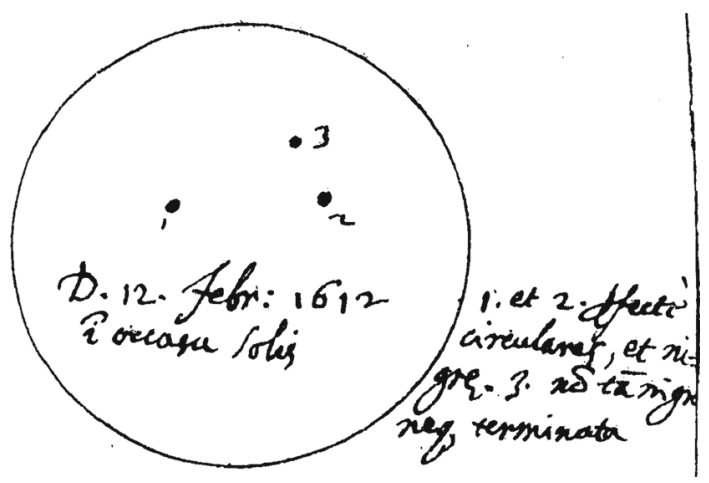

Aug 21 (all Gregorian for Galileo), while nine cut-out drawings of a sunspot group are available for 1612 April 5-7 as well as April 26-May 3 (Galilei 1613).

The telescope of Galileo is described by King (1955) as having a lens diameter of $5.1 \mathrm{~cm}$, but having been stopped down by Galileo to $2.6 \mathrm{~cm}$ for better quality. These diameters respectively correspond to roughly $2.7^{\prime \prime}$ and $5.3^{\prime \prime}$ theoretically achievable angular resolutions. Abetti (1954) describes a test of one of Galileo's first telescopes and found the resolving power to be limited by $10^{\prime \prime}$ which is compatible with the above numbers, since lens-grinding was still developing at the time. Tests with a facsimile of one of Galileo's telescopes revealed remarkable detail though on the Moon, the planets and the Sun (Ringwood 1994).

The earliest available drawings of spots on the solar disk are the ones of 1612 February 12, 17, and 23, March 16, 17, 18, 20, 21, and 31, and April 3, 5, 6, 7, 10, 16, 19, 20, 26, 28, 29, and 30, and May 1 and 3, which can be found in Favaro (1895). The first drawing is shown in Fig. 6. The orientation of the drawings is not indicated. Spot positions may be derived for March 16-21, March 31-April 10 as well as April 26-May 3, but are only available starting from May 3 in Vokhmyanin and Zolotova (2018b). While Galileo used a pair of compasses for most drawings, he did not for March 31-April 16, and the disk images therefore deviate from circular shapes significantly.

The full-disk drawings of 1612 May-August are of outstanding quality given the limited power of the telescope. They show by far the most realistic representations of sunspot groups at the time. The drawing of 1612 August 19 is accompanied by a statement that Galileo saw the spot also by the naked eye (see discussion by Vaquero 2004). An analysis of the sunspot positions of the June-July drawings from Galileo was published by Casas et al. (2006), aiming to determine the rotation profile of the Sun in the 17 th century and finding a tendency toward stronger differential rotation in Galileo's data. Updated sunspot positions, then including also the drawings of May and August 1612, were derived recently by Vokhmyanin and Zolotova (2018b) using a rotational matching method which minimises the variations of spot latitudes. The accuracy of the sunspot positions in the May and later drawings was most likely better than in the early drawings of Scheiner (see following Section) of 1611-1612. Note, however, that there is no direct overlap of the Galileo data in Vokhmyanin and Zolotova 
(2018b) and the Scheiner data in Arlt et al. (2016). The early drawings by Galileo need to be analyzed in order to make a direct comparison.

The butterfly diagram of Galileo's observations looks fairly much like a modern one with the June-August data, while the May data show three activity bands, two at \pm 20 to $25^{\circ}$ and one at $-5^{\circ}$ (Vokhmyanin and Zolotova 2018b). The band near the equator is caused by three sunspot groups, while the other two bands are formed by four and eight groups, respectively. The data are included in the 400-year butterfly diagram in Fig. 27. Again, the earlier observations of February 12 to May 1 will shed more light on the significance of this distribution.

\subsection{Christoph Scheiner (1573-1650)}

By far the largest dataset of sunspot observations before the Maunder minimum was compiled by Christoph Scheiner from 1611 to 1631. The first drawings of 1611 Oct 21 to 1612 Apr 7 (all dates by Scheiner are Gregorian) are very small with mostly exaggerated spot sizes.

The letters of Scheiner to Marcus Welser are available in Reeves and Van Helden (2010). Quite precise drawings were published by Scheiner (1615) for 1612 Nov 27, Nov 29, Dec 26, and 1613 Jan 6. There is an imaginary circle for Venus in these drawings, which is not a spot, at least not visible in Harriot's drawing of the same period which otherwise agree very well with Scheiner's figures. There is one occasion when Harriot observed exactly on the same day as Scheiner-within $1 \mathrm{~h}$ even-and the agreement of the drawings is remarkable (Fig. 7).

The book "Rosa Ursina sive sol" by Scheiner (1630) is the main compilation of observations and discussions of the phenomena of sunspots and faculae. More than 50 copies are still available in-mostly European-libraries. The book has also been digitized entirely a few times.

The following remark about the necessary telescope for the precise enough study of the spots' motion was given by Scheiner (1630, p. 129-2):

Quarto. Ad quam rem mire conducet si lens non tantum sit magnae spherae portio, cuius semidiameter 20. 30. aut plures palmos Romanos complectatur, sed etiam ipsa sit ampla satis, unius minimum aut duorum palmorum; sic enim eadem aliquid digni praestabis, dummodo in materiam probam, forma inculpabilis inducatur.

which translates to

Fourth. We obtain this [to trace the motion of spots without error] to an extraordinary degree, if the lens is not only a portion of a large sphere, whose semi-diameter spans 20, 30, or more Roman palms, but also if the same [lens] is sufficiently wide, of at least one or two palms; so it will lend itself to do something adequate, as long as it is made of material of good quality and shaped without defects.

If we assume the Roman palm to be $74 \mathrm{~mm}$ (Brockhaus, 1991), the lens diameters result in $7-15 \mathrm{~cm}$. The curvature radii given would correspond to nearly 3 and $4.4 \mathrm{~m}$ 


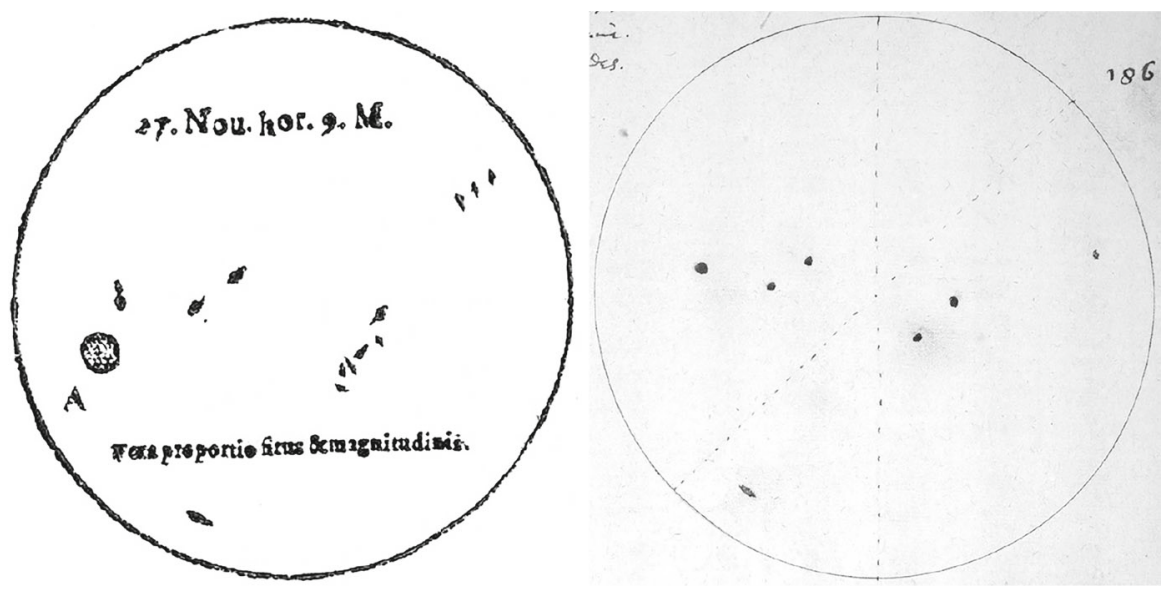

Fig. 7 Comparison of an early drawing in Scheiner (1615) on 1612 Nov 27 (left panel) with the drawing by Thomas Harriot on the same day (right panel). Scheiner gave a clock time of $9 \mathrm{~h}$ am, which is about 8:10h Greenwich time, while Harriot in London gives 8:45 am. Harriot noted that the westernmost spot was "dimly seen". In the left panel, Scheiner gave the expected size of Venus denoted by 'A' for comparison with the spots (actually, Venus is a bit less than half that size in its lower conjunction). There was no Venus transit or any conjunction on this date

Fig. 8 Composite image of the sunspots observed on 1625 June 8-24 by Scheiner (1630). The evolution of several sunspot groups over the course of the month as well as faculae surrounding the groups are shown. There are also indications of the directions to the zenith and nadir at the northwestern and southeastern limbs

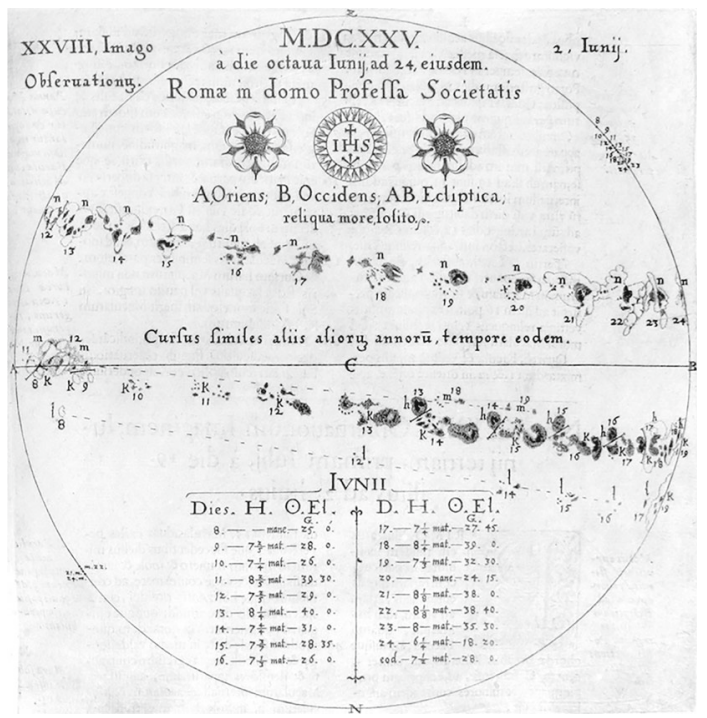

focal length for a plano-convex lens, or to 1.5 and $2.2 \mathrm{~m}$ for a biconvex lens (refractive index 1.5).

The drawings in Scheiner (1630) and Scheiner (1651) consist of the solar disk in which the evolution of selected sunspot groups is plotted over several days, as shown in the example in Fig. 8. Note the remarkable wealth of detail in the groups and the presence of very small pores in these drawings. If the Sun was crowded with groups, 
Table 1 Available days with drawings for given years, reported by Scheiner, mostly made by himself with some drawings from colleagues (Arlt et al. 2016)

\begin{tabular}{llllll}
\hline Year & Days & Year & Days & Year & Days \\
\hline 1611 & $41^{1}$ & 1622 & $17^{1}$ & 1626 & $169^{2}$ \\
1612 & $31^{1}$ & 1623 & $9^{1}$ & 1627 & $55^{1}$ \\
1618 & $7^{1}$ & 1624 & $40^{1}$ & 1629 & $49^{3}$ \\
1621 & $27^{1}$ & 1625 & $343^{2}$ & 1631 & $12^{1}$ \\
Total & 800 & & & & \\
\hline
\end{tabular}

${ }^{1}$ Five days were not analysed because of unreliable positional results.

${ }^{2}$ One day showed only faculae. ${ }^{3}$ On two days, groups were not drawn completely

some groups were plotted in another drawing, i.e. the information on sunspots of a given day may be scattered over several drawings. The drawings of 1618 and later always contain the ecliptic fixing the position angle of the disk. In a few cases, also the direction to the zenith is indicated for individual days (Fig. 8). The average error between the actual ephemeris angle between zenith and ecliptic and the drawings is $0.9^{\circ}$ and is remarkably good. The total number of days covered by all the drawings is 800 (Arlt et al. 2016) (Table 1).

The butterfly diagram generated from the sunspot positions by Scheiner is a rather mixed bag. The earliest observations of 1611 and early 1612 show a fully filled latitude range from $-35^{\circ}$ to $+35^{\circ}$, which is certainly a result of the very limited accuracy Scheiner and his colleagues were able to implement in their first observations. Interestingly, the following data of 1612 March-April show much better agreement with what we would expect from modern observations, i.e. spots limited to latitude bands between roughly $5^{\circ}$ and $35^{\circ}$ north and south of the equator. The accuracy had increased significantly for the observations of 1618-1631 when more confined sunspot belts are formed by the positions measured by Arlt et al. (2016) (see Fig. 27).

\subsection{Johannes Hevelius (1611-1687)}

The brewer and enthusiastic amateur astronomer Johannes Hevelius (German: Johannes Hevel, Johann Hewelcke; Polish: Jan Heweliusz) reported on sunspots since 1642. Hevelius had read Scheiner (1630) and presented his sunspot observations in the same style when publishing (Hevelius 1647). This book is mostly about the Moon, but Chapter 5 contains a discussion on the Sun and sunspots, and an appendix lists the sunspot observations with drawings. An example of the composite images of the evolution of sunspot groups and faculae in August 1643 is shown in Fig. 9. The book also contains observations of the moons of Jupiter.

The second source of sunspot observations is Hevelius (1679) where he compiled a large number of observations beginning in 1630 when he studied as a 19-year-old in Leiden. Sunspots appear in the third volume of the publication among measurements of the altitude of the Sun. Sometimes spots are mentioned in the remarks, sometimes zero spots are noted. Most observations have no remark at all. For their group sunspot number database, Hoyt and Schatten (1998) considered all solar observations without 
Fig. 9 Composite image of the sunspots observed on 1643 August 12-24 by Hevelius (1647). Similarly to Fig. 8, the plate shows the evolution of sunspot groups and faculae. Note that the groups near the limb were plotted at another position angle to avoid overlaps and confusion

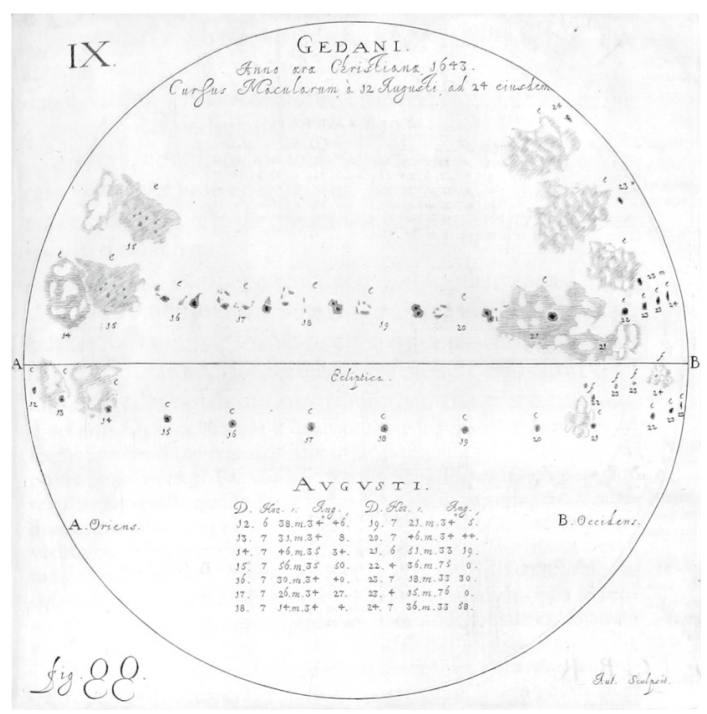

a remark as nil reports. However, only the explicit zeros should be used. Hevelius used a 10-in. quadrant without telescope for the solar altitudes (Hevelius 1679; Cook 1998). He was therefore unable to decide whether or not there were sunspots in the solar disk and so left no remark on them. These zeros need to be removed from the group sunspot number database (Carrasco et al. 2015a). The updated group number database by Vaquero et al. (2016) omits the years entirely filled with zeros by Hoyt and Schatten (1998), but has not yet scrutinized all the individual cases in other years in the current version 1.2.

Sunspot group numbers and individual sunspot positions and areas from the drawings made by Hevelius (1647) in 1642-1644 were published by Carrasco et al. (2019a). The analysis was straight-forward, since Hevelius used the same style as Scheiner, indicating the ecliptic as a reference line.

\subsection{The Jesuits Malapert, Smogulecz and Schoenberger}

Positional information of sunspots can also be derived from the observations that the Jesuit Charles Malapert (Lat. Carolus Malapertius) made in 1618-1626, of which most are already included in Scheiner (1630). The drawings can be found in Malapertius (1620) and Malapertius (1633). The drawing in the first reference (plotted twice, on p. 21 and 22) contains a second group not present in the same drawing in the second reference. Malapert apparently showed only the motion of the larger group to demonstrate how the group extent is large in the disk centre, but compressed near the edges of the disk. Malapertius (1633) also contains a few observations made in Kalisz (Poland), Coimbra (Portugal) and Rome. The description in the latter reference, in the first drawing for 1619, mentions there were two clumps of spots on Jan 15-18, but only one clump on Jan 20. The drawing shows just a single spot for each day. Malapert apparently saw a sunspot group of any Waldmeier type between D and G which then 
evolved into an $\mathrm{H}$ type group on Jan 20. The message here is that the drawings are often simplified as to demonstrate the rotation of the Sun. The textual information indicates that there were more than just one spot (see also the discussion in Carrasco et al. 2019b). A counter-example is the drawing of 1618 Mar 8-18 showing details of a group of type $\mathrm{E}$ or even $\mathrm{F}$ at maximum, with up to 12 individually plotted spots on Mar 12. This is the same above mentioned sequence in which a smaller group of type B-D was left out as compared to Malapertius (1620).

A similar situation is encountered with the 55 sunspot observations in 1625 by Smogulecz and Schönberger (1626) whose textual information also contains more spots than the drawings. The confusing fact in this source is that the spots are called "stellæ" in the textual information, since the observers still believed they are observing small planets close to the Sun. The differences in sunspot numbers between the textual reports and the drawings are given by Usoskin et al. (2015) and provide updates to the group numbers given by Hoyt and Schatten (1998).

\subsection{Pierre Gassendi}

Pierre Gassendi (originally Gassend; 1592-1655) was a French philosopher and scientist who made a fairly large number of astronomical observations. In his book "De apparente magnitudine Solis humilis et sublimis", sunspots are briefly described on p. 78 but no observational details are given. Sunspot observations with full-disk drawings are available for 1633-1635 in Gassendi's six-volumes work "Opera omnia", namely in part IV called "Astronomica" (Gassendi 1658). A total of 11 drawings contain information on 40 days. The positions and areas of the sunspots were recently analysed by Vokhmyanin and Zolotova (2018a) using a rotational matching which minimised latitudinal variations of sunspots from day to day. Since there is a reprint of the book from 1727 made in Florence, differences between the drawings in the two versions may indicate the uncertainties involved. Vokhmyanin and Zolotova (2018a) find from this comparison that the sunspot areas are particularly uncertain.

\subsection{Georg Marcgraf}

Georg Marcgraf (1610-1644) made sunspot observations on 17 days from 1637 January 19 to 1637 October 15 (Vaquero et al. 2011). His manuscripts of astronomical observations containing information on sunspots are preserved in the Leiden Regional Archive (Collection Marcgraf LB7000/1). His notes are accompanied by three drawings of the solar disc (Fig. 10). The progression of these spots indicate heliographic latitudes ranging from $+1^{\circ}$ to $-16^{\circ}$, dominating the southern hemisphere. The solar cycle was certainly beyond maximum at the time, but not very close to the following minimum. Such low-latitude spots may occur right after the solar maximum as indicated by modern butterfly diagrams (e.g., McClintock et al. 2014). In any case, a few sunspot groups hardly define the exact phase of the solar cycle. 


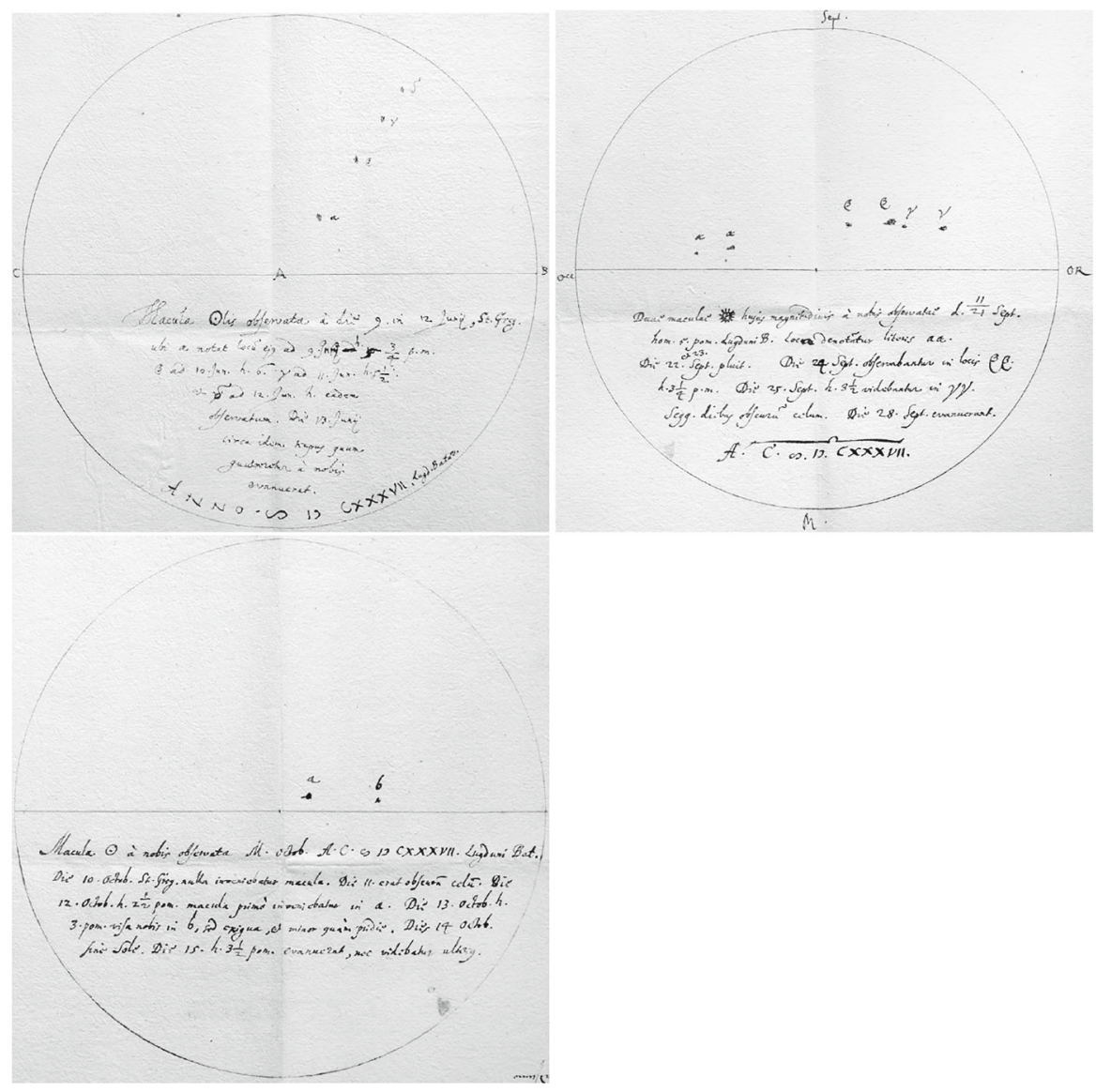

Fig. 10 Solar disk drawings by Georg Marcgraf for 1637 June 9-12, September 21, 24, 25 as well as October $12-13$ in the three panels, respectively

\subsection{Jean Tarde}

Jean Tarde (1561-1636) was a cathedral canon of Sarlat-la-Canéda, France, interested in geographical, astronomical and theological problems. After having met Galileo in Florence and Christopher Grienberger in Rome in the winter of 1614/1615, both having reported about sunspots, Tarde started his own observations of the Sun when returning to Sarlat (Baumgartner 1987). In his book "Borbonia sidera, id est planetæ qui solis limina circumvolitant motu" (Tarde 1620), we find six figures of the solar disk which contain sunspot information on 1615 August 25 (many spots, Fig. 11), 1615 November 17-27, 1616 March 3-14, 1616 April 16-27, 1616 May 17-28, and 1617 May 27-June 6. The drawings have not been analysed in terms of positions yet. A French version of the book appeared a few years later (Tarde 1627). Like Malapert, he argued that sunspots are small planets orbiting the Sun, while he did favour the Copernican system. The development of Tarde's detailed views can be found 
Fig. 11 Solar disk drawing by Jean Tarde of 1615 August 25 with an apparently complete set of sunspots seen, taken from Tarde (1620)

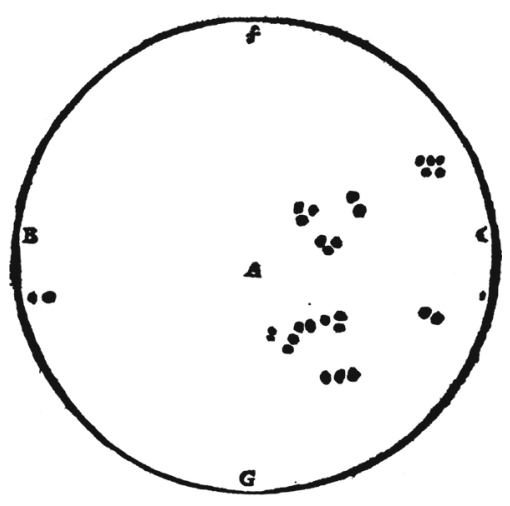

in Baumgartner (1987). A comparison with other observers at the time, especially with Saxonius (see next paragraph) was made by Neuhäuser and Neuhäuser (2016).

\subsection{Petrus Saxonius}

Twelve drawings of 1616 are available from Petrus Saxonius (1591-1625; for some biographical facts, see Neuhäuser and Neuhäuser 2016) who observed from Altdorf near Nuremberg, Germany. The dates given are 1616 February 24, 26, March 5, 6, $7,8,9,11,12,14,16$, and 17 (Julian) which translate to the Gregorian dates 1616 March 5, 7, 15-19, 21, 22, 24, 26, and 27. Printed versions of his observations are available at Germanisches Nationalmuseum in Nuremberg and in the Russian National Library, St. Petersburg (as part of the literary estate of the astronomer Georg Christoph Eimmart).

\section{The Maunder minimum}

As the 17th century progressed, a period of very rare occurrences of sunspots occurred and lasted into the early 18th century (e.g., Spörer 1889; Maunder 1894; Eddy 1976; Usoskin et al. 2015). The lowest activity was encountered in the period of 1645-1700 (Vaquero and Trigo 2015) when on average definitely less than one sunspot group per year was observed. We need to keep in mind though, that many of the nil reports in the sunspot group number database by Hoyt and Schatten (1998) are either deduced from generic statements about long periods or from observations with instruments that did not allow the detection of sunspots (cross-staff, quadrant, sextant; see previous Section). As we will see below, however, there is ample evidence that the Maunder minimum did not result from a lack of solar observation.

The last drawing of a sunspot available before the Maunder minimum dates from 1644 Oct 8 by Hevelius. The spot was located in the northern hemisphere of the Sun at a latitude of $b=+16.5^{\circ}$.

In 1645, Hoyt and Schatten (1998) list a group seen or reported by Pierre Gassendi on Aug 21 as the only non-zero report in that year. While they refer to Gassendi 
(1658) we cannot find any sunspot observation in the six volumes of that work. In Vol. I, there is a short section on the "historical" sunspot observations on p. 553 and no own observations. Vol. III contains general comments on sunspots and the Mercury transit of 1631 Nov 7 on p. 441. Vol. IV ("pars astronomica") does contain sunspot observations, but for 1645 mentions the word 'spot' only in connection with a lunar eclipse on Feb 10, where it refers to structures on the Moon (p. 451-453). The solar eclipse observations on Aug 21 do not mention spots. In the compilations of letters in Vol. VI, the ones to Godefroy Wendelin, Johannes Hevelius, and Jacob Revensburg (p. 243-253) about the same eclipse do not contain any information on spots. Gassendi talks again about lunar spots in a 1647 letter to Wendelin (p. 263), apparently observed during the lunar eclipse on 1647 Jan 20. Also Wolf (1857a, p. 49) and Wolf (1857c, p. 388) do not report on spots in 1645 , while they do for the 1630 s. We conclude that there is no positive report on sunspots in 1645 .

Further on, not a single sunspot was reported for 1646-1651 inclusive. Hevelius (1652) reports about 5 spots for 1652 Apr 1, clustered in probably two groups, as well as 2 spots for April 3, probably forming one group (Vaquero and Trigo 2014). April 6-8 were reported to be spotless. Note there was a partial solar eclipse on 1652 Apr 8 elaborately described (Hevelius 1652, 1679), which may have triggered sunspot observations beforehand.

The spot reported by Hoyt and Schatten (1998) for 1667 as seen by Athanasius Kircher (1602-1680) is a misinterpretation of the German text by Frick (1681), which reads

...daß unser Kunstliebende, nunmehr Seel. Herr Christoff Weickman, welcher sonderlich in opticis wol erfahren, und viel schöne und vortreffliche tubos verfertiget, zu unterschiedenen Zeiten nach der Sonnen mit einem gar schönen tubo gesehen, und verhoffte, er wolte auch dergleichen an der Sonnen vermercken, aber er konte dergleichen niemahls gewahr werden, ..., als hat ehrngedachter Herr Weickman an P Kircherum selbsten geschrieben, und ihme entdecket, daß er solches nicht an der Sonnen mercken könne, wisse nicht woher es komme, oder wo der Fehler stecke: Darauf P. Kircher von Rom auß 2. Sept. 1667. geantwortet; Es geschehe gar selten, daß man die Sonne also sehen könne, wie Er sie dann selbsten nicht mehr als einmahl in solcher Gestalt nemlich Anno 1639 gesehen und gefunden habe, und werde offt kaum in 100. Jahren 3. oder 4. mahl also gesehen.

translating to

that the late Christoff Weickman, who was experienced in optics and made a number of excellent telescopes, watched the Sun at various times hoping to see the like [sunspots] on the Sun, but could never get a glimpse of them [...] So Mr Weickman wrote to Father Kircher and uncovered him that he could not see such things on the Sun, does not know why this is or where the mistake could be. Father Kircher answered from Rome on 2 September 1667 that it happens very rarely that one could see the Sun as such; he had not seen it in such a manner more than once, namely Anno 1639, and it is seen as such just 3-4 times in 100 years. 
The date of 1667 is the date of the letter by Kircher in which he wrote that he apparently saw the last spots in 1639, not in 1667. The positive entry in Hoyt and Schatten (1998) therefore needs to be removed.

A counter-example is the negative report by Weigel in 1665 about sunspots in the 1660s as quoted by Spörer (1889, p. 315). The report, according to Spörer, says:

Es haben sich anhero viel fleissige Himmelsbeobachter gewundert, dass so lange Zeit keine Flecken an der Sonne zu spüren gewesen. Und müssen wir allhier zu Jena bekennen, dass, ob wir es wohl auf allerhand Weise versuchet, grosse und kleine Perspectiven aufgestellet und nach der Sonne gerichtet, wir dennoch von dergleichen Erscheinungen eine geraume Zeit nichts befunden.

translating to

Many diligent observers of the skies have wondered here that for such a long time no spots were noticeable on the Sun. And we need to admit here in Jena that, despite having tried in many ways, setting up large and small spotting scopes pointed to the Sun, we have not found such phenomena for a considerable amount of time.

This remark was used by Hoyt and Schatten (1998) to fill the entire years 1662-1664 with zero sunspot groups in their database. While the statement is a clear indication of extremely low solar activity, it is very difficult to encode it in a database of daily sunspot reports.

This means that for the Maunder minimum, there was a period of almost 10 years duration, from 1661 October 15 to 1671 July 31, for which no positive spot reports exist, even though we have a fair number of reports on the absence of spots, mostly from Hevelius, Jean Picard, and Martin Fogel. A second, very long period lasted from 1689 March 7 to 1700 November 1, in which only a single sunspot group was reported by three observers on 1695 May 27-30.

A large fraction of the observations around 1700, when solar activity started to recover from the Maunder minimum, were made at Paris observatory, most notably through the continuous observations by Philippe de la Hire, whose log books are preserved in the library of Paris Observatory at Avenue de l'Observatoire, but have not been studied in detail yet. There is also a fair number of sunspot reports with drawings there from periods within and after the Maunder minimum. Observers with single or up to tens of drawings in and after the Maunder minimum are, alphabetically, Nicolas Bion (1652-1733), Philippe de la Hire (1640-1718) and his son Gabriel Philippe de la Hire (1677-1719), Joseph-Nicolas Delisle (de l'Isle, 1688-1768), Antoine Laval (1664-1728, observed in Marseille and Toulon; Mulcrone 2001), Eustachio Manfredi (1674-1739), Luigi Ferdinando Marsigli (1658-1730), Esprit Pézenas (1692-1776, drawings for 1750-1751), Jean Picard (1620-1682), Paris Maria (Marquis de) Salvago (died in 1745, observed in Genua; Poggendorf 1863b), Vittorio Francesco Stancari (1678-1709), Achille Tondu (1760-1787, more than 60 drawings for 1778), Estienne Villiard (student of Picard; Jones 2008), and others. The observations of 1660-1719 were analyzed by Ribes and Nesme-Ribes (1993) confirming the strong dominance of - albeit low - activity in the southern hemisphere of the Sun found by Spörer (1889) as well as giving results for the differential rotation during the Maunder minimum. 
A machine-readable version of the sunspot position provided by Spörer (1889) and Ribes and Nesme-Ribes (1993) is available from Vaquero et al. (2015).

Gottfried Kirch (1639-1710) and his second wife Maria Margaretha née Winckelmann (1670-1720) reported about sunspot observations in 1680-1709 in letters to various other astronomers. The latitudes of 19 sunspot groups seen within 1680-1709 were constrained from these letters as well as information from letters to the Kirch family by Neuhäuser et al. (2018). In most cases, radial distances from the solar limb were available for a given sunspot group on several days. They allowed a rotational matching (see Sect. 3.2), but were sometimes indecisive of the hemisphere.

William Derham (1657-1735) was a theologian, who dealt with a variety of problems of natural sciences. In astronomy, he made various observations, most notably of the moons of Jupiter and sunspots. He also measured the speed of sound with a fair accuracy (Atkinson 1952). There are three full-disk drawings with information on 12 days in 1703 June-July in Derham (1703). In a follow-up paper (Derham 1710), two tables contain spot detections of 1703 October 9 (Julian) / 1703 October 19 (Gregorian) to 1710 October 18 (Julian) / 1710 October 28 (Gregorian). Two more drawings summarize the paths of various groups seen in this period. A comparison of the tables, drawings and descriptions led to improved numbers of sunspots and sunspot groups for the first decade of the 18th century (Carrasco et al. 2019b).

Peter Becker (1672-1753) observed from Rostock, Germany, in 1708-1710 and left one drawing with the progression of sunspot group on 1709 January 5-9 of which the larger spot had a heliographic latitude of $-10^{\circ}$ (Neuhäuser et al. 2015). The other spot locations need to be reconstructed from the textual information where one spot was roughly on the solar equator and another group was also at about $-10^{\circ}$ latitude. A compilation of sunspot latitudes inferred from a number of the above manuscript is shown in Fig. 12.

Johann Leonard Rost (1688-1727) provides three fairly precise sunspot drawings of 1717 September 10, September 11, and November 8 in his astronomical handbook (Rost 1718, note that the figures at the end of the book may be missing in some versions since the plates were apparently detachable from the book for educational purposes; the book was also reprinted in 1726).

Many of the corrections that need to be applied to the Hoyt and Schatten (1998) database were applied by Vaquero et al. (2016) in an updated version. For example, in the most substantial revision, more than 7000 daily observations of spotless days during the 1650-1700 depths of the Maunder minimum were eliminated. The improvement of the sunspot group database is of course a continuous process.

The period after the Maunder minimum is very poorly covered by observations. This does not appear to be a matter of lost observations, but of a real lack of interest, as we can read from the comment by (Schröter 1789, p. 4):

Wenigstens scheint dieser Gegenstand, so viel ich es besonders nach den Denkschriften der Pariser Akademie zu beurtheilen mag, seit 1719, und besonders seit 1722 mehr aus vergnügender Speculation, als aus wahrem Forschungseifer, und überhin nur sehr selten beobachtet zu seyn.

which translates to 


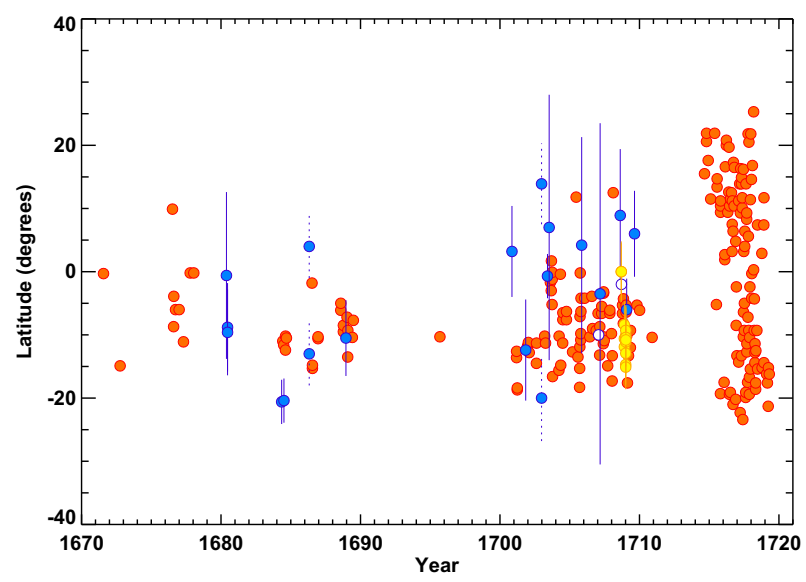

Fig. 12 Time-latitude diagram inferred from sunspot observations during the Maunder minimum. Red dots were taken from the analysis by Ribes and Nesme-Ribes (1993) based on the manuscripts at Paris observatory, blue dots are from Neuhäuser et al. (2018), based on letters written and received by Gottfried Kirch, and yellow dots are from Neuhäuser et al. (2015), based on observations by Peter Becker. Confidence intervals are not available for the first source. Among Kirch's spots, two spots allowed for two solutions each, indicated by broken lines for their confidence intervals. Two open symbols denote latitudes from Kirch's manuscripts which were highly uncertain and are given without error margins

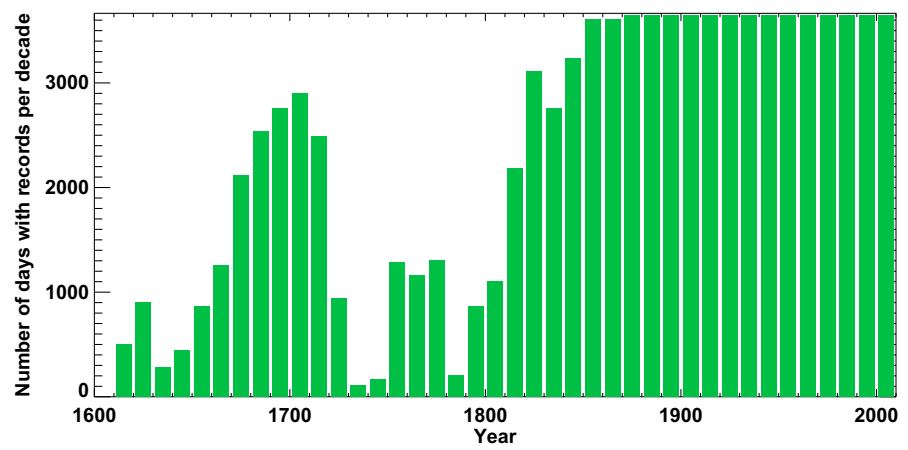

Fig. 13 Coverage of decades by days with observations, adapted from Vaquero et al. (2016). The numbers include all sunspot observations, also the ones without drawings, and zero-spot detections

It so appears that this subject, as far as I can judge especially according to the Paris memoirs, was cursorily very rarely observed since 1719, and since 1722 in particular, rather out of amusing speculation than out of true scientific zeal.

In the statistics of the recent update of the group sunspot number database (Fig. 13), we can indeed see the low numbers of observed days in the decades of 1720-1810 (Vaquero et al. 2016).

The last observer we are addressing for the period of recovery from the Maunder minimum is the Swedish astronomer and demographer Pehr Wargentin (1717-1783), before we go on to the second half of the 18th century. A three-page manuscript by him is stored in the Centre for History of Science of the Royal Swedish Academy of 
Sciences (Centrum för Vetenskapshistoria, Kungliga Vetenskapsakademien). It contains information on sunspots for 48 days from March 1 to May 13, 1747. While 17 drawings of the solar disk provide information on the locations of the sunspots, Wargentin also made measurements of the right ascension and declination differences of the spots from the centre of the solar disk. Those measurements provide a higher accuracy than the drawings and are available for 11 days (of which seven also include drawings) and delivered 43 sunspot positions (Arlt 2018). The drawings provided positional information for 10 additional days.

\section{The period before the Dalton minimum}

In general, observations of sunspots were scarce during the 18th century. Therefore, the recovery of old forgotten observations is a task of enormous interest today. We will begin this Section by reviewing in more detail the two longest observing records of the 18th century, namely the ones by Johann Caspar Staudacher and by the observers at Copenhagen Observatory under Christian Horrebow.

\subsection{Johann Caspar Staudacher}

During the period of recovering from the Maunder minimum, a large number of observers made drawings or measurements of sunspots, at least on a few occasions. Fewer people were interested in sunspots in the second half of the 18th century. The longest time series of drawings then is the one by Staudacher (or Staudach; he used both names with roughly the same frequency).

A compilation of observations of sunspots, solar and lunar eclipses is stored in the library of Leibniz Institute for Astrophysics Potsdam (AIP), Germany, and is in very good condition. The book also contains geographical drawings and architectural drawings made by Staudacher. The book has not been digitized completely as yet.

There is little information on the telescopes used by Staudacher. In his book of observations, he mentions an occultation of Saturn by the Moon on 1775 February 18, observed with a telescope of 3 feet focal length. In his preparations for the Venus transit on 1761 June 6, he talks about a "tubus colestis" with 4 feet focal length (Haase 1869), apparently an astronomical (Keplerian) telescope, showing the solar disk with a diameter of 3.75 in. on a sheet of paper. The foot in Nuremberg was $30.4 \mathrm{~cm}$ (Aldefeld 1838), resulting in focal lengths of, respectively, 91 and $121.5 \mathrm{~cm}$. The diameter of the solar disk was therefore $9.5 \mathrm{~cm}$ which is reasonably large for drawing the locations of sunspots. It is not large enough though to plot the size of the spots to scale.

The sunspot observations cover Feb 15, 1749-Nov 23, 1799, while the drawings end on Jan 31, 1796. All later reports are on spotless days. The record, however, has a very uneven distribution of observing dates (Arlt 2008). There are only 57 dates with reports on zero spots, with 40 of them falling into the second half of the observing period. 
Fig. 14 Sunspot drawing by Johann Caspar Staudacher showing 1760 February 13
Fig. 15 Sunspot drawing by Johann Caspar Staudacher on 1768 December 2, $10 \mathrm{~min}$ before sunset, corresponding to about $3: 45$ pm local time in Nuremberg
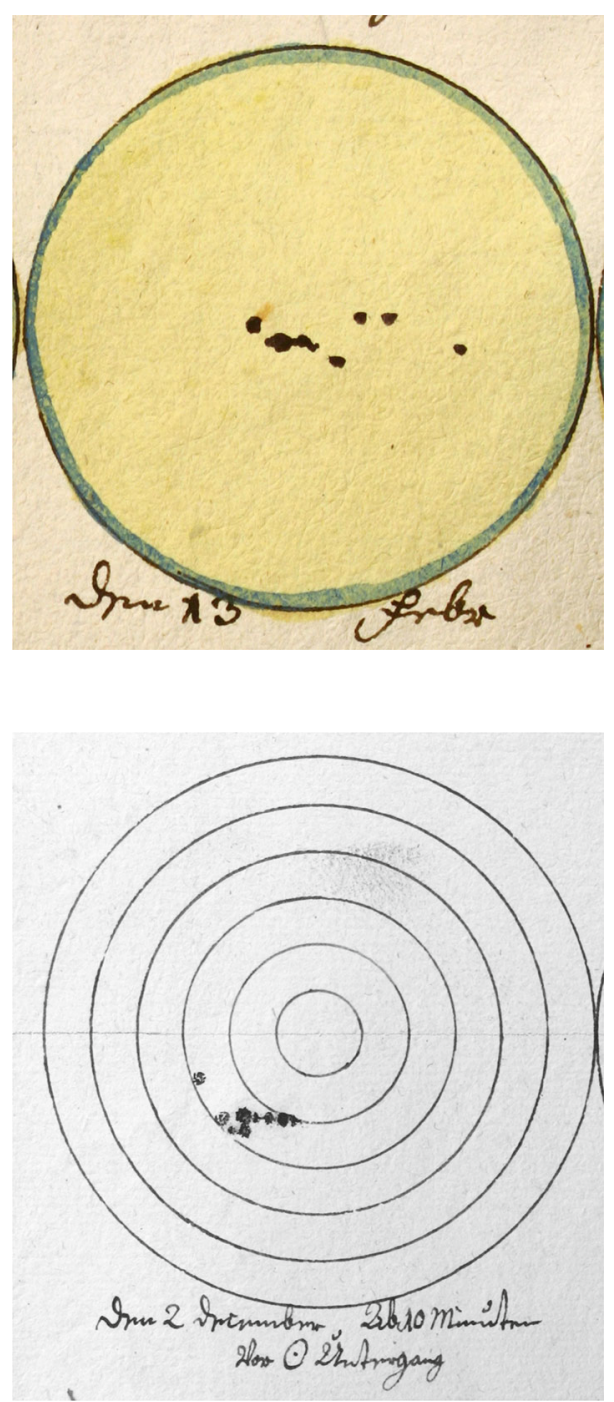

The example in Fig. 14 shows the typical style of the drawings until the end of 1760. After that the motion of the spots changed from right-left to left-right indicating a change in telescope. The detail with which the sunspot groups were drawn increases gradually until the style shown in Fig. 15 is reached. Staudacher also used the way of dividing the solar disk into six concentric rings as described in Sect. 3.3. The rings appear first on 1764 January 17.

There is no indication of the position angle of the solar disk. Arlt (2009a) used three different methods to infer estimates of the spot positions: (i) a rotational matching of adjacent drawings shown at least one common spot, (ii) the assumption that the drawings are plotted in the way they are visible in the sky (horizontal coordinate 
system), and (iii) the subjective interpretation of the distribution of the spots on the disk.

The two examples in Figs. 14 and 15 also demonstrate the problem of grouping the spots into sunspot groups in historical records. While Hoyt and Schatten (1998) listed one sunspot group for both 1760 February 13 and 1768 December 2, they did not have the drawings by Staudacher at hand as they were recovered later, by Arlt (2008). The numbers were taken from Wolf (1857b) instead, who listed one group with 8 spots and one group with 9 spots for these dates, respectively. Figure 14, however, shows clearly three groups and Fig. 15 shows two groups-the concept of a sunspot groups was apparently too broad by Wolf. An updated group count was made by Svalgaard (2017) and incorporated in version 1.2 of the database by Vaquero et al. (2016).

The butterfly diagram resulting from the positions derived by Arlt (2009a) shows an abundance of spots on the solar equator during cycles 0 and 1 (1749-1766), with hardly any migration in the two hemispheres (Fig. 27). A quantitative comparison with the observers described below may provide a clarification, whether this phenomenon was real or a result of the limited accuracy of Staudacher's drawings.

\subsection{Christian Horrebow and colleagues}

The second, very important set of data from the the second half of the 18th century was created at the observatory of Copenhagen. The building called Rundetån was erected in 1637-1642 and equipped as an observatory (Nissen 1937).

Christian Horrebow (1718-1776) was one of twenty children of Peder Horrebow and succeeded his father in being the head of the Royal Danish Observatory at Rundetårn (Poggendorf 1863a). Note that one of the children of Peder Horrebow senior was also named Peder Horrebow (1728-1812) and was also a mathematician and astronomer who, among other things, published meteorological data of 26 years at the Observatory (Poggendorf 1863a). Here, we report on the sunspot observations made under the supervision of Christian Horrebow. The information is taken from Jørgensen et al. (2019) and Karoff et al. (2019) unless otherwise noted.

Data are preserved from two distinct periods: 1761-1766 and 1767-1777. The instruments used in the first period consisted of a quadrant, a meridian circle (Rota Meridiana), and an instrument called a Machina Parallactica, which probably allowed transit time measurements together with declination measurements when the object was not in the south. In the second period, the primary instrument was a Machina Æquatorea, probably similar in construction as the Machina Parallactica. A comparable instrument is the Troughton telescope at Armagh Observatory shown in Fig. 20 (see Sect. 7.2). A typical example of a log book of the second period preserved from Horrebow is shown in Fig. 16.

Denmark (which included Norway and Iceland at the time) adopted the Gregorian calendar together with the protestant parts of the Holy Roman Empire in 1700 (Steinmetz 2011). We do not need to worry about the calendar system of the dates given by Horrebow and colleagues anymore. 


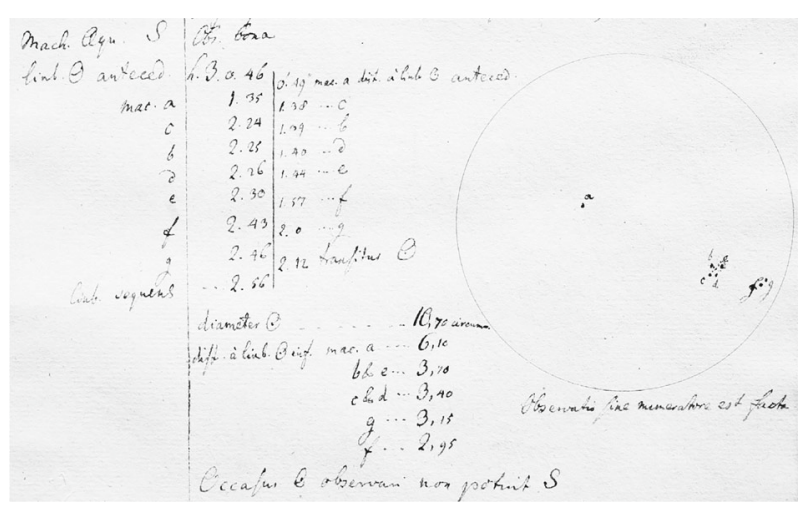

Fig. 16 Sunspot observation at Copenhagen Observatory of 1773 May 11. There are first transit time readings for the solar limbs and the sunspots a, c, b, d, e, f, and g, followed by vertical micrometer measurements for the same spots

\subsection{Other observers before the Dalton minimum}

An important series of drawings, in particular for the comparison with Staudacher, was published by Zucconi (1760). The precise full-disk drawings cover the period of 1754 April 19 to 1760 June 19. Even the sunspot areas are fairly realistic and penumbrae and umbrae were discriminated. A full set of measurements including the areas was made by Cristo et al. (2011). We will return to a result derived from Staudacher and Zucconi in Sect. 11.

A set of 23 sheets with drawings of sunspots in the solar disk, made by Johann Carl Schubert in 1754-1758, were mentioned and analysed by Kayser (1868). The tables in that publication contain mostly midpoint positions of sunspot groups and areas of individual spots from 1754 April 23 to 1758 May 12. They will provide another cross-check with Zucconi and Staudacher, but have so far not been used.

Although sunspot observations were mainly made in Europe, observations were also made in other parts of the world. In the oriental context, Hayakawa et al. (2018a) presented sunspot observations made by the official Japanese astronomers in 1749 and 1750. There are 15 drawings of telescopic observations. Hayakawa et al. (2018b) also report about one observation made by Iwahashi Zenbei on 1793 August 26, while a second observation is undated. In addition, observations of sunspots made by Jesuits in China were reviewed by Vaquero et al. (2007).

In North America, we can emphasize that Domínguez-Castro et al. (2017) recovered a couple of sunspot observations with drawings of the solar disk made during the eclipses of the Sun in 1777. Moreover, the collection of more than 300 sunspot drawings made by Humphry Marshall, probably made in the early 1770s, continues lost (Marshall 1774; Vaquero 2012). In the European context, several papers have been published recently reviewing the observations of additional observers such as Weidler in 1728-1729 (Carrasco et al. 2015b) and Toaldo in 1779 (Domínguez-Castro and Vaquero 2017). The former provided textual information on the number of sunspots with estimates of sunspot sizes, whereas from the latter we only have a note about the 
number of sunspots on 1779 November 3, while the note indicates that he must have made at least several sunspot observations in 1779 .

A set of seven drawings of the solar disk with sunspots was made by Georg Wilhelm Sigismund Beigel (1753-1837) in Dresden (Beigel 1785). The dates covered are 1785 October 26, 29, 31, November 6, 12, 15, and 17 (pers. comm. with R. Neuhäuser). The drawings have no indication of the position angle of the Sun, but appear to be of similar or somewhat higher accuracy than the ones by Staudacher. An analysis is yet to be done.

\section{The Dalton minimum}

\subsection{Honoré Flaugergues (1755-1835)}

Besides holding a number of administrative posts, Honoré Flaugergues (1755-1835; Poggendorf 1863a) observed astronomical and meteorological phenomena for many years. He recorded daily observations in large books stored at the library of Paris Observatory at Avenue de l'Observatoire. ${ }^{6}$ Some additional biographic information can be found in Wolf (1861) and Lynn (1905).

The first book starts with a two-line note on the Mercury transit on 1782 November 12, but regular notes begin with 1786 May 3 describing another Mercury transit, which actually took place on May 4 during sunrise. Flaugergues observed the exit of the Mercury disk which he compared to the appearance of a small sunspot: "rond et noir dans toute son etendu sous la figure d'une petite tache." Apparently, Flaugergues had seen sunspots before, but not recorded them in the books available.

On that first page, Flaugergues mentions a 15-in. telescope and a 3-foot astronomical telescope. These sizes correspond to focal lengths of, respectively, $40.6 \mathrm{~cm}$ and $97.4 \mathrm{~cm}$, using the standardized units of France of 1793, or $42.8 \mathrm{~cm}$ and $103 \mathrm{~cm}$, respectively, according to the still-in-use units of Lyon which were likely the relevant ones for Viviers (Aldefeld 1838).

The first sunspot observation was recorded for 1788 June 3 with measurements of four spots. Later, between the notes of 1792 and 1793, Flaugergues added a relatively precise drawing of the solar disk of 1788 June 3. Sunspots apear more regularly in his notes from 1794 onward. Flaugergues's handwriting ends in the last book on 1830 November 18 saying that the sunspot had vanished which was measured on November 15.

Less than a dozen full-disk drawings were made by Flaugergues. The usefulness of the data lies in the measurements he made using cross-hairs in the eyepiece, whose orientation has not been fully clarified. In most cases, transits across a vertical and a horizontal hair were recorded. Figure 17 shows an example with one of the rare drawings next to the transit times.

In a number of cases, Flaugergues wrote about an oblique hair, first mentioned in 1795. Preliminary work on the resulting sunspot positions indicated that the hair was

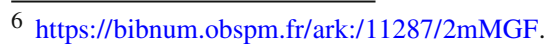




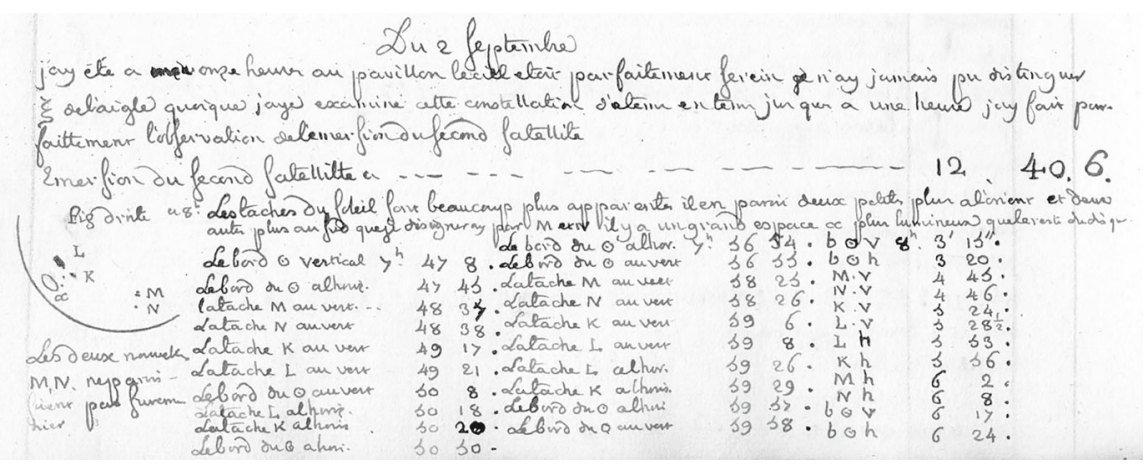

Fig. 17 The sunspot observation by Honoré Flaugergues of 1796 September 2. The abbreviations 'vert', 'horiz', 'v' and 'h' stand for the vertical and horizontal cross-hairs in the eyepiece, respectively (manuscript at Bibliothéque de l'Observatoire de Paris)

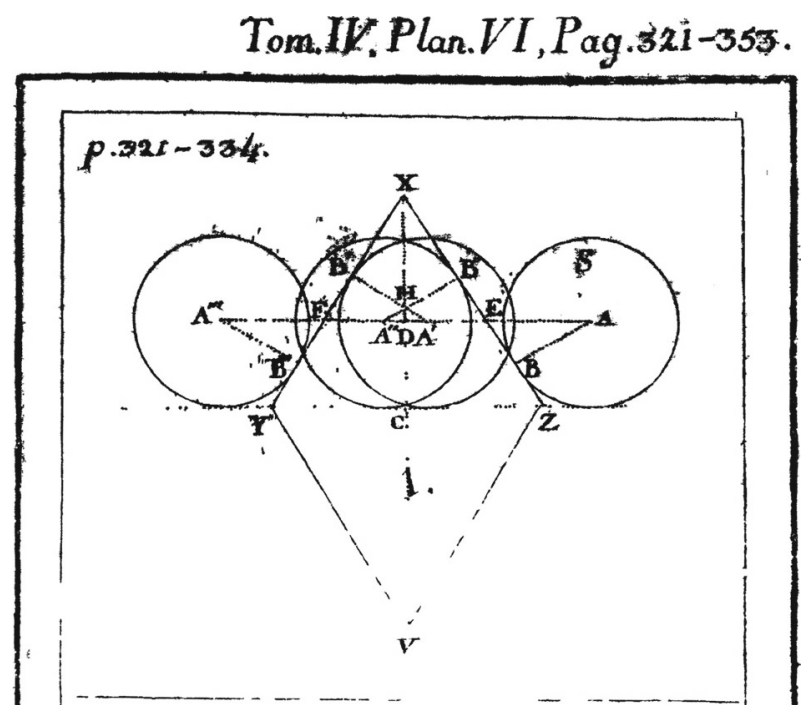

Fig. 18 Rhomb-shaped cross-hairs for measuring positions in the eyepiece as described by Flaugergues (1813)

inclined at $45^{\circ}$. However, a particular rhomb-shaped setup called a reticulum was in use in the 18th century to obtain unambiguous positions within the eyepiece (Fig. 18).

The positional information from the sunspot observations provided by Honore Flaugergues still need to be analyzed in detail. The sunspot positions may lead to a few updated group counts as compared to the original group counts by Wolf (1861) and Hoyt and Schatten (1998) as well as even compared to the update by Vaquero et al. (2016), but the amendments are expected to be very few. The carefulness of Wolf was in fact very high. The observation of 1800 December 4 , for example, contains passage times of four spots, of which the last two are only $5 \mathrm{~s}$ of time apart. The two spots may therefore have been as close as $4.5^{\circ}$ in heliographic coordinates (heliocentric angle), 
Fig. 19 Simple line-up of four spots as derived from the transit times measured on 1800 December 4 by Flaugergues. The small dot in the middle is the timing of the disk centre given by Flaugergues, probably computed from the limb timings

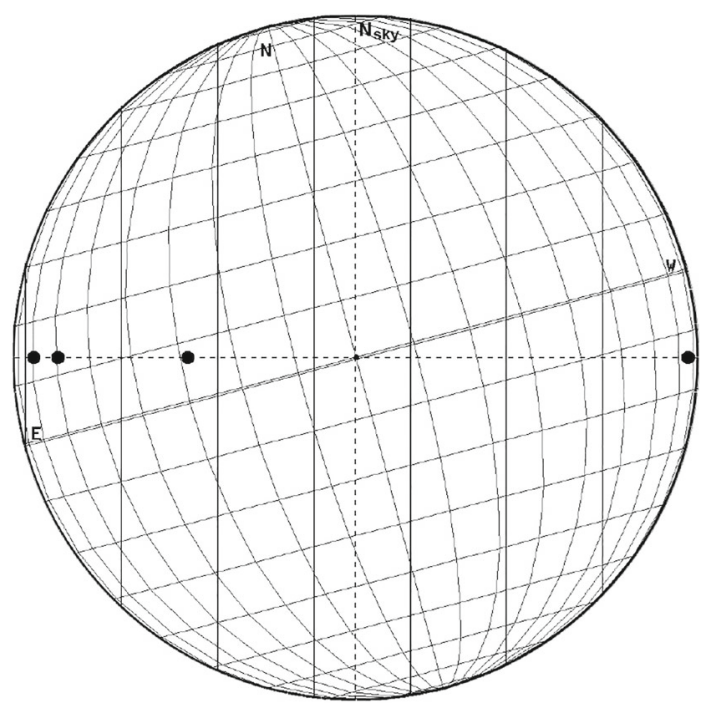

if the spots were in the disk centre and at similar latitude. Wolf therefore counted the two spots as one group. The simplest-possible reconstruction is shown in Fig. 19, but note that the two spots may as well have been on totally different latitudes.

\subsection{Other observers near the Dalton minimum}

Further data in the Dalton minimum include drawings and measurements made by Hamilton and Gimingham at Armagh Observatory in Northern Ireland (Arlt 2009b). Their main telescope is preserved and has been excellently restored (Fig. 20). Due to ambiguities, the accuracy of the reconstructions of sunspot locations is not very high, but given the scarcity of reports from the end of the 18th century, any data point is valuable.

Johann Hieronymus Schröter ran an extremely well equipped observatory in Lilienthal near Bremen, Germany, and published his main results on sunspots in Schröter (1789). There is a total of 44 detailed drawings of sunspot groups and faculae, but no full-disk drawing. In the magnifications, sometimes the solar limb or a parallel to the solar equator is indicated. The dates covered are 1786 November 7, December 27, 1787 January 7, 14, February 20-22, September 10, 22, 26, 28, 30, October 1, 5, 7, 19, November 7, 8, 11, December 1, 1788 February 28, March 3, 5, 9, 11, while three drawings are undated. There are no sunspot drawings in Schröter (1788); the spot-like structure shown in his Fig. 27 on plate VI is actually the Ring Nebula M57. He does describe, however, a projection device for solar and lunar observations in that book. Schröter later-from 1794-owned the largest German telescope of the time with a focal length of 27 feet and a mirror diameter of 20 in. (corresponding to, respectively, $7.9 \mathrm{~m}$ and $0.49 \mathrm{~m}$ (Schröter 1796; Aldefeld 1838). The very elaborate book on Jupiter and its satellites (Schröter 1798) contains one plate (VII) in the end with a full-disk drawing of the Sun, apparently of 1795 November 30 and described in a second part of 
Fig. 20 Equatorially mounted transit time instrument at Armagh Observatory with finely spaced hour-angle and declination scales, made by Troughton in 1795 (photo by the authors)

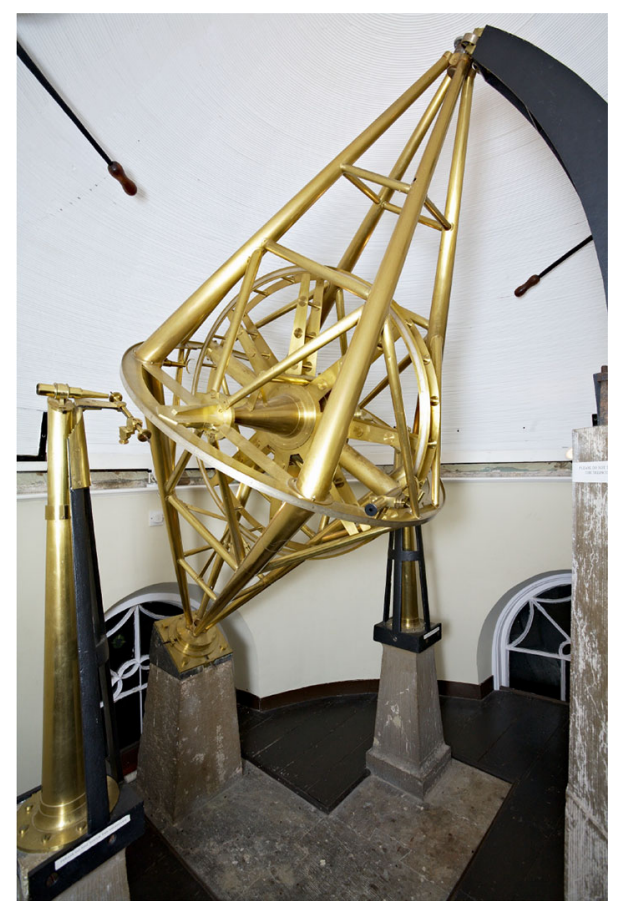

the book containing a section "Beobachtung eines vorzüglich merkwürdigen Sonnenfleckens, samt weitern Bemerkungen über den Naturbau der Sonne" (Gerdes 1995). The full-disk drawing shows 2 groups, one with 6 small spots and one near the southeastern limb with one big spot, which is the one Schröter described in detail. The same plate also contains four magnifications of the big spot as seen on 1795 December 3 as well as of one or two new groups on December 3 and 5.

Kremsmünster Abbey, Austria, constructed an observatory in the middle of the 18th century. Thaddäus Derfflinger (1748-1824) worked as a teacher at the monastery in the beginning and in parallel at the observatory from 1776 to 1824 (Bode 1824, p. 225), having been its director from 1791, and observed also sunspots (Poggendorf 1863a). Drawings of 1802 September 26 until 1824 September 21 are preserved in the archives of the monastery. These 487 drawings were mostly made before noon with an azimuthal quadrant during the observations of the solar elevation, but a few of them are rotated in a way that they appear to be made in the afternoon. This is in fact consistent with the meteorological log books, which contain rough sketches of the Sun which are at times also given for the afternoon-session of solar-elevation measurements. The drawings were analysed by Hayakawa et al. (2020) who delivered sunspot numbers as well as positions for this period in the Dalton minimum.

Denig and McVaugh (2017) describe sunspot observations by Jonathan Fisher (1768-1847) with drawings made at Blue Hill, Maine, from 1816 July 12 to 1817 September 4. In total, there are 25 drawings of which three show no sunspots. While the images clearly miss small pores, a number of bipolar sunspot groups can be iden- 


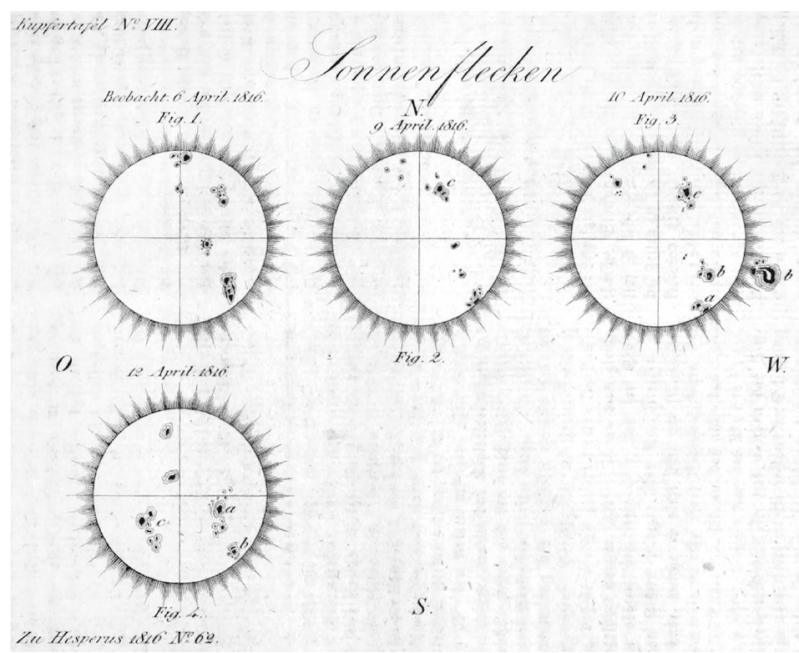

Fig. 21 Sunspot drawings by Franz Ignatz Cassian Hallaschka of 1816 April 6, 9, 10, and 12 (Hallaschka 1816b)

tified. Their tilt angles are difficult to assess since there are no indications of the orientation of the solar disk. There are also rather few sequences of drawings showing the same spots on different days in order to fix the position angle by rotational matching (see Sect. 3.2). The only sequences interesting for this method are

- 1817 June 24 and 28, and July 2;

- 1817 July 19 and 22;

- 1817 August 6 and 16 potentially;

- 1817 August 22 and 25 potentially; and

- 1817 August 29 and September 4.

Franz Ignatz Cassian Hallaschka (1780-1847) was a Czech researcher who carried out meteorological and astronomical observations in the beginning of the 19th century. A total of nine drawings of the solar disk with sunspots are available in his publications (Hallaschka 1814, 1816a,b). The textual information as well as the drawings were analyzed by Carrasco et al. (2018b). The spot areas are very much exaggerated though, and also the positional accuracy is only partly good (Fig. 21).

Johann Wilhelm Pastorff (1767-1838; Poggendorf 1863b) observed sunspots regularly from Drossen (now Ośno Lubuskie, Poland) for about nine years and occasionally reported sunspots during another five years before that. Original records are available at the library of the Royal Astronomical Society in London from 1819 March 4 to 1833 November 4 (Hoyt and Schatten 1995).

Franz von Paula Gruithuisen (1774-1852) was a Bavarian physician dealing also with astronomical and geological problems. Unrealistic already at the time was his conception of life on the Moon (Leibbrand 1966). In connection with eccentric ideas of the influence of solar activity, he also made sunspot observations and talks about "his solar observations of many years" (Gruithuisen 1836). In fact, manuscripts by Gruithuisen are preserved in the Bavarian States Library in Munich labelled Gruithuisiana. Obser- 

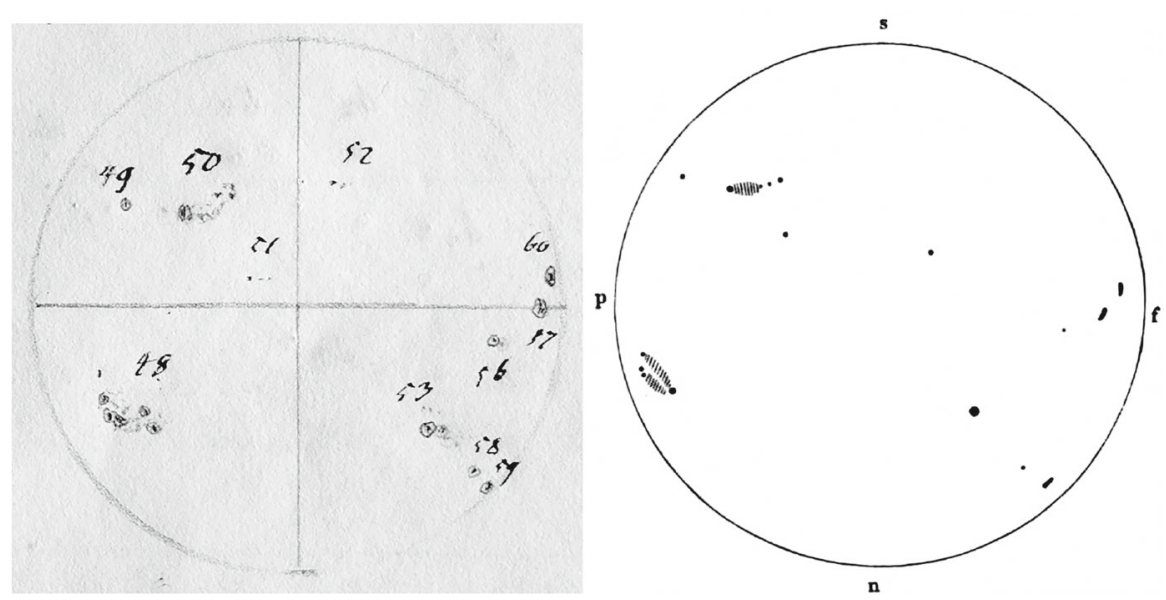

Fig. 22 Comparison of the drawing by Schwabe on 1837 February 11 (Arlt et al. 2013) and the one by Herschel, one day later, on 1837 February 12 (Herschel 1847). Both images show the Sun as seen through a Keplerian telescope, i.e. rotate by $180^{\circ}$. Note that the sunspot groups have progressed towards the left from February 11 to 12 due to the upside-down view

vations with more than 400 drawings cover the period of 1817-1848 (per. comm. with Hisashi Hayakawa). The observations have yet to be digitized and analyzed.

Kunimoto Toubei observed and recorded sunspots in the form of drawings from Japan from 1835 February 3 to 1836 March 24, with an additional single observation on 1836 September 25 (Fujiyama et al. 2019).

John F.W. Herschel published a book with astronomical results from the southern hemisphere (Herschel 1847) with two full-disk drawings of 1837 January 10 and 1837 February 12. There is also a plate with 13 detailed drawings of sunspot groups. Those drawings have varying scales but show lines spaced by 2 arcmin. The book was also known to Wolf (1858) and mentions 90 days for which Herschel made drawings "of the state of the Sun's surface." The original observing notes with drawings are stored in the library of the Royal Astronomical Society in London within their Herschel archive. Bennett (1978) counted 176 drawings of the solar disk and 13 magnified drawings (which are the ones mentioned above). We have not yet checked the difference of the 176 drawings to the 90 days mentioned above; more than one drawing was probably made during most days (Fig. 22).

Davis (1841) published a few drawings he made in Armagh on 1839 August 30 to September 4 of which four are full-disk drawings. The first images shows highly exaggerated sunspot areas, while the others are somewhat more realistic.

\section{The period before photographic records}

\subsection{Samuel Heinrich Schwabe (1789-1875)}

A very large collection of 8486 drawings and 3699 textual reports of sunspots seen in period 1825-1867 are available from Samuel Heinrich Schwabe who observed in 
Dessau, Germany (Arlt et al. 2013). The observing books of 1825-1867 are stored in the library of the Royal Astronomical Society in London, UK, and are in very good condition (Huggins 1876; Bennett 1978). Schwabe actually observed until 1868 Dec 15 (Schwabe 1869), but the observing book of the last year was apparently never sent to England and is probably lost.

The reason for Schwabe to observe sunspots systematically is sometimes given to have been the search for a new planet becoming visible by transits. Schwabe (1857b) describes the reasons as follows:

It was in consequence of a representation of my old and valued friend Harding of Göttingen, who wrote to me that there was a great want of physical observations of the sun, that the subject presented an almost unworked field, and that labour therein might be rewarded by the discovery of a planet interior to Mercury.

The possibility to find a planet was stated by Harding, who had discovered the asteroid (3) Juno in 1804, not by Schwabe. Since there is almost no mention by Schwabe about possible planets among his sunspot observing logs, we can conclude that the planet search was not the primary motivation of Schwabe to carry out his observations. One exception is $1862 \mathrm{Aug}$ 6, when Schwabe noted "[Group] 101 is a newly entered large dot. Is 101 perhaps a planet between Mercury and the Sun? But its motion at $12 \mathrm{~h}$ was unnoticeable." He also came back to this question, when Leverrier (1859, p. 379) proposed a planet inside the orbit of Mercury to explain the difference in Mercury's perihelion migration between observations and Newtonian solutions. Schwabe noted on 1860 Mar 26: "No planet was seen from 9h, from 11 to 11 3/4h, 2h, 3 1/2h, 4h pm". Since Schwabe was ill, the observer of the Sun was actually Emilie Wurzler who made similarly careful observations as Schwabe himself. Again, on Mar 27: "7h, 10 1/2, 11-12h noon, 2-3h pm no planet". Negative results on the potential planets continued on Mar 27-Apr 13, including a number of observations made by Schwabe personally. On Apr 24, he noted "[Group] 50 increased somewhat in size and constituted a small, round, sharply confined spot, which, if one hadn't assured himself of its fixed position, may have mistaken as the new planet between Mercury and the Sun."

Schwabe used several telescopes for his observations:

- 17-in. with eyepieces for magnifications 26,34

- 18-in. comet finder (same as 17-in.?)

- 2.5-foot (29-in. $=758.5 \mathrm{~mm}$ ) by Winkler with eyepiece for magnifications $36-38$ (Schwabe gives various measurements thereof), 56, and 84 times (5 November 1825-15 February 1828) aperture according to note on 1827 Jun 11: 1.5 in.

- 2.5-foot with eyepieces for magnifications 40 and 60 times (first observation on 9 November 1852)

- 3.5-foot with eyepieces for magnifications 48, 54-56, 84, 126, 168, and 184 times (since January 1826; telescope received Jan 22, 1826); aperture was $34^{\prime \prime \prime}=$ $76.7 \mathrm{~mm}$

- 6-foot with eyepieces for magnifications 30, 64, 81, 96, 108, 144, 216, and 324 times (received 13 February 1829, first observation of Saturn on 17 February, of the Sun on 26 February)

- 20-in. meridian telescope by Bobbe ("Mittagsfernrohr", erected 20-25 June 1840) 
The foot unit was the same as in Prussia at the time, defined within the Confederation of Rhine, and was equal to $313.85 \mathrm{~mm}$. Within the same system, the inch was $26.15 \mathrm{~mm}$ (Aldefeld 1838).

The "classical" setup of Schwabe's observations consisted of the 3.5-foot Fraunhofer refractor with roughly 45 times (notes vary from 42 to 48 times) and 84 times magnification and the 6-foot Fraunhofer refractor with an eyepiece of 64 times, plus a second eyepice with 96 times for closer inspection. The 3.5-foot refractor had an aperture of $34^{\prime \prime \prime}=77 \mathrm{~mm}$, according to the invoice from Fraunhofer (Fraunhofer 2017).

Schwabe stopped down the telescopes to $13 / 4$ in. (46 mm) and $2.5 \mathrm{in}$. (65 mm), respectively (Schwabe 1838). Later, Schwabe (1866) gave the apertures in Paris Lignes converting to $77 \mathrm{~mm}$ full aperture and $45 \mathrm{~mm}$ stopped down for the 3.5 -foot telescope, and $122 \mathrm{~mm}$ full aperture and $68 \mathrm{~mm}$ stopped down for the 6-foot telescope. These apertures were widened if sky conditions required that. At least the 3.5-foot telescope was equatorially mounted (Schwabe 1866). This is the reason why most of the drawings could easily be measured assuming an equatorial coordinate system. Filters on the eyepieces made by Utzschneider and Fraunhofer dimmed the sunlight adequately (Schwabe 1838, 1841). According to his notes, Schwabe added a 2.5-foot Fraunhofer in November 1852, which he apparently started using regularly in May 1853, and which he first mentioned in his publications in Schwabe (1856) for 1855, with 40 times magnification. His notes describe it as "small but superb" ("klein aber vortrefflich").

Possible changes in the quality of the observations due to changes in the telescope were evaluated by Schwabe (1861):

Ich trug sie wie früher mit dem 3 1/2 füss., 42 mal. Vergr. ein, weil ich mich überzeugte, dass das $21 / 2$ füss. und das 6 füss. keinen erheblichen Unterschied in der Zahl der Gruppen machte.

translating to

I plotted them [spots], as in the past, with the 3-1/2-foot [telescope], 42 times magnification, since I convinced myself that the 2-1/2-foot and the 6-foot ones do not make any significant difference in the number of groups.

The whole inventory of Schwabe's sunspot observations is summarized in Table 2, where the numbers of drawings and the additional number of days with textual reports per year is given. A detailed illustration of the enormous number of observations is shown in Fig. 23 based on monthly numbers. We can see the lower probability of carrying out an observation in the winter months, and we can also see the low number of drawings compared with the textual reports in solar minima, when many days exhibited zero spots.

An example of Schwabe's observations when he did not distinguish umbrae from penumbrae in his full-disk drawings is shown in Fig. 24. The second, much longer period when Schwabe plotted sunspots with penumbrae, started in 1831. An example of this period is shown in Fig. 25.

We can see-in both figures - that Schwabe briefly described the appearance of sunspot groups, but not to the extent that precise sunspot numbers could be derived from the textual reports. This is important to note, in particular, since there is a large number 
Table 2 Available days with drawings for given years, reported by Schwabe, mostly made by himself with some drawings from assistants, and additional days with purely textual resports

\begin{tabular}{lllllllll}
\hline Year & Drawings & Text & Year & Drawings & Text & Year & Drawings & Text \\
\hline 1825 & 24 & 14 & 1840 & 248 & 15 & 1855 & 97 & 216 \\
1826 & 165 & 121 & 1841 & 241 & 40 & 1856 & 75 & 245 \\
1827 & 274 & 25 & 1842 & 216 & 89 & 1857 & 203 & 120 \\
1828 & 269 & 20 & 1843 & 131 & 177 & 1858 & 245 & 88 \\
1829 & 233 & 26 & 1844 & 158 & 161 & 1859 & 263 & 79 \\
1830 & 191 & 26 & 1845 & 222 & 109 & 1860 & 255 & 77 \\
1831 & 225 & 34 & 1846 & 223 & 96 & 1861 & 243 & 76 \\
1832 & 167 & 99 & 1847 & 227 & 49 & 1862 & 242 & 75 \\
1833 & 74 & 169 & 1848 & 243 & 35 & 1863 & 244 & 87 \\
1834 & 84 & 189 & 1849 & 227 & 58 & 1864 & 244 & 79 \\
1835 & 131 & 108 & 1850 & 229 & 77 & 1865 & 221 & 86 \\
1836 & 163 & 24 & 1851 & 231 & 79 & 1866 & 189 & 161 \\
1837 & 153 & 3 & 1852 & 280 & 56 & 1867 & 88 & 224 \\
1838 & 204 & 0 & 1853 & 231 & 69 & 1868 & $(301)$ & \\
1839 & 199 & 4 & 1854 & 213 & 120 & & & \\
Total & 12,491 & & & & & & & \\
\hline
\end{tabular}

The observing book of 1868 is not available; the total number of observing days is taken from another manuscript by Schwabe (Arlt et al. 2013)

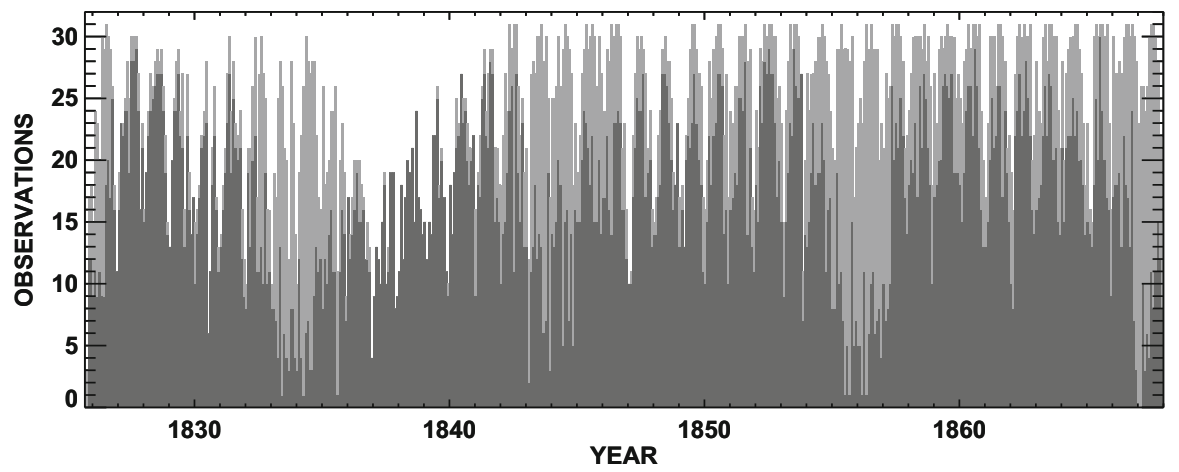

Fig. 23 Monthly numbers of observations by Schwabe. Black are days with drawings; grey are days with textual reports

of 3699 reports without drawings, but with descriptions of how the groups evolved as compared with the previous observation. Since the vanishing, or sometimes also the emergence, of groups is noted, the textual reports may be useful in determining group sunspot numbers for many more days than the days with drawings. The textual reports were listed by Wolf (1860), but probably not used, because the exact number of spots is missing. They did serve for the purpose of group sunspot numbers though (Hoyt and Schatten 1998). Schwabe's grouping of spots was in many cases too sloppy. A revised 


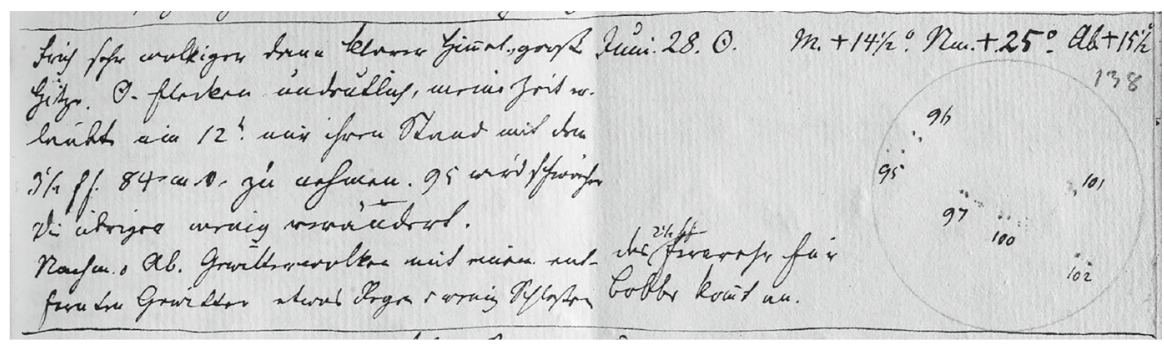

Fig. 24 Record of 1829 June 28 from Samuel Heinrich Schwabe's observing books. The text reads: "In the morning very cloudy then clear skies, very hot. Sunspots indistinct, my time allowed to note the position of the spots with the 3-1/2-foot and 84 times magnification at $12 \mathrm{~h}$. Group 95 becomes weaker. The others with little changes. In the afternoon and evening, storm clouds with distant thunder and some rain and a little bit of hail. Bobbe arrived"

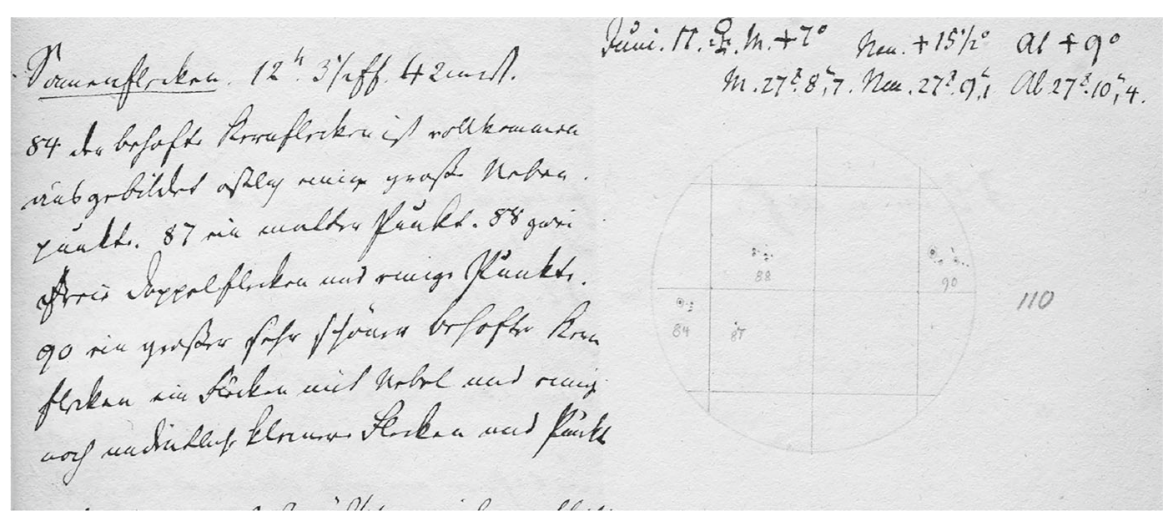

Fig. 25 Record of 1847 June 11 from Samuel Heinrich Schwabe's observing books. The text reads: "Sunspots. $12 \mathrm{~h}$ with 3-1/2-foot and 42 times magnification. The spot 84 with a penumbra is fully developed with some large secondary spots to the east. 87 is a faint dot. 88: two detached double-spots and some dots. 90 is a large, very nice spot with a penumbra and a spot with an envelope and a few, still indistinct, smaller spots and dots"

group number can be deduced from the group designations used in the database of sunspot positions by Senthamizh Pavai et al. (2015, http://cdsarc.u-strasbg.fr/viz-bin/ Cat?J/A\%2bA/584/A73).

Schwabe (1838) reported about "several thousand spots and dots" seen in 1837, without giving a date. In the database by Senthamizh Pavai et al. (2015), we find the maximum number of individual spots on 1837 Jan 4 with 73 measurements. The question is to which extent Schwabe mistook the granulation or other effect for pores here. In Schwabe (1857a), we find the remark

...mit dem 6 ff. 64 mal. Vergr. fand ich die Sonnenscheibe oft mit feinern Punkten und grauen Poren fast völlig überdeckt.

which means

With the 6-foot and 64 times magnification, I often found the solar disk almost entirely covered with finest dots and grey pores. 
Since these structures cannot be actual spots, we have to be careful with the above statement about thousands of spots.

In the majority of cases, the drawings are aligned with the celestial coordinate system and allow straight-forward measuring. The remaining part of the observations without indications of the position angle of the solar disk were analyzed using the rotational matching of drawings adjacent in time. The full set of data was published by Arlt et al. (2013) with updates in Senthamizh Pavai et al. (2015).

While the sunspot drawings, in particular the ones starting in 1831, look fairly realistic, the sizes of the spots are clearly overestimated. This holds true especially for the smallest spots and pores, since the pencil tip just does not allow plotting extremely small structures. A statistical approach was therefore used by Senthamizh Pavai et al. (2015) to map the drawn sizes to actual sunspot areas. The method led to an area distribution that is quite similar to the one obtained by Bogdan et al. (1988). The areas are also fairly consistent with the observations by Sestini (1853) who provides a number of sunspots commonly observed with Schwabe, but at a much better plotting scale. The two drawbacks of the method are, firstly, the dependence on modern data, implying we may not detect whether the area distribution was truly different from the 20th century, and, secondly, the method is sensitive to the minimum spot area which was assumed to be the lower detection limit of Schwabe.

After decades of observing sunspots, Schwabe noticed that it is not easy to determine the length of the solar cycle as he mentioned in Schwabe (1861):

Die Periodicität scheint mir nach drei bis vier Perioden, nähmlih von 1826 bis 1860 noch nicht bis auf ein Jahr mit Sicherheit bestimmt werden zu können, wie ich schon früher gegen A. v. Humboldt äusserte.

\section{which translates to}

It appears to me after three to four periods, namely from 1826 to 1860 , that the periodicity cannot yet be determined with a certainty of one year, as I mentioned earlier to A. v. Humboldt.

Since he then compares the cycle with the seasons varying in length from year to year, he obviously considered sunspots a solar "weather phenomenon" and assumed it was not a lack of accuracy, but a physical variability which the cycle showed.

Schwabe was never counting spots explicitly, but noticed how difficult it is to find their exact number and to define a spotless day. Schwabe (1864) wrote:

An zwei Tagen, nämlich am 5. und 6. September bemerkte ich keine Flecke, ...die mit dem 3 1/2-f. Fernrohr bei 42mal. Vergröss. sichtbar waren, obgleich sie mit dem 6-f. bei 64-mal. Vergr. viele deutliche Poren zeigte.

which translates to

On two days, namely the 5th and 6th of September, I did not notice any spots, ... as observed with the 3.5-foot telescope at 42 times magnification, whereas the Sun showed many distinct pores in the 6-foot one at 64 times magnification.

With almost 12,500 observing days, the sunspot record by Schwabe is the largest made before the photographic era. He was awarded the Gold Medal of the Royal 
Astronomical Society in 1856 for his efforts (Johnson 1857). Cliver (2005) recounts the interaction between Richard Carrington, who likely helped to write Johnson's Gold Medal address, and Schwabe. The Medal was transmitted personally by Carrington who visited Schwabe on 1856 October 15, as documented by Schwabe's brief comment "Richard Carrington from Redhill visited me," and by Carrington (1856).

\subsection{Richard Carrington (1826-1875)}

After having worked on a stellar catalogue from Durham observatory and later from his own observatory at Redhill near Reigate, Surrey, UK, Richard Christopher Carrington started sunspot observations on November 9, 1853 (Clerke 1887; Carrington 1863). Cliver and Keer (2012) give a recent account of Carrington's life and work.

The original manuscripts by Carrington are stored by the Royal Astronomical Society at Burlington House in London, UK. The MSS 3.1-3.3 contain full-disk drawings of the Sun with its spots from 1853-1861. MSS 1.1-1.3 contain the original notes of the observations and cover 1853-1861. The detailed data reduction was made in MSS 2.1-2.7. Beyond collecting momentaneous drawings of the solar surface, Carrington started to reconstruct the sunspot distribution over the whole heliographic longitude range from observations of a full solar rotation. These kind of Carrington maps or synoptic maps are shown in MSS 4. It is a way of showing the solar surface still in use today. Carrington also went one step further and compiled the latitudes of sunspots over many rotations in a time-latitude diagram which we today know as the butterfly diagram (Carrington 1858).

All sunspot observations with positional data from 1853 Nov 9 to 1861 Mar 24 including synoptic maps are compiled in Carrington (1863). The positions can be used in a straight-forward way, except if one uses longitudes, the difference between Carrington's original longitude definition and the today's definition of the solar rotational frame has to be taken into account. The data were scrutinized and transcribed into machine-readable form by Casas and Vaquero (2014).

The areas of sunspots were not measured by Carrington, but they are represented approximately in the synoptic maps at the end of the book. This would mean the areas are not available for every day a group was visible but only once, near the solar central meridian. There is an analysis of the drawings by De la Rue et al. (1866) giving the sunspot areas for all individual days, but co-author Benjamin Loewy was later accused of uncandid computations (see Charbonneau 2002, and references therein). The former publication also indicates, as a result from conversations with C. M. Bose, an assistant of Carrington, that the drawings were made by the projection method. Carrington (1863) actually names a number of assistants for observing and data reduction, namely Mr Simmonds, J. Breen, H. Criswick, Dr von Bose as well as Dr Schröder. Bose's notes-about 150 pages with computations and some details of sunspot groups-are preserved in the library of Archenhold Observatory in Berlin. Carrington wrote that he actually stopped observing because he could not find an assistant after Dr Schröder left. 


\subsection{Gustav Spörer (1822-1895)}

Inspired by the observations by Richard Carrington, Friedrich Wilhelm Gustav Spörer began sunspot observations in 1860 when working as a grammar school teacher in Anklam, Germany. Being an expert on ephemeris and orbital computations, he started taking positional data in December 1860 (Spoerer 1861).

When the Astrophysical Observatory Potsdam was founded in 1874, he became one of the first three astronomers who were supposed to study the physical processes on the Sun and stars.

Spörer created heliographic longitude-latitude diagrams which were known from Carrington and are often called Carrington maps or synoptic maps of the Sun.

Spörer $(1874$, p. 1) reports that he did not measure all sunspot groups visible on a given day in 1861-1864:

In the beginning, I used a 3.5-foot telescope for my observations and took only the positions of selected spots with a circular micrometer. [...] After I had received a 7-foot telescope in 1865, I had a grid plate made with which then the positions of all major spots, the start and end points of the groups, could be measured with sufficient accuray.

Starting with Aug 18, 1861, Spörer added observations by Heis (marked by ' $\mathrm{H}$ ' in the publications) to fill gaps in his own record. Additionally, observations by Pietro Angelo Secchi in Rome ('Rom' and 'R') and some data from the observatories in Vienna ('W'), as well as Leipzig and Berlin (no explicit positions printed) were used.

The synoptic maps published by Spörer were digitized and measured by Diercke et al. (2015). Note that, again, the sunspot groups were plotted when they were near the central meridian, i.e. the date for which the positions hold was inferred from the position of the groups in the maps. In some cases, errors in the positional tables could be found.

\subsection{Further data from the 19th century}

Benedict Sestini (1816-1890) went from Italy to the United States in 1848 and made sunspot observations at Georgetown College in 1850. The precise drawings by Sestini (1853) cover only a short period of 1850 September 19 to 1850 November 4 , but are a valuable data set for comparison with Schwabe.

A large set of sunspot positions is also available in Peters and Frost (1907), where actually Frost published Peters's observations from 1860 May 23 to 1870 May 30. There are no drawings in that book though. Machine-readable versions were also created by Casas and Vaquero (2014).

A collection of 109 sunspot drawings made in the Royal Astronomical Observatory of the Spanish Navy located in San Fernando, Cadiz (Southern Spain) from 1884 August 1 to August 18 was studied by Galaviz et al. (2016b). These drawings represent the entire solar disk displaying, in some cases, enlargements of the sunspots with details such as light bridges, darker regions in the umbra or penumbral filaments. 
The pioneers at solar photography at Kew Observatory in Richmond, UK, derived sunspot positions and areas in (De la Rue et al. 1869, 1862-1863) and (De la Rue et al. 1870, 1864-1866), but see note in Sect. 8.2. The data were converted into digital format by Casas and Vaquero (2014). The actual photos are not published in these references.

Starting in 1874, an exceptionally long time-series of full-disk solar photographs was eventually compiled by the Royal Greenwich Observatory, made at Greenwich until 1949 May 2, then from Herstmonceux until the end of 1976, and supplemented by observations from associate observatories in South Africa, India and Mauritius, as well as by occasional gap-fillings from Australia and the US (e.g., Dezsö 1987; Willis et al. 2013, 2016).

\section{Collections of sunspot drawings around 1900}

Two valuable sets of full-disk drawings of the Sun are available at the Heliophysical Observatory of the Research Centre for Astronomy and Earth Sciences in Hungary, ${ }^{7}$ featuring digital images of observations at Ogyalla Observatory (now Hurbanovo, Slovakia) from 1872 May 16 to 1891 December 27 as well as images from the observations at Haynald Observatory in Kalocsa, Hungary, covering 1880 June 9 to 1919 May 13 (Baranyi et al. 2016).

Alfred Wolfer (1854-1931) was the successor of Rudolf Wolf at the Observatory of Zurich (Eidgenössische Sternwarte) and observed sunspots, first in parallel with the latter, and after Wolf's death in 1893 as the director until 1928. Detailed sunspot observations from Zurich are available in digital form for $1883-1908 .{ }^{8}$ There is a second set of less detailed drawings made for the determination of the sunspot number for 1881 September 4 to 1928 October $28 .^{9}$ The solar disks contain no information on the position angle and the disks are not even drawn with a pair of compasses until 1883 April 13. Instead, the sunspot number is given in Wolf's syntax 〈groups〉.〈spots〉 with each drawing. The second set of volumes also contain 20th-century drawings by Beck, Broger, Brunner, and Buser (observing from Arosa, Grisons).

Sunspot drawings made with the 150-feet solar tower telescope at Mount Wilson start on 1917 January 4 with a drawing by Ferdinand Ellerman and are available at the University of California Los Angeles. ${ }^{10}$ The drawings exclude the poles of the Sun, but contain part of the solar limb as well as orientation markings. The whole archive was digitized and solar features were extracted leading to half a million measurements of sunspot umbrae and pores (Tlatova et al. 2018).

\footnotetext{
7 http://fenyi.solarobs.csfk.mta.hu/en/databases/HHSD/.

8 http://www.e-manuscripta.ch/sonnenbeobachtung/nav/classification/1726380.

9 https://www.e-manuscripta.ch/zut/content/structure/2052922.

$10 \mathrm{ftp} / / /$ howard.astro.ucla.edu/pub/obs/drawings.
} 


\section{The understanding of sunspots over time}

The first understanding of sunspots as a feature of the solar body is typically attributed to Galileo who rather unbiasedly noticed the variability and the irregularity of the spot. While first proposing the opposite, Scheiner later adopted this view and argued similarly in Scheiner (1630). An early mention of the same facts is preserved from William Crabtrie, who wrote a letter to William Gascoigne in 1640 (Derham 1710):

I have often observed these Spots; yet from all my Observations cannot find one Argument to prove them other than fading Bodies. But that they are no Stars, but unconstant (in regard of their Generation) and irregular. Excrescences arising out of, or proceeding from the Suns Body, many things seem to me to make it more than probable.

While astronomers tended to adopt that sunspots are part of the Sun, the wider scientific community appears to have been sceptical about spots on the solar surface. Smogulecz and Schönberger (1626) plotted the spots as round objects and talked about 'stars' (e.g., "Anno 1625.Ingolstadij 27. Augusti hora 1.min 34. visæ stellæ 6"-6 spots seen on 1625 August 27) in the textual description of the spots. They were therefore overlooked as sunspot observations by Hoyt and Schatten (1998). Much later, multitalented but non-astronomer Otto von von Guericke (1672) still wrote about sunspots:

Etiamsi enim disco Solari tam vicinæ videantur, ut ab eo quasi nullo modo queant separari, ac proinde nobis tanquam maculæ appareant, nihilominus tamen Sidera sunt, propriis circulis circa Solem haud aliter delata, quam Mercurius \& Venus.

which translates to English:

Even though we see them so close to the solar disk, that they could not be separated from the Sun and appear to us as spots, they are still celestial bodies with their own circles around the Sun not different from the ones of Mercury and Venus.

Von Guericke even repeated this belief in 1680 in his last scientific statement about the nascent thermodynamics in a letter to Georg Caspar Kirchmaier Schneider (1997, p. 131):

Die Sonne mit ihren Flecken - nach der üblichen Bezeichnungsweise - die man richtiger als zwischen Sonne und Merkur befindliche Planeten ansprechen sollte, trägt wohl kaum zur Entstehung der Winde bei, ...

translating to

The Sun with its spots - according to the usual terminology - which one should name more correctly as planets between the Sun and Mercury, does not contribute to the origin of winds, ...

At the same time, Kirch (1681) writes at the end of his section on sunspots seen in 1680: 
Es haben zwar etliche vorgeben wollen/die Maculn wären kleine Planeten/welche nahe um die Sonne ihren Lauff hätten; aber es laufft wider die Erfahrung. Denn es entstehen etliche Maculen mitten in der Sonnen/werden kleiner oder größer/solches kan bey ordentlichen Planeten nicht seyn. So sind auch die Planeten rund / die Maculen aber in mancherley Form/denen Wolcken gleich.

\section{of which the English translation reads}

Though some have claimed the spots were small planets revolving closely round the Sun, it is counter to expectations. For several spots form in the middle of the Sun, become smaller or larger, not being possible for ordinary planets. Planets are also round, the spots however of various shape, similar to clouds.

There is a number of thoughts on the nature of sunspots in the 18th century. Their full account goes beyond the scope of this review. Cassini (1730), for example, wrote about his observations of the penumbra in 1684:

Cette nébulosité s'arrondit à mesure que la Tache approcha du centre, cela ne manque jamais d'arriver, et c'est une marque que cette nébulosité est platte, qu'elle ne paroît étroite que parce qu'elle se présente obliquement, comme la surface du Soleil vers le bord apparent, sur laquelle elle doit être couchée.

which translates to English:

This penumbra becomes typically rounder, when the spot approaches the centre, this is an indication for a flat penumbra, and that it looks slim only because it appears in an oblique manner, just as the surface of the Sun near the limb, on which it [the penumbra] has to lie.

In the observing records discussed here, we find the remark by Staudacher from 1761 or 1762, as an annotation to an undated drawing with a single spot:

Diesen Flecken hab ich sonst nicht mehr gesehen, gleich den andern Tag nicht mehr, war nicht röthlicht auch nicht blaulicht wie die andern $\odot$ enflecken, sondern ganz schwarz und rund, war es etwan ein neuer Planeto?

which translates to

This spot I have not seen on other occasions, not even on the next day, it was neither reddish nor bluish like the other sunspots, but entirely black and round, was it perhaps a new planet?

It seems evident that Staudacher did not take sunspots for planets as he was distinguishing the appearance of the two kinds of objects.

A wide-spread concept was that sunspots are dark mountains sticking out of a liquid, luminous envelope of the Sun. In line with this, we read another comment by Horrebow (1770), whose records are presented in this review:

...that virtually all of the spots are observed close to the Sun's equator, where in theory the highest mountains should be, just as we on Earth observe that the highest mountains are in the lands which are closest to the equator. 


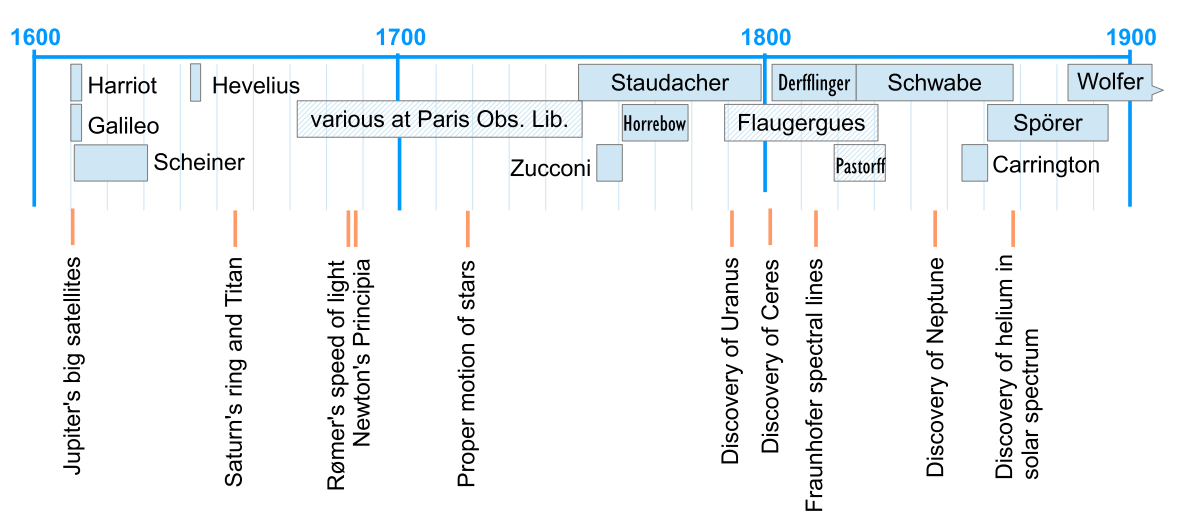

Fig. 26 Time line of the telescopic era of sunspot observations with the major observers from whom we have substantial positional sunspot information and some additional astronomical discoveries for context

The thought shows how easily one can draw wrong conclusions from analogy, but, frankly, we still do not know for sure why sunspots appear only at low latitudes.

The fact that sunspots constitute depressions in the visible surface of the Sun was convincingly demonstrated by Alexander Wilson (1774). In view of the picture at the time, that the Sun is a solid sphere with a luminous fluid ocean, this explanation was questioned by Jérôme Lalande (1779, p. 508) arguing that depressions would cause an inflow of the ocean to the umbra and, therefore, a spot lifetime proportional to the spot area. Since that was not observed, spots could not be depressions (at least of constant depth). Another argument was that the light bridge between two very close umbra is observed to be remarkably bright, while a luminous fluid floating into two umbra should easily run empty and be fainter. He favoured the topography of the dark solid sphere below the ocean as the reason for spots and penumbrae. Some mountains stick out of the fluid and are visible as spots, shallow parts of the ocean around these rocks appear as penumbrae. Challenged by the criticism, Wilson (1783, p. 155) even constructed a wooden model of the Sun with engraved spots and showed how the umbra of a spot can actually disappear before the spot reaches the very limb. Wilson's observations were backed up by detailed descriptions of the appearance of sunspots near the solar limb by Herschel (1795).

Even though there was a debate on what sunspots really are, it was widely accepted that sunspots are part of the Sun. For example, William Herschel viewed sunspots as glimpses of a dark and solid inner solar sphere through transient holes in a luminous solar atmosphere. Herschel's general "scheme of solar constitution held its ground until the physics of the Sun were revolutionized by the spectroscope" (Clerke 1885, p. 62). A review on the general development of the view of the Sun as a gaseous body with many historical sources beyond the ones on sunspots can be found in Robitaille (2011). A graphical time-line of important records of sunspot drawings along with some astronomical discoveries is shown in Fig. 26. 


\section{Physical quantities derived from sunspot drawings}

As we have seen, in many cases, the heliographic coordinates of individual sunspots can be derived from historical drawings. Sometimes they are mere estimates with hardly better than $10^{\circ}$ accuracy, but in the majority of cases, the accuracy is good and can be better than $3^{\circ}$. The sunspot areas can be determined with somewhat lesser confidence. The spots are usually not drawn to scale and require a calibration which is typically non-linear, i.e. more than just a correction factor. A simple group-averaged time-latitude distribution (butterfly diagram) covering the period 1610-2016 is shown in Fig. 27.

Instead of the absolute spot area, the ratio of penumbral to umbral area may be an interesting quantity, as it suffers less from the scale problem and is also applicable to drawings which do not show the entire solar disk. The evolution of this quantity over time has not been studied much; an attempt was made for the Maunder minimum by Carrasco et al. (2018a) and compared with data from de la Rue of 1862-1866 (Vaquero et al. 2005, see also references therein).

In general, once the positions and areas of individual sunspots are determined, derived quantities may become accessible, such as

- an improved sunspot number, since the groups can be discriminated;

- the average group locations;

- the tilt angle of the groups;

- the polarity separation of the groups;

- the rotation of the Sun;

- the growth and decay rates of sunspot.

The sunspot numbers can also be divided into northern and southern numbers. These allow for studies of the asymmetry of the solar cycle as well as phase differences in the progression of the cycle in the two hemispheres (e.g., Zolotova et al. 2010; Norton et al. 2014 , and references therein). Both quantities have implications for the coupling of the two hemispheres in any dynamo model of the Sun's magnetic field. The positions can also be used for separating the cycles in time and latitude, i.e. for drawing a separation line between "wings" in the butterfly diagram (e.g., Leussu et al. 2017). Similarly, the latitudinal information was used to increase the significance of a possible weak cycle between cycles 4 and 5, in about 1793-1800 (Usoskin et al. 2009).

Another quantity, of which the importance for the underlying dynamo is not entirely clear, is the tilt angle of bipolar sunspot groups. The two main polarities of bipolar sunspot groups form certain angles with the latitude circles. These angles show a very large scatter but average to about $4^{\circ}-7^{\circ}$, where the leading polarity is closer to the equator than the following polarity, on both hemispheres. The deviation from $0^{\circ}$ is significant. If the average is taken for individual bands in latitude, an increase of the tilt angle with latitude is found and is typically called Joy's law (Hale et al. 1919; Pevtsov et al. 2014). With historical drawings, the total average tilt angle can be computed for various solar cycles in the past. An attempt by Senthamizh Pavai et al. (2016) is shown in Fig. 28. While historical tilt angles tend to average somewhat closer to zero because of plotting uncertainties, an interesting drop to about $0^{\circ}$ occurred in 1750 1760 , obtained from two independent observers, Staudacher and Zucconi, who were 

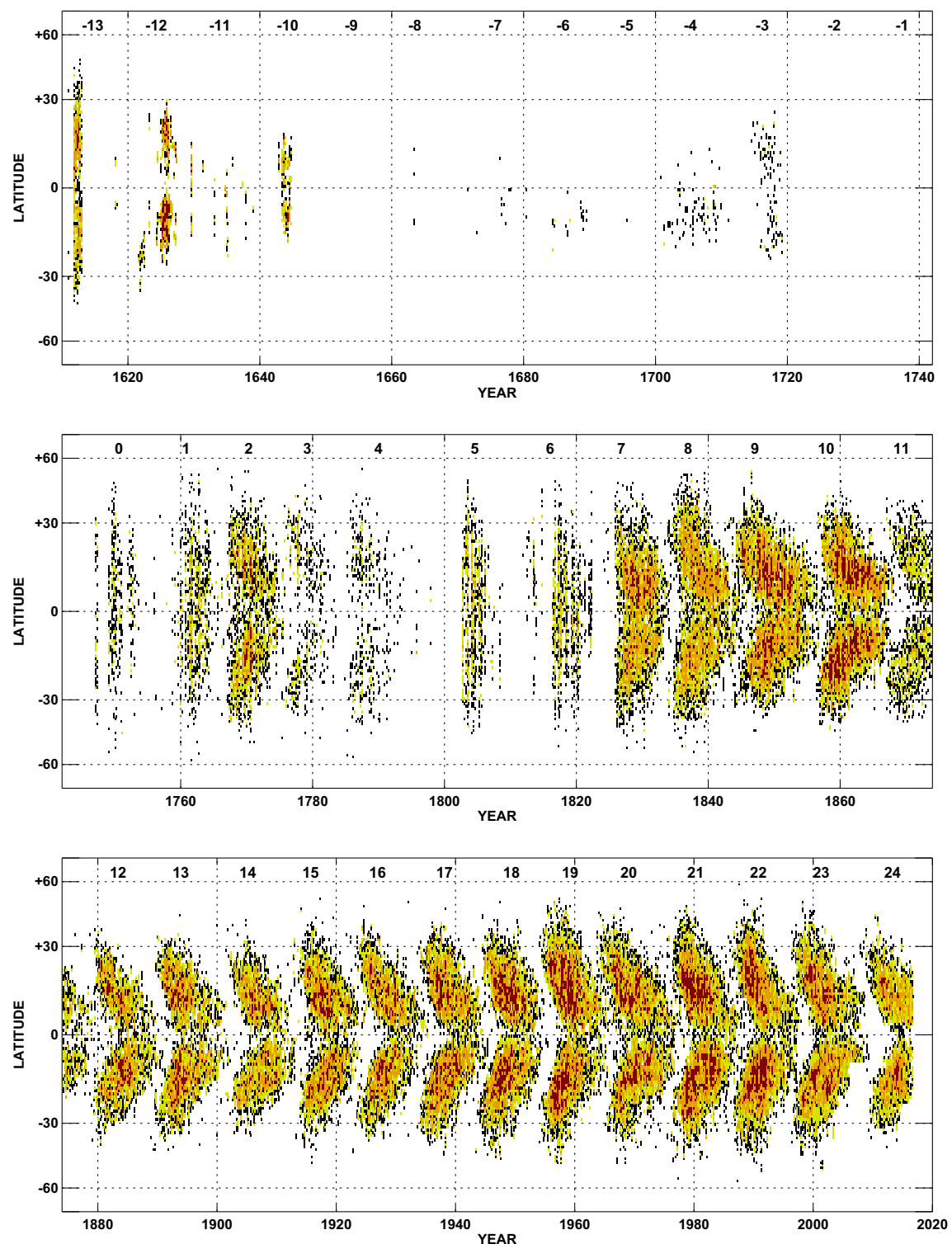

Fig. 27 Composite time-latitude diagram (butterfly diagram) of sunspot positions from Harriot (Vokhmyanin et al., submitted), Galileo (Vokhmyanin and Zolotova 2018b), Gassendi (Vokhmyanin and Zolotova 2018a), Scheiner (Arlt et al. 2016), Marcgraf (Vaquero et al. 2011), Hevelius (Carrasco et al. 2019a), observations at Paris Observatory (Vaquero et al. 2015), Kirch (Neuhäuser et al. 2018), Becker (Neuhäuser et al. 2015), Wargentin (Arlt 2018), Staudacher (Arlt 2009a), Horrebow (Karoff et al. 2019), Hamilton (Arlt 2009b), Schwabe (Arlt et al. 2013), Spörer (Diercke et al. 2015), and the Royal Greenwich Observatory (RGO) data set, continued by USAF/NOAA (https://solarscience.msfc.nasa.gov/greenwch. shtml). In order to be compatible with the RGO data set, sunspot positions were averaged into sunspot groups for all datasets. Since the quality of sunspots is areas is highly diverse, area information was neglected for this plot. Groups are counted in time bins of three synodic solar rotations and latitude bins of $1^{\circ}$. Cycle numbers are given at the top of each panel 


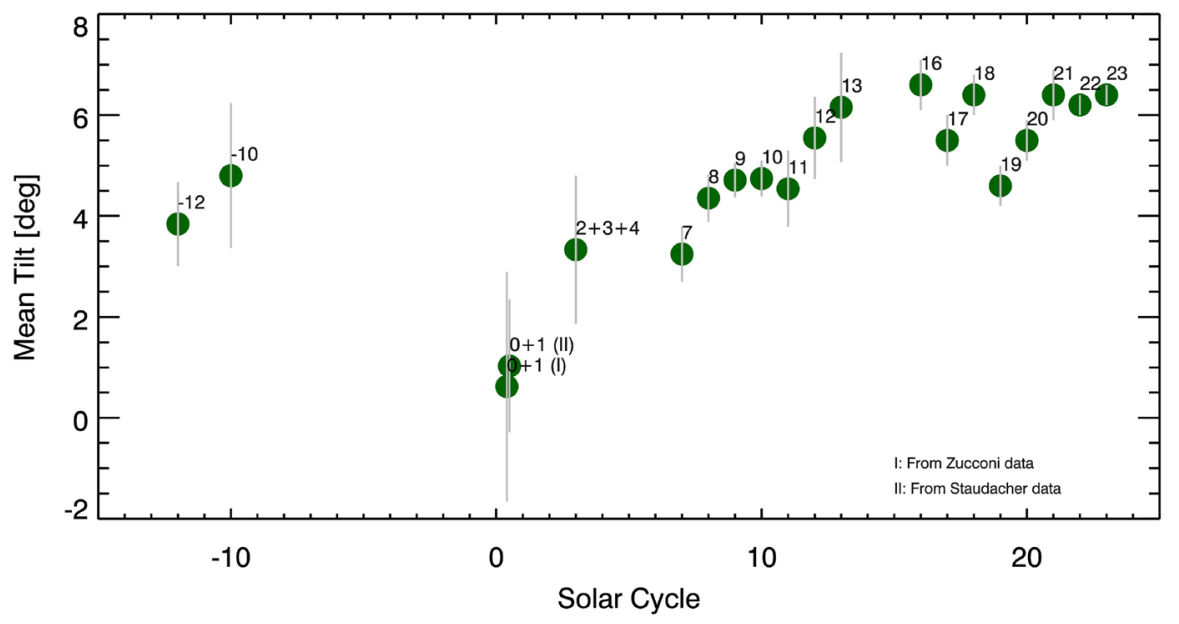

Fig. 28 Average sunspot group tilt angles as a function of time, compiled from Senthamizh Pavai et al. (2016). The bullets are annotated with the solar cycle(s) over which the tilt angle was averaged. For cycles $0+1$, the bullet (I) is from data by Staudacher, the bullet (II) is from data by Zucconi. Confidence intervals are standard errors

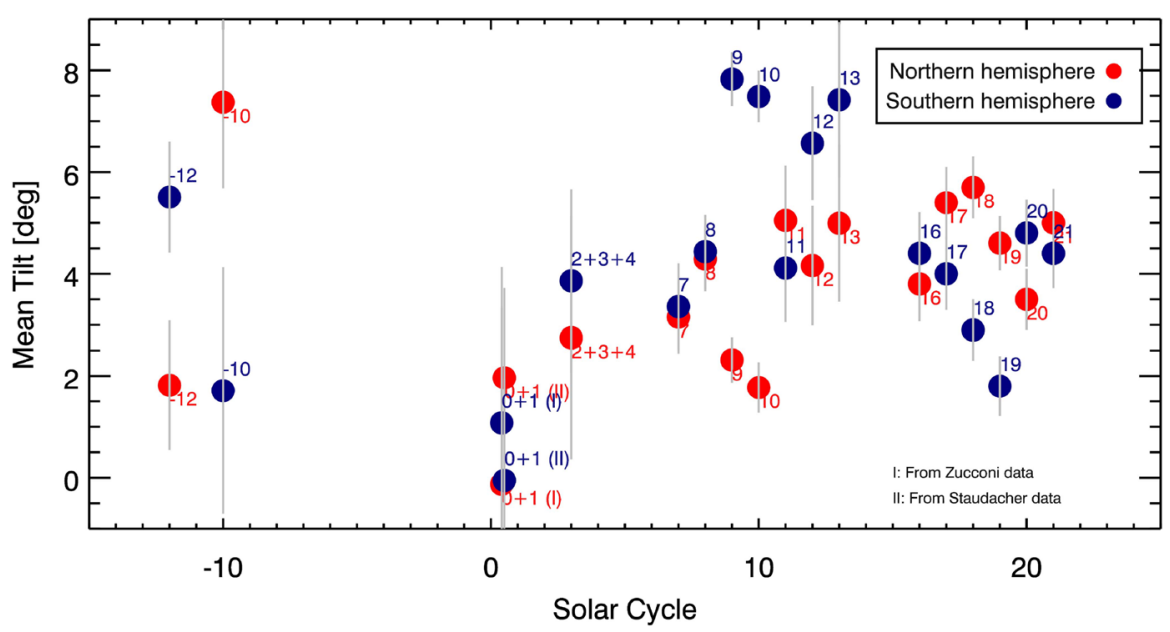

Fig. 29 Average sunspot group tilt angles separated into groups on the northern and southern hemispheres (this work)

described in earlier sections. The same data can also be split into northern and southern hemisphere tilt angles. The result (Fig. 29) shows significant differences between the hemispheres but no clear pattern. The differences were extreme before the Maunder minimum, but also in the middle of the 19th century, without an upcoming grand minimum.

The motion of the spots around the Sun was noticed already by the earliest sunspot observers. Periods of 25 to 28 days were determined by Scheiner (1630, p. 559): 
Nam multi cursus bene explorati dies 25. vix excedunt. Multi ad 27. perueniunt: et nonnulli ad 28. aspirare videntur. Deducuntur ista euidenter, ex indagatis locis et motibus veris, per datos apparentes.

\section{which translates to}

For many with certainty determined courses, they hardly exceeded 25 days, many reached 27 , and some try to get to 28 . The deduced values are evidenced from the studied locations and true motion, through the observed data.

There is no indication though, that Scheiner understood the latitudinal dependence of the rotation periods.

Carrington (1863, p. 221) described the latitudinal rotation profile by $\Omega=A+$ $B \sin ^{q} b$, where $A$ and $B$ are constants and $b$ is the heliographic latitude. He found $A=14.418^{\circ} / \mathrm{d}$ and $B=-2.75^{\circ} / \mathrm{d}$, while the exponent $q$ was $7 / 4$ in his case, after explicitly rejecting $q=2$. The introduction of the equation with $q=2$ is sometimes attributed to Hervé Faye (Broszus 1884; Solonskiy and Khilov 1989) who argued that the convective motions start from spheroidal isothermal surfaces. Since the shape of a spheroid can be approximated by $\sin ^{2} b$, Faye (1865) concluded that also the

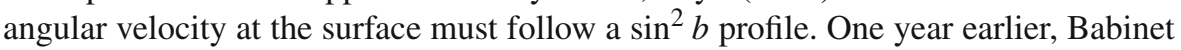
(1864) argued that the exponent should be even, in order to avoid sign problems with northern and southern latitudes. Later, most authors indeed simplified the problem to $q=2$ (e.g., Maunder and Maunder 1905). This reduces the problem to the two unknowns $A$ and $B$ which need to be determined from the apparent spot positions changing with time. While this is usually good enough for sunspots because of their rather low latitudes, an additional term $C \sin ^{4} b$ was introduced by Dyson (1924) to fit higher-latitude phenomena such as faculae appropriately.

There have been various attempts to measure the differential rotation of the Sun in historical sunspot data. Eddy et al. (1976) measured the differential rotation of the Sun before the Maunder minimum using the observations by Hevelius (Sect. 4.4). Since most spots recorded by Hevelius are below $15^{\circ}$ latitude, the differential rotation can only be seen in the latitude bin of $15^{\circ}-20^{\circ}$. According to that study, the sidereal rotation rate near the equator is shorter by about half a day than the 20th-century value of 24.75 days at the solar equator (Balthasar et al. 1986). The observations were revisited by Yallop et al. (1982) and who found the rotation period to be "normal". The results indicate that systematic effects were perhaps not accounted for in the confidence intervals given by Eddy et al. (1976).

The authors continued their efforts in Eddy et al. (1977) to derive the rotation profile from the sunspots recorded by Scheiner (Sect. 4.3) and found a differential rotation quantitatively very similar to the rotation in the 20th century (Balthasar et al. 1986). This was confirmed by Yallop et al. (1982) and Nesme-Ribes et al. (1994).

Herr (1978) used a subset of positions measured in the drawings by Thomas Harriot to derive angular velocities for seven latitude bands for the year 1612. While the shape of the rotation period was very similar to the rotation of the Sun in the 20th century (e.g., Balthasar et al. 1986), all rotation periods are 1.5-2 days shorter than the ones we observe today. Casas et al. (2006) revisited the solar rotation in the 17 th century by adding Galileo's data and confirmed the agreement with 20 th century data, but also the 
indication of somewhat steeper differential rotation found by Ribes and Nesme-Ribes (1993).

The period after the Maunder minimum was studied by Arlt and Fröhlich (2012) who derived the differential rotation from the observations by Staudacher (Sect. 6.1). A stronger differential rotation - in particular slower high latitudes - than in the 20th century was tentatively found for Cycles 0 and 1 . The Bayesian approach revealed the full uncertainties of the free parameters which may be underestimated in studies assuming Gaussian statistics.

An analysis of the differential rotation from the observations by Richard Carrington, Christian Heinrich Friedrich Peters, and Warren de la Rue was made by Casas and Vaquero (2015, see also the numerous references therein, for other differential rotation measurements). The study found no significant differences among the three data sets, while a slight tendency towards a slower equatorial rotation velocity was found for Carrington.

For the problems of measuring the solar surface differential rotation, see the review by, e.g., Schroeter (1985). Note also that the individual rotation periods indicated by sunspot groups most likely depend on the age of the groups (Pulkkinen and Tuominen 1998), a fact which is attributed to the anchoring depth in the solar convection zone (Brandenburg 2005). A preference of large sunspot groups due to small telescopes may lead to a general bias in determining the rotation profile of the Sun by spots.

\section{Concluding remarks}

We tried to show the value of historical drawings of sunspots on the solar disk, made from naked-eye observations and, since $1610 \mathrm{CE}$, from telescopic observations. The positional information as well as morphological information accessible from drawings can deliver quantitative results on the evolution of sunspot groups and the rotation of the Sun. The variability of such quantities over centuries is highly interesting for the understanding of the solar dynamo (for a review on the dynamo, see Charbonneau 2010), in particular in connection with the occurrence of grand minima of solar activity (for a review on the long-term variability of solar activity, see Usoskin 2017).

A critical view on the original documents, and the inference of sunspot positions and areas in particular, often illuminate into how many groups the observed sunspots need to distributed. The group count gives a fairly robust and direct measure of solar activity over more than 400 years and can serve as a proxy for solar irradiance at Earth. The solar variability over centuries is an input to many climate simulations and needs to be known as good as possible.

Several of the historical sources still need to be studied in detail; the present review is therefore rather a list of existing records than a review of the physical understanding achieved from them. The authors encourage any efforts of digitizing astronomical manuscripts to make them available to researchers and to preserve them from potential loss. Along these lines, the International Astronomical Union adopted the resolution 2018/B3 "on preservation, digitization and scientific exploration of historical astronomical data." 
Acknowledgements We are grateful to V. Senthamizh Pavai, supported by grant AR355/12-1 from Deutsche Forschungsgemeinschaft, for the help with some graphs in this article, to Yori Fournier for translating various paragraphs written in French, to Federico Spada for translating Latin texts, and to Hisashi Hayakawa and Víctor M. S. Carrasco for helpful discussions. We thank the International Space Science Institute (ISSI-Bern) and the members of its team 'Recalibration of the Sunspot Number Series' as well as the two anonymous referees for useful comments and suggestions. JMV was supported by the Department of Economy and Infrastructure of the Junta of Extremadura through project IB16127 and grant GR18097 (co-financed by the European Regional Development Fund), and by the Ministerio de Ciencia of the Spanish Government (CGL2017-87917-P). The authors also benefitted greatly from the digitization and cataloguing efforts of Münchner DigitalisierungsZentrum (https://www.digitale-sammlungen.de) and Gallica from the Bibliothèque Nationale de France (https://gallica.bnf.fr).

Open Access This article is licensed under a Creative Commons Attribution 4.0 International License, which permits use, sharing, adaptation, distribution and reproduction in any medium or format, as long as you give appropriate credit to the original author(s) and the source, provide a link to the Creative Commons licence, and indicate if changes were made. The images or other third party material in this article are included in the article's Creative Commons licence, unless indicated otherwise in a credit line to the material. If material is not included in the article's Creative Commons licence and your intended use is not permitted by statutory regulation or exceeds the permitted use, you will need to obtain permission directly from the copyright holder. To view a copy of this licence, visit http://creativecommons.org/licenses/by/4.0/.

\section{References}

Abetti G (1954) The history of astronomy. Sidgwick and Jackson, London

Aldefeld CLW (1838) Die Maaße und Gewichte der deutschen Zoll-Vereins-Staaten und vieler anderer Länder und Handelsplätze in ihren gegenseitigen Verhältnissen. J.G. Cotta, Stuttgart

Arlt R (2008) Digitization of sunspot drawings by Staudacher in 1749-1796. Sol Phys 247:399-410. https:// doi.org/10.1007/s11207-007-9113-4

Arlt R (2009a) The butterfly diagram in the eighteenth century. Sol Phys 255:143-153. https://doi.org/10. 1007/s11207-008-9306-5. arXiv:0812.2233

Arlt R (2009b) The solar observations at Armagh Observatory in 1795-1797. Astron Nachr 330:311. https:// doi.org/10.1002/asna.200911195

Arlt R (2018) Sunspot observations by Pehr Wargentin in Uppsala in 1747. Astron Nachr 339:647-655. https://doi.org/10.1002/asna.201913544

Arlt R, Fröhlich HE (2012) The solar differential rotation in the 18th century. Astron Astrophys 543:A7. https://doi.org/10.1051/0004-6361/201219266. arXiv:1205.6679

Arlt R, Leussu R, Giese N, Mursula K, Usoskin IG (2013) Sunspot positions and sizes for 1825-1867 from the observations by Samuel Heinrich Schwabe. Mon Not R Astron Soc 433:3165-3172. https://doi. org/10.1093/mnras/stt961. arXiv:1305.7400

Arlt R, Senthamizh Pavai V, Schmiel C, Spada F (2016) Sunspot positions, areas, and group tilt angles for 1611-1631 from observations by Christoph Scheiner. Astron Astrophys 595:A104. https://doi.org/10. 1051/0004-6361/201629000. arXiv:1608.07172

Atkinson AD (1952) William Derham, F.R.S. (1657-1735). Ann Sci 8:368-392

Babinet J (1864) Sur la rotation du Soleil. C R Hebd Seanc Acad Sci 59:480-481

Balthasar H, Vázquez M, Wöhl H (1986) Differential rotation of sunspot groups in the period from 1874 through 1976 and changes of the rotation velocity within the solar cycle. Astron Astrophys 155:87-98

Baranyi T, Győri L, Ludmány A (2016) On-line tools for solar data compiled at the Debrecen Observatory and their extensions with the Greenwich sunspot data. Sol Phys 291:3081-3102. https://doi.org/10. 1007/s11207-016-0930-1. arXiv:1606.00669

Baumgartner FJ (1987) Sunspots or Sun's Planets: Jean Tarde and the sunspot controversy of the early seventeenth century. J Hist Astron 18:44. https://doi.org/10.1177/002182868701800103

Beigel GWS (1785) Adversaria Astronomica. Mscr.Dresd.R.241, Dresden

Bekli MR, Zougab N, Belabbas A, Chadou I (2017) Non-parametric data analysis of low-latitude auroras and naked-eye sunspots in the Medieval epoch. Sol Phys 292:52. https://doi.org/10.1007/s11207-0171084-5 
Bennett JA (1978) Catalogue of the archives and manuscripts of the Royal Astronomical Society. Mem R Astron Soc 85:1-70

Bode JE (1824) Astronomisches Jahrbuch für das Jahr 1827 nebst einer Sammlung der neuesten in die astronomischen Wissenschaften einschlagenden Abhandlungen, Beobachtungen und Nachrichten, vol 52. Ferdinand Dümmler, Berlin

Bogdan TJ, Gilman PA, Lerche I, Howard R (1988) Distribution of sunspot umbral areas: 1917-1982. Astrophys J Lett 327:451-456. https://doi.org/10.1086/166206

Brandenburg A (2005) The case for a distributed solar dynamo shaped by near-surface shear. Astrophys J 625:539-547. https://doi.org/10.1086/429584. arXiv:astro-ph/0502275

Brockhaus (1991) Brockhaus-Enzyklopädie, vol 16. Nos-Per. F.A. Brockhaus, Mannheim

Broszus JE (1884) Die Theorie der Sonnenflecken. Springer, Berlin. https://doi.org/10.1007/978-3-66234047-9

Carrasco VMS, Álvarez JV, Vaquero JM (2015a) Sunspots During the Maunder minimum from Machina Coelestis by Hevelius. Sol Phys 290:2719-2732. https://doi.org/10.1007/s11207-015-0767z. arXiv: 1502.06270

Carrasco VMS, Villalba Alvarez J, Vaquero JM (2015b) Improving sunspot records: observations in 17281729 by J. F. Weidler. Observatory 135:257-265

Carrasco VMS, García-Romero JM, Vaquero JM, Rodríguez PG, Foukal P, Gallego MC, Lefèvre L (2018a) The Umbra-Penumbra area ratio of sunspots during the Maunder minimum. Astrophys J 865:88. https://doi.org/10.3847/1538-4357/aad9f6. arXiv:1809.08670

Carrasco VMS, Vaquero JM, Arlt R, Gallego MC (2018b) Sunspot observations made by Hallaschka during the Dalton minimum. Sol Phys 293:102. https://doi.org/10.1007/s11207-018-1322-5. arXiv: 1807.03014

Carrasco VMS, Vaquero JM, Gallego MC, Muñoz-Jaramillo A, de Toma G, Galaviz P, Arlt R, Senthamizh Pavai V, Sánchez-Bajo F, Villalba Álvarez J, Gómez JM (2019a) Sunspot characteristics at the onset of the Maunder minimum based on the observations of Hevelius. Astrophys J 886(1):18. https://doi. org/10.3847/1538-4357/ab4ade

Carrasco VMS, Vaquero JM, Gallego MC, Villalba Álvarez J, Hayakawa H (2019b) Two debatable cases for the reconstruction of the solar activity around the Maunder Minimum: Malapert and Derham. Mon Not R Astron Soc 485:L53-L57. https://doi.org/10.1093/mnras1/slz027

Carrington RC (1856) Mon Not R Astron Soc 17:43-47. https://doi.org/10.1093/mnras/17.2.43a

Carrington RC (1858) On the distribution of the solar spots in latitudes since the beginning of the year 1854, with a map. Mon Not R Astron Soc 19:1-3. https://doi.org/10.1093/mnras/19.1.1

Carrington RC (1863) Observations of the spots on the Sun from November 9, 1853, to March 24, 1861, nade at Redhill. Williams \& Norgate, London

Casas R, Vaquero JM (2014) The sunspot catalogues of Carrington, Peters and de la Rue: quality control and machine-readable versions. Sol Phys 289:79-90. https://doi.org/10.1007/s11207-013-0342-4. arXiv: 1307.3507

Casas R, Vaquero JM (2015) The solar rotation in the period 1853-1870 from the sunspot catalogues of Carrington, Peters, and de la Rue. Sol Phys 290:2189-2198. https://doi.org/10.1007/s11207-0150756-2. arXiv:1410.8286

Casas R, Vaquero JM, Vazquez M (2006) Solar rotation in the 17th century. Sol Phys 234:379-392. https:// doi.org/10.1007/s11207-006-0036-2

Cassini GD (1730) Description d'une tache qui a paru dans le Soleil mois de May dernier 1684. Memoires de l'académie royale des sciences Depuis 1666 jusqu'á 1699 10:653-656

Charbonneau P (2002) The rise and fall of the first solar cycle model. J Hist Astron 33(113):351-372. https://doi.org/10.1177/002182860203300402

Charbonneau P (2010) Dynamo models of the solar cycle. Living Rev Sol Phys 7(1):3. https://doi.org/10. 12942/1rsp-2010-3

Clerke AM (1885) A popular history of astronomy during the nineteenth century. Adam \& Charles Black, Edinburgh

Clerke AM (1887) Carrington, Richard Christopher. In: Stephen L (ed) Dictionary of National Biography. IX Canute-Chaloner, MacMillan \& Co., Smith, Elder \& Co., New York, London

Cliver EW (2005) Carrington, Schwabe, and the Gold Medal. EOS Trans 86(43):413-418. https://doi.org/ $10.1029 / 2005 \mathrm{EO} 430002$

Cliver EW, Keer NC (2012) Richard Christopher Carrington: briefly among the great scientists of his time. Sol Phys 280(1):1-31. https://doi.org/10.1007/s11207-012-0034-5 
Cook A (1998) Edmond Halley: charting the heavens and the seas. Clarendon Press, Oxford

Cristo A, Vaquero JM, Sánchez-Bajo F (2011) HSUNSPOTS: a tool for the analysis of historical sunspot drawings. J Atmos Sol-Terr Phys 73:187-190. https://doi.org/10.1016/j.jastp.2009.12.010

Davis HS (1841) Schreiben des Herrn Majors Davis an den Herausgeber. Astron Nachr 18:65-66

De la Rue W, Stewart B, Loewy B (1866) Area-measurements of the sun-spots observed by Carrington during the seven years from 1854-1860 inclusive, and deductions therefrom. Taylor and Francis, London

De la Rue W, Stewart B, Loewy B (1869) Researches on solar physics. Heliographical positions and areas of sun-spots observed with the Kew Photoheliograph during the years 1862 and 1863. Philos Trans R Soc London Ser I 159:1-110

De la Rue W, Stewart B, Loewy B (1870) Researches on solar physics. No. II. The positions and areas of the spots observed at Kew during the years 1864, 1865, 1866, also the spotted area of the Sun's visible disk from the commencement of 1832 up to may 1868. Philos Trans R Soc London Ser I 160:389-496

Denig WF, McVaugh MR (2017) Early American sunspot drawings from the "year without a summer". Space Weather 15:857-860. https://doi.org/10.1002/2017SW001647

Derham W (1703) Some observations on the spots of the Sun. Philos Trans Ser I 23:1504-1507

Derham W (1710) Observations upon the spots that have been upon the Sun, from the Year 1703 to 1711. With a letter of Mr. Crabtrie, in the year 1640, upon the same subject. Philos Trans Ser I 27:270-290

Dezsö L (1987) An account of the Greenwich photoheliographic results of 1874-1976 and of Debrecen's first catalogue of 1977. Publ Debrecen Heliophys Obs 1:231-242

Diercke A, Arlt R, Denker C (2015) Digitization of sunspot drawings by Spörer made in 1861-1894. Astron Nachr 336:53. https://doi.org/10.1002/asna.201412138

Domínguez-Castro F, Vaquero JM (2017) The sunspot observations by Toaldo and Comparetti in 1779 November. Observatory 137:240-241

Domínguez-Castro F, Gallego MC, Vaquero JM (2017) Sunspots sketches during the solar eclipses of 9th January and 29th December of 1777 in Mexico. J Space Weather Space Clim 7(27):A15. https://doi. org/10.1051/swsc/2017012

Dyson FW (1924) The rotation period of the sun derived from measures of solar faculæ Greenwich, Royal Observatory. Mon Not R Astron Soc 84:431. https://doi.org/10.1093/mnras/84.6.431

Eddy JA (1976) The Maunder minimum. Science 192:1189-1202. https://doi.org/10.1126/science.192. 4245.1189

Eddy JA, Gilman PA, Trotter DE (1976) Solar rotation during the Maunder minimum. Sol Phys 46:3-14. https://doi.org/10.1007/BF00157550

Eddy JA, Gilman PA, Trotter DE (1977) Anomalous solar rotation in the early 17th century. Science 198:824-829. https://doi.org/10.1126/science.198.4319.824

Fabricius J (1611) De maculis in sole observatis, et apparente earum cum Sole conversione. Seuberlich, Börner \& Rehefeld, Wittenberg

Favaro A (1895) Le opere de Galileo Galilei, vol V. G. Barbèra, Florence

Faye H (1865) Sur la constitution physique du Soleil. C R Hebd Seanc Acad Sci 60:138-150

Flaugergues H (1813) Mémoire sur l'usage du réticule rhombe, pour les observations des taches du soleil et de la lune. Ann Math Pures Appl 4:321-331

Fraunhofer J (2017) Briefe von Joseph von Fraunhofer. In: Riekher R, Dick WR, Hamel J (eds) Der Briefwechsel Joseph von Fraunhofers, Acta Historica Astronomiae, vol 62. AVA Akademische Verlagsanstalt, Leipzig, pp 330-331

Frick J (1681) Philosophisches und Theologisches Bedencken. In: welchem die vornehmste Meynungen von den Cometen vorgetragen und examiniert werden. G.W. Kühnen, Ulm

Frisius RG (1545) De radio astronomico \& geometrico liber. Greg. Bontius, Antwerp

Fujiyama M, Hayakawa H, Iju T, Kawai T, Toriumi S, Otsuji K, Kondo K, Watanabe Y, Nozawa S, Imada S (2019) Revisiting Kunitomo's sunspot drawings during 1835-1836 in Japan. Sol Phys 294(4):43. https://doi.org/10.1007/s11207-019-1429-3. arXiv:1903.03092

Galaviz P, Sánchez-Bajo F, Vaquero JM (2016a) Determining sunspot positions in the classroom using the Carrington method. Eur J Phys 37(4):045707. https://doi.org/10.1088/0143-0807/37/4/045707

Galaviz P, Vaquero JM, Gallego MC, Sánchez-Bajo F (2016b) A small collection of sunspot drawings made in the Royal Astronomical Observatory of the Spanish Navy in 1884. Adv Space Res 58(11):22472254. https://doi.org/10.1016/j.asr.2016.08.013

Galilei G (1613) Istoria e dimostrazioni intorno alle macchie solari. Mascardi, Rome

Gassendi P (1658) Opera omnia in sex tomos divisa. Anisson \& Devenet, Lyon 
Gerdes D (1995) Johann Hieronymus Schroeter, Sternwarte Lilienthal: Beobachtungen über die Sonnenfackeln und Sonnenflecken. M. Simmering, Lilienthal

Gruithuisen FvP (1836) Naturgeschichte des gestirnten Himmels. E. A. Fleischmann, Munich

Guhrauer GE (1850) Joachim Jungius und sein Zeitalter. J.G. Cotta, Stuttgart

Haase C (1869) Beitrag zu der Frage, ob ausser Mercur und Venus in dem Raume zwischen Sonne und Erde noch andere planetenartige Körper vorhanden sind. Zeitschrift für populäre Mittheilungen aus dem Gebiete der Astronomie und verwandter Wissenschaften 3:1

Hale GE, Ellerman F, Nicholson SB, Joy AH (1919) The magnetic polarity of Sun-spots. Astrophys J 49:153. https://doi.org/10.1086/142452

Hallaschka FIC (1814) Meteorologische Beobachtungen im Jahre 1813 von Cassian Hallaschka in Brünn. Hesperus 6:292-296

Hallaschka FIC (1816a) Beobachtete Sonnenflecke am 28. Februar bis 15. März 1816. Hesperus (Außerordentliche Beilage zum Hesperus, Nr 4) 8:25-26

Hallaschka FIC (1816b) Fortsetzung der Beobachtungen der Sonnenflecke von 4. April bis bis 1. August 1816. Hesperus 8:495-496

Hammond JH (1981) The camera obscura. A chronicle. Adam Hilger Ltd, Bristol

Harriot T (1613) Spots on the Sun. Petworth House, HMC 241 VIII, http://echo.mpiwg-berlin.mpg.de/ MPIWG:FAYG83FB

Hayakawa H, Iwahashi K, Tamazawa H, Ebihara Y, Kawamura AD, Isobe H, Namiki K, Shibata K (2017a) Records of auroral candidates and sunspots in Rikkokushi, chronicles of ancient Japan from early 7th century to 887. Publ Astron Soc Japan 69:86. https://doi.org/10.1093/pasj/psx087. arXiv:1708.01045

Hayakawa H, Tamazawa H, Ebihara Y, Miyahara H, Kawamura AD, Aoyama T, Isobe H (2017b) Records of sunspots and aurora candidates in the Chinese official histories of the Yuán and Míng dynasties during 1261-1644. Publ Astron Soc Japan 69:65. https://doi.org/10.1093/pasj/psx045. arXiv:1705.02238

Hayakawa H, Iwahashi K, Fujiyama M, Kawai T, Toriumi S, Hotta H, Iijima H, Imada S, Tamazawa H, Shibata K (2018a) Sunspot drawings by Japanese official astronomers in 1749-1750. Publ Astron Soc Japan 70:63. https://doi.org/10.1093/pasj/psy066. arXiv:1804.08614

Hayakawa H, Iwahashi K, Tamazawa H, Toriumi S, Shibata K (2018b) Iwahashi Zenbei's sunspot drawings in 1793 in Japan. Sol Phys 293:8. https://doi.org/10.1007/s11207-017-1213-1. arXiv:1711.08143

Hayakawa H, Besser BP, Iju T, Arlt R, Bourdin P, Uneme S, Imada S, Toriumi S, Kraml A (2020) Derfflinger's sunspot observations during 1802-1824: revision based on the original manuscripts. Astrophys J 890:98. https://doi.org/10.3847/1538-4357/ab65c9

Herr RB (1978) Solar rotation determined from Thomas Harriot's sunspot observations of 1611 to 1613. Science 202:1079-1081. https://doi.org/10.1126/science.202.4372.1079

Herschel JFW (1847) Results of astronomical observations made during the years 1834, 5, 6, 7, 8, at the Cape of Good Hope; being the completion of a telescopic survey of the whole surface of the visible heavens. Smith, Elder and Co., London

Herschel W (1795) III. On the nature and construction of the sun and fixed stars. Philos Trans R Soc London Ser I 85:46-72

Hevelius J (1647) Selenographia: sive lunae descriptio. Hünefeld, Danzig

Hevelius J (1652) Illustribus viris, Petro Gassendo, et Ismaeli Bullialdo, Philosophis ac Mathematicis nostri seculi summis, amicis suis officiose honorandis. Gdańsk

Hevelius J (1679) Machina coelestis / 2: Rerum Uranicarum Observationes / and 3: Altitudines videlicet Solares. S. Reiniger, Danzig

Horrebow C (1770) Om Soelpletterne [On sunspots]. In: Dansk Historisk Almanak, Universitets Bogtrykkerie, København

Hoyt DV, Schatten KH (1995) A revised listing of the number of sunspot groups made by Pastorff, 1819 to 1833. Sol Phys 160:393-399. https://doi.org/10.1007/BF00732818

Hoyt DV, Schatten KH (1998) Group sunspot numbers: a new solar activity reconstruction. Sol Phys 181:491-512. https://doi.org/10.1023/A:1005056326158

Huggins W (1876) Sun-spot drawings of the Rev. Frederick Howlett and Hofrath Schwabe. Mon Not R Astron Soc 36:297-299

Johnson MJ (1857) Address delivered by the President, M. J. Johnson, Esq., on presenting the Gold Medal of the Society to M. Schwabe. Mon Not R Astron Soc 17:126. https://doi.org/10.1093/mnras/17.4. 126

Jones M (2008) Tycho Brahe (Tyge Ottesen Brahe). In: Lorimer H, Withers CWJ (eds) Geographers. Biographical Studies, pp 1-27 
Jørgensen CS, Karoff C, Senthamizh Pavai V, Arlt R (2019) Christian Horrebow’s sunspot observations - I. Life and published writings. Sol Phys 294(6):77. https://doi.org/10.1007/s11207-019-1465-z. arXiv:1906.10884

Kangro H (1974) Jungius, Joachim. In: Wagner F (ed) Neue deutsche Biographie. Zehnter Band, Duncker \& Humblot, Berlin

Karoff C, Jørgensen CS, Senthamizh Pavai V, Arlt R (2019) Christian Horrebow’s sunspot observations II. Construction of a record of sunspot positions. Sol Phys 294(6):78. https://doi.org/10.1007/s11207019-1466-y. arXiv:1906.10895

Kayser E (1868) Resultate aus Beobachtungen von Sonnenflecken während der Jahre 1754-1758. Schrift Naturforsch Gesell Danzig 2:2-46

Kepler J (1609) Phaenomenon singulare seu Mercurius in Sole. Thomas Schürer, Leipzig. https://doi.org/ $10.3931 /$ e-rara-3181

King HC (1955) The history of the telescope. Griffin, New York

Kirch G (1681) Gottfried Kirchs Neue Himmels-Zeitung. Endter, Nuremberg

Lalande JJL (1779) Mémoire sur les taches du soleil, et sur sa rotation. Hist Acad R Sci 1776:457-514

Leibbrand W (1966) Gruithuisen, Franz von Paula. In: Oea Graf zu Stolberg-Wernigerode (ed) Neue deutsche Biographie. Siebenter Band, Duncker \& Humblot, Berlin

Leussu R, Usoskin IG, Senthamizh Pavai V, Diercke A, Arlt R, Denker C, Mursula K (2017) Wings of the butterfly: sunspot groups for 1826-2015. Astron Astrophys 599:A131. https://doi.org/10.1051/0004$6361 / 201629533$

Leverrier UJ (1859) Lettre de M. Le Verrier à M. Faye sur la théorie de Mercure et sur le mouvement du périhélie de cette planète. C R Hebd Seanc Acad Sci 49:379-383

Lieske JH, Lederle T, Fricke W, Morando B (1977) Expressions for the precession quantities based upon the IAU (1976) system of astronomical constants. Astron Astrophys 58:1-16

Lynn WT (1905) Honoré Flaugergues. Observatory 28:391-392

Ma LH, Vaquero JM (2009) Is the Suess cycle present in historical naked-eye observations of sunspots? New Astron 14:307-310. https://doi.org/10.1016/j.newast.2008.09.003

Malapertius C (1620) Oratio de novis Belgici telescopii phaenomenis. Balthasar Beller, Douai

Malapertius C (1633) Austriaca sidera heliocyclia astronomicis hypothesibus illigata. Balthasar Beller, Douai

Marshall H (1774) Extract of a letter from Mr. Humphry Marshall, of West Bradford, in Chester County, Pennsylvania, to Dr. Franklin, Sent with Sketches of the solar spots, dated May 3, 1773. Philos Trans R Soc London Ser I 64:194-195

Maunder EW (1894) A prolonged sunspot minimum. Knowl: Illus Mag Sci 17:173-176

Maunder EW, Maunder ASD (1905) Sun, rotation period of the, from Greenwich Sun-spot measures, 1879-1901. Mon Not R Astron Soc 65:813-825. https://doi.org/10.1093/mnras/65.8.813

McClintock BH, Norton AA, Li J (2014) Re-examining sunspot tilt angle to include anti-hale statistics. Astrophys J 797:130. https://doi.org/10.1088/0004-637X/797/2/130. arXiv:1412.5094

Muñoz-Jaramillo A, Vaquero JM (2019) Visualization of the challenges and limitations of the long-term sunspot number record. Nat Astron 3:205-211. https://doi.org/10.1038/s41550-018-0638-2

Mulcrone T (2001) Laval, Antoine de. In: O’Neill C (ed) Diccionario histórico de la Compañía de Jesús, p 618

Nesme-Ribes E, Sokoloff D, Ribes JC, Kremliovsky M (1994) The Maunder minimum and the solar dynamo. In: Nesme-Ribes E (ed) The solar engine and its influence on terrestrial atmosphere and climate, p 71

Neuhäuser R, Arlt R, Pfitzner E, Richter S (2015) Newly found sunspot observations by Peter Becker from Rostock for 1708, 1709, and 1710. Astron Nachr 336:623. https://doi.org/10.1002/asna.201512203. arXiv: 1508.05798

Neuhäuser R, Neuhäuser DL (2016) Sunspot numbers based on historic records in the 1610s: Early telescopic observations by Simon Marius and others. Astron Nachr 337:581. https://doi.org/10.1002/asna. 201512292. arXiv:1604.03724

Neuhäuser R, Arlt R, Richter S (2018) Reconstructed sunspot positions in the Maunder minimum based on the correspondence of Gottfried Kirch. Astron Nachr 339:219-267. https://doi.org/10.1002/asna. 201813481

Nissen A (1937) Rundetaarn som Observatorium. In: 1637-1937, Rundetaarn, et mindeskrift udgivet af Københavns magistrats 1ste afdeling paa 300-aarsdagen for grundstenens nedlæggelse den 7. juli. Levin \& Munksgaard, Copenhagen 
Norton AA, Charbonneau P, Passos D (2014) Hemispheric coupling: comparing dynamo simulations and observations. Space Sci Rev 186:251-283. https://doi.org/10.1007/s11214-014-0100-4. arXiv: 1411.7052

Pearson W (1829) An introduction to practical astronomy. Woodfall, London

Peters CHF, Frost EB (1907) Heliographic positions of sun-spots observed at Hamilton College from 1860 to 1870. Carnegie Institution of Washington, Washington, DC

Pevtsov AA, Clette F (2017) To understand future solar activity, one has to know the past. Eos 99:12-13. https://doi.org/10.1029/2017EO083277

Pevtsov AA, Berger MA, Nindos A, Norton AA, van Driel-Gesztelyi L (2014) Magnetic helicity, tilt, and twist. Space Sci Rev 186(1-4):285-324. https://doi.org/10.1007/s11214-014-0082-2

Poggendorf JC (1863a) Biographisch-literarisches Handwörterbuch zur Geschichte der exacten Wissenschaften. Erster Band A-L. J.A. Barth, Leipzig

Poggendorf JC (1863b) Biographisch-literarisches Handwörterbuch zur Geschichte der exacten Wissenschaften. Zweiter Band M-Z. J.A. Barth, Leipzig

Pulkkinen P, Tuominen I (1998) Velocity structures from sunspot statistics in cycles 10 to 22. I. Rotational velocity. Astron Astrophys 332:748-754

Reeves E, Van Helden A (2010) On sunspots, Galileo Galilei and Christoph Scheiner. University of Chicago Press, Chicago

Regiomontanus J (1561) De triangulis planis et sphaerius libri quinque. H. Petri \& P. Perna, Basel

Ribes JC, Nesme-Ribes E (1993) The solar sunspot cycle in the Maunder minimum AD1645 to AD1715. Astron Astrophys. 276:549

Ringwood SD (1994) A Galilean telescope. Quart J R Astron Soc 35:43

Robitaille PM (2011) A thermodynamic history of the solar constitution. I: The journey to a gaseous sun. Prog Phys 7(3):3-25

Rost J (1718) Astronomisches Handbuch. P.C. Monath, Nuremberg

Scheiner C (1615) Sol ellipticus: hoc est novuum et perpetuum Solis contrahi soliti Phaenomenon, quod noviter inventum Strenae loco. C. Mangius, Augsburg

Scheiner C (1630) Rosa Ursina sive Sol. Andreas Phaeus, Bracciano

Scheiner C (1651) Prodromus pro sole mobili et terra stabili. Collegium Nissense Societatis Iesu. Nysa, Silesia

Schneider D (1997) Otto von Guericke: Ein Leben für die Alte Stadt Magdeburg. B. G. Teubner, Stuttgart

Schroeter EH (1985) The solar differential rotation-Present status of observations. Sol Phys 100:141-169. https://doi.org/10.1007/BF00158426

Schröter JH (1788) Beiträge zu den neuesten astronomischen Endeckungen. A. G. Lange, Berlin

Schröter JH (1789) Beobachtungen über die Sonnenfackeln und Sonnenflecken. G.A. Keyser, Erfurt

Schröter JH (1796) Aphroditographische Fragmente, zur genauern Kenntniss des Planeten Venus; sammt beygefügter Beschreibung Lilienthalischen 27füssigen Telescops. C. G. Fleckeisen, Helmstedt

Schröter JH (1798) Neuere Beyträge zur Erweiterung der Sternkunde. Vandenhoek-Ruprecht, Göttingen

Schwabe M (1856) Sonnen-Beobachtungen im Jahre 1855. Astron Nachr 42:269. https://doi.org/10.1002/ asna.18550421704

Schwabe M (1857a) Sonnen-Beobachtungen im Jahre 1856, von Herrn Hofrath Schwabe. Astron Nachr 45:111. https://doi.org/10.1002/asna.18570450707

Schwabe SH (1857b) Extract of a letter to Mr. Carrington. Mon Not R Astron Soc 17:241. https://doi.org/ 10.1093/mnras/17.8.241

Schwabe M (1861) Sonnenflecken-Beobachtungen im Jahre 1860, von Herrn Hofrath Schwabe. Astron Nachr 54:301-302. https://doi.org/10.1002/asna.18610541906

Schwabe S (1838) Über die Flecken der Sonne Von Herrn Hofrath Schwabe. Astron Nachr 15:243-248

Schwabe S (1841) Beobachtungen von Sonnenflecken im Jahre 1840 von Herrn Hofrath Schwabe. Astron Nachr 18:149-152. https://doi.org/10.1002/asna.18410181003

Schwabe S (1844) Sonnenbeobachtungen im Jahre 1843. Von Herrn Hofrath Schwabe in Dessau. Astron Nachr 21:233-236

Schwabe SH (1864) Sonnenbeobachtungen im Jahre 1863. Von Herrn Hofrath S. H. Schwabe. Astron Nachr 62:175. https://doi.org/10.1002/asna.18640620906

Schwabe SH (1866) Sonnen-Beobachtungen. Von Hrn. Hofrath Schwabe in Dessau. Astron Nachr 64:129_ 132. https://doi.org/10.1002/asna.18650640902

Schwabe SH (1869) Sonnen-Beobachtungen von 1868. Astron Nachr 73:93 
Senthamizh Pavai V, Arlt R, Dasi-Espuig M, Krivova NA, Solanki SK (2015) Sunspot areas and tilt angles for solar cycles 7-10. Astron Astrophys 584:A73. https://doi.org/10.1051/0004-6361/201527080. arXiv: 1508.07849

Senthamizh Pavai V, Arlt R, Diercke A, Denker C, Vaquero JM (2016) Sunspot group tilt angle measurements from historical observations. Adv Space Res 58:1468-1474. https://doi.org/10.1016/j.asr.2016.03. 002. arXiv: 1603.02510

Sestini B (1853) Observations on solar spots made at the observatory of Georgetown College. C. Alexander, Washington

Shirley JW (1983) Thomas Harriot: a biography. Clarendon Press, Oxford

Simpson J (2018) A previously unreported naked-eye sunspot observation: 1604 November. J Brit Astron Assoc 128:175-176

Smogulecz JN, Schönberger G (1626) Sol illustratus ac propugnatus. T. Meyer, Freiburg im Breisgau

Solonskiy YA, Khilov ED (1989) Solnce - zagadki i otkrytiya. Znanie, Leningrad

Spoerer FWG (1861) Beobachtungen von Sonnenflecken und daraus abgeleitete Elemente der Rotation der Sonne, von Herrn Dr. Spoerer in Anclam. Astron Nachr 55:289. https://doi.org/10.1002/asna. 18610551902

Spörer G (1874) Beobachtungen der Sonnenflecken zu Anclam. Wilh. Engelmann, Leipzig

Spörer G (1889) Ueber die Periodicität der Sonnenflecken seit dem Jahre 1618. Wilh. Engelmann, Leipzig

Steinmetz D (2011) Die Gregorianische Kalenderreform von 1582: Korrektur der christlichen Zeitrechnung in der frühen Neuzeit. D. Steinmetz, Oftersheim

Stephenson FR, Willis DM (1999) The earliest drawing of sunspots. Astron Geophys 40:21

Svalgaard L (2017) A recount of sunspot groups on Staudach's drawings. Sol Phys 292:4

Tamazawa H, Kawamura AD, Hayakawa H, Tsukamoto A, Isobe H, Ebihara Y (2017) Records of sunspot and aurora activity during 581-959 CE in Chinese official histories concerning the periods of Suí, Táng, and the Five Dynasties and Ten Kingdoms. Publ Astron Soc Japan 69:22. https://doi.org/10. 1093/pasj/psw132. arXiv:1612.03283

Tanner A (1626) Universa theologia scholastica. Johannes Bayer \& Wilhelm Eder, Ingolstadt

Tarde J (1620) Borbonia sidera, id est planetæ qui solis limina circumvolitant motu. J. Gesselin, Paris

Tarde J (1627) Les astres de Borbon, et apologie pour le soleil. J. Gesselin, Paris

Teague ETH (1996) Carrington's method of determining sunspot positions. J Brit Astron Assoc 106:82-85

Tlatova K, Tlatov A, Pevtsov A, Mursula K, Vasil'eva V, Heikkinen E, Bertello L, Pevtsov A, Virtanen I, Karachik N (2018) Tilt of sunspot bipoles in solar cycles 15 to 24. Sol Phys 293:118. https://doi.org/ 10.1007/s11207-018-1337-y. arXiv:1807.07913

Usoskin IG (2017) A history of solar activity over millennia. Living Rev Sol Phys 14:3. https://doi.org/10. 1007/s41116-017-0006-9

Usoskin IG, Mursula K, Arlt R, Kovaltsov GA (2009) A solar cycle lost in 1793-1800: early sunspot observations resolve the old mystery. Astrophys J Lett 700:L154-L157. https://doi.org/10.1088/0004637X/700/2/L154. arXiv:0907.0063

Usoskin IG, Arlt R, Asvestari E, Hawkins E, Käpylä M, Kovaltsov GA, Krivova N, Lockwood M, Mursula K, O'Reilly J, Owens M, Scott CJ, Sokoloff DD, Solanki SK, Soon W, Vaquero JM (2015) The Maunder minimum (1645-1715) was indeed a grand minimum: a reassessment of multiple datasets. Astron Astrophys 581:A95. https://doi.org/10.1051/0004-6361/201526652. arXiv:1507.05191

Usoskin IG, Kovaltsov GA, Lockwood M, Mursula K, Owens M, Solanki SK (2016) A new calibrated sunspot group series since 1749: statistics of active day fractions. Sol Phys 291:2685-2708. https:// doi.org/10.1007/s11207-015-0838-1. arXiv:1512.06421

Vaquero JM (2004) A forgotten naked-eye sunspot recorded by Galileo. Sol Phys 223:283-286. https://doi. org/10.1007/s11207-004-1041-y

Vaquero JM (2007) Historical sunspot observations: a review. Adv Space Res 40:929-941. https://doi.org/ 10.1016/j.asr.2007.01.087. arXiv:astro-ph/0702068

Vaquero JM (2012) The lost sunspot drawings of Humphry Marshall (1722-1801). Observatory 132:267268

Vaquero JM, Trigo RM (2012) A note on solar cycle length during the Medieval Climate Anomaly. Sol Phys 279:289-294. https://doi.org/10.1007/s11207-012-9964-1. arXiv:1203.1073

Vaquero JM, Trigo RM (2014) Revised Group sunspot number values for 1640, 1652, and 1741. Sol Phys 289:803-808. https://doi.org/10.1007/s11207-013-0360-2. arXiv:1307.2725

Vaquero JM, Trigo RM (2015) Redefining the limit dates for the Maunder minimum. New Astron 34:120122. https://doi.org/10.1016/j.newast.2014.06.002. arXiv:1406.1630 
Vaquero JM, Vázquez M (eds) (2009) The sun recorded through history: scientific data extracted from historical documents. In: Astrophysics and space science library, vol 361. https://doi.org/10.1007/ 978-0-387-92789-3

Vaquero JM, Gallego MC, García JA (2002) A 250-year cycle in naked-eye observations of sunspots. Geophys Res Lett 29:1997. https://doi.org/10.1029/2002GL014782

Vaquero JM, Gordillo A, Gallego MC, Sanchez-Bajo F, Garcia JA (2005) The umbra-penumbra area ratio of sunspots from the de la Rue data. Observatory 125:152-156

Vaquero JM, Gallego MC, Sanchez-Bajo F (2007) Improving sunspot records: the observations by M. Hell revisited. Observatory 127:221-224

Vaquero JM, Gallego MC, Usoskin IG, Kovaltsov GA (2011) Revisited sunspot data: a new scenario for the onset of the Maunder minimum. Astrophys J Lett 731:L24. https://doi.org/10.1088/2041-8205/731/ 2/L24. arXiv:1103.1520

Vaquero JM, Nogales JM, Sánchez-Bajo F (2015) Sunspot latitudes during the Maunder minimum: a machine-readable catalogue from previous studies. Adv Space Res 55:1546-1552. https://doi.org/10. 1016/j.asr.2015.01.006. arXiv:1501.05989

Vaquero JM, Svalgaard L, Carrasco VMS, Clette F, Lefèvre L, Gallego MC, Arlt R, Aparicio AJP, Richard JG, Howe R (2016) A revised collection of sunspot group numbers. Sol Phys 291:3061-3074. https:// doi.org/10.1007/s11207-016-0982-2. arXiv:1609.04882

Vokhmyanin M, Zolotova N (2018a) Sunspot positions and areas from observations by Pierre Gassendi. Sol Phys 293:150. https://doi.org/10.1007/s11207-018-1372-8

Vokhmyanin MV, Zolotova NV (2018b) Sunspot positions and areas from observations by Galileo Galilei. Sol Phys 293:31. https://doi.org/10.1007/s11207-018-1245-1

von Guericke O (1672) Experimenta nova (ut vocantur) Magdeburgica. Janssonius van Waesbergen, Amsterdam

Wendehorst A (1990) In: Wagner F et al (eds) Neue deutsche Biographie. Sechzehnter Band. Duncker \& Humblot, Berlin

Willis DM, Coffey HE, Henwood R, Erwin EH, Hoyt DV, Wild MN, Denig WF(2013) The Greenwich photoheliographic results (1874-1976): summary of the observations, applications, datasets, definitions and errors. Sol Phys 288(1):117-139. https://doi.org/10.1007/s11207-013-0311-y

Willis DM, Wild MN, Warburton JS (2016) Re-examination of the daily number of sunspot groups for the Royal Observatory, Greenwich (1874-1885). Sol Phys 291(9-10):2519-2552. https://doi.org/10. 1007/s11207-016-0856-7

Wilson A (1774) Observations on the solar spots. By Alexander Wilson, M. D. Professor of Practical Astronomy in the University of Glasgow. Communicated by the Rev. Nevil Maskelyne. Astron R Philos Trans R Soc London Ser I 64:1-30

Wilson A (1783) An answer to the objections stated by M. De la Lande, in the Memoirs of the French Academy for the Year 1776, against the solar spots being excavations in the luminous matter of the sun, together with a short examination of the views entertained by him upon that subject. Philos Trans R Soc London Ser I 73:144-168

Wolf R (1857a) Mittheilungen über die Sonnenflecken. III. Vierteljahrsschr Naturforsch Ges Zürich 2:109_ 132

Wolf R (1857b) Mittheilungen über die Sonnenflecken. IV. Vierteljahrsschr Naturforsch Ges Zürich 2:272_299

Wolf R (1857c) Mittheilungen über die Sonnenflecken. V. Vierteljahrsschr Naturforsch Ges Zürich 2:349_ 395

Wolf R (1858) Mittheilungen über die Sonnenflecken. VI. Vierteljahrsschr Naturforsch Ges Zürich 3:124154

Wolf R (1860) Mittheilungen über die Sonnenflecken. Vierteljahrsschr Naturforsch Ges Zürich 5:1-59

Wolf R (1861) Mittheilungen über die Sonnenflecken. XIII. Vierteljahrsschr Naturforsch Ges Zürich 6:416451

Wu CJ, Usoskin IG, Krivova N, Kovaltsov GA, Baroni M, Bard E, Solanki SK (2018) Solar activity over nine millennia: a consistent multi-proxy reconstruction. Astron Astrophys 615:A93. https://doi.org/ 10.1051/0004-6361/201731892. arXiv:1804.01302

Yallop BD, Hohenkerk C, Murdin L, Clark DH (1982) Solar rotation from 17th-century records. Quart J R Astron Soc 23:213 
Zito RR (2016) Possible mesoamerican naked-eye observation of sunspots - V: Evidence from Rio Azul Tomb I murals and related artifacts. Sociol Anthropol 4:953-965. https://doi.org/10.13189/sa.2016. 041102

Zito RR (2017) Possible mesoamerican naked-eye observation of sunspots - VI: Evidence from Yaxchilan Lintel 48. Sociol Anthropol 5:1041-1051. https://doi.org/10.13189/sa.2017.051209

Zolotova NV, Ponyavin DI, Arlt R, Tuominen I (2010) Secular variation of hemispheric phase differences in the solar cycle. Astron Nachr 331:765. https://doi.org/10.1002/asna.201011410. arXiv:1009.5889

Zucconi L (1760) De heliometri structure et usu. D. Lovisa, Venice

Publisher's Note Springer Nature remains neutral with regard to jurisdictional claims in published maps and institutional affiliations. 